University of Zurich

Department of Economics

Working Paper Series

ISSN 1664-7041 (print)

ISSN 1664-705X (online)

Working Paper No. 350

\title{
Are the Effects of Informational Interventions Driven by Salience?
}

Eric Bettinger, Nina Cunha, Guilherme Lichand and Ricardo Madeira

Revised version, May 2021 


\title{
Are the Effects of Informational Interventions Driven by Salience?*
}

\author{
Eric Bettinger $†$ Nina Cunha $\ddagger$ Guilherme Lichand, Ricardo Madeira $\mathbb{I}$
}

May 14, 2021

\begin{abstract}
Informational interventions have been shown to significantly change behavior across a variety of settings. Is that because they lead subjects to merely update beliefs in the right direction? Or, alternatively, is it to a large extent because they increase the salience of the decision they target, affecting behavior even in the absence of inputs for belief updating? We study this question in the context of an informational intervention with school parents in Brazil. We randomly assign parents to either an information group, who receives text messages with weekly data on their child's attendance and school effort, or a salience group, who receives messages that try to redirect their attention without child-specific information. We find that information makes parents more accurate about student attendance, and has large impacts on their test scores and grade promotion relative to the control group. Even though salience messages, in contrast, do not make parents more accurate about attendance levels, learning outcomes in the salience group improve by at least as much. Why? We show that treated parents across both conditions become more accurate about changes in their children's grades over time, although not about grade levels. Such coarse belief updating is consistent with independent information acquisition in response to salience effects from both interventions. Our results have implications for the design and interpretation of informational interventions across a range of domains.
\end{abstract}

Keywords: Information; Salience; Inattention

JEL Classifications: C93, D83, D91, I25, I31

\footnotetext{
${ }^{*}$ We acknowledge valuable comments from Lorenzo Casaburi, Ernst Fehr, Susanna Loeb, George Loewenstein, Nick Netzer, Jesse Shapiro, Dmitry Taubinsky and Heather Schofield. This research was funded by Stanford University's Lemann Center, Itau BBA and the University of Zurich. We thank Daniele Chiavenato, Julien Christen and Carlos Alberto Doria for excellent research assistance. Any remaining errors are ours.

${ }^{\dagger}$ Stanford University

${ }^{\ddagger}$ FHI 360

$\S$ University of Zurich

I University of São Paulo
} 


\section{Introduction}

In 2012, Vitória da Conquista - a municipality in a poor Brazilian State - spent over USD 700,000 on microchips embedded in public school students' uniforms. Their hope was to decrease truancy by informing parents in real-time when their children missed classes. ${ }^{1}$ This policy was inspired by the success of informational interventions in affecting many fundamental economic decisions, including those linked to improved educational outcomes. ${ }^{2}$ Having said that, it is unclear whether those interventions work because of the specific information they convey, tailored to the circumstances of the recipient. Alternatively, it could be that those work mainly because such messages make particular issues top-of-mind, i.e. they induce recipients to refocus their attention on the salient issue that is addressed by the informational intervention. ${ }^{3}$ If that is the case, then salience interventions that do not require recipient-specific information (such as nudges) may do equally well - and perhaps even better. In fact, it could even be that those interventions induce individuals themselves to collect the relevant data such that they update beliefs in the correct direction, much the same way as informational interventions would do, except that at much lower cost for implementers (no microchips needed!). This paper provides first-hand evidence for this mechanism outside the lab. ${ }^{4}$

Whether such mechanism is quantitatively important matters. After all, salience interventions have the advantage of demanding less or no information and, thus, requiring less knowledge by policy-makers. What is more, if refocusing attention is the key mechanism, salience interventions are bound to have even larger effects than information disclosure. The reason is two-fold. First, informational interventions are constrained by the frequency at which information is available (often only at low frequency in developing countries like Brazil), while nudging can be implemented at much higher frequency; in fact, our results show that the frequency of messaging matters greatly in the context of communication with school parents. ${ }^{5}$ Second, nudges also allow for additional features to manipulate attention; for instance, our results show that redirecting attention to student attendance in general improves educational outcomes across different classes, in contrast to conveying child-specific information about math attendance - which affects student outcomes only in this particular class.

\footnotetext{
${ }^{1}$ http://www.bbc.com/news/world-latin-america-17484532 (accessed on October 11, 2020).

${ }^{2}$ Information about children's school effort increases parental monitoring and improves learning outcomes (e.g. Bergman, 2021), information about labor market returns to education increases enrollment and educational attainment (Jensen, 2010), information about employees' productivity makes turnover of low-productivity staff more likely (Rockoff et al., 2012), and information about husbands' support for female labor market participation increases investments in labor market skills (Bursztyn et al., 2018), among many other applications.

${ }^{3}$ To that point, in Dizon-Ross (2019), parents randomly assigned to receive information about their children's school performance substantially change educational investments, even though such data were already available to them before the experiment through children's scorecards.

${ }^{4}$ Gabaix et al. (2006) documents that receiving news directs subjects' attention within a lab experiment; Ambuehl et al. (2017) shows that certain types of financial education messages - those that emphasize abstract benefits rather than specifying concrete actions - affect behavior without affecting financial knowledge in an online experiment.

${ }^{5}$ Section 7 discusses the limits of this argument.
} 
To study this question, in the context of communication between schools and parents, the ideal experiment would evaluate the impacts of sending parents information about their children's attendance while holding their attention fixed. But this is impossible; information disclosure presumably always attracts attention (Golman and Loewenstein, 2018; Loewenstein et al., 2014). What we do instead is compare parents who receive information to other parents whose attention is manipulated while their beliefs about their children's behavior are not made more accurate. To do that, we randomly assign parents to either school messages that contain child-specific information or to school messages that try to direct their attention to the behaviors reported on - without, however, conveying child-specific information. The idea is that, by comparing the two groups of parents, the experiment allows us to capture the additional effects of information on parent's beliefs and behavior above and beyond those that operate through the salience mechanism (if any).

Communication between schools and parents is a great setting to study this question for the following reasons. First, because of a clear moral hazard problem between parents and children: as children grow older, their goals may drift increasingly apart from those of their future-oriented parents; moreover, it becomes progressively harder for parents to observe children's effort at school (Cunha and Heckman, 2007; Heckman and Mosso, 2014). ${ }^{6}$ Second, because there are objective dimensions of children's effort (such as attendance) on which we can report or to which we can direct parents' attention. Third, because of administrative data on school outcomes (such as standardized test scores), which we can use to track the impacts of the experiment above and beyond surveying parents about their beliefs and behavior.

Concretely, in the experiment - across 287 schools in São Paulo, Brazil, encompassing 19,300 ninth graders -, math teachers provide weekly information about their students' behavior (attendance, punctuality and homework completion) through a platform over the course of 18 weeks. Taking advantage of a partnership with an edtech startup ${ }^{7}$, we randomly assign parents to different messages within each classroom, shared by the platform over text messages (SMS). Some parents receive child-specific information (e.g.: "Nina missed between 3 and 5 math classes over the last 3 weeks"), some receive a salience message, emphasizing the importance of paying attention to that dimension (e.g.: "It is important that Nina attends every math class"), while others receive no message at all (the control group). While the salience message potentially conveys additional information (although not child-specific; e.g. on social expectations about parenting), the message with child-specific information presumably does the same. ${ }^{8}$ Last, because we anticipate that parents' or peer interactions may generate large spillovers, we randomize treatment

\footnotetext{
${ }^{6}$ To that effect, poor parents in Brazil prefer conditional cash transfers that mandate school attendance - such that parents get notified when students miss over $15 \%$ of classes - to unconditional ones (Bursztyn and Coffman, 2012). Consistent with the moral hazard mechanism, such preference disappears when schools systematically share information about their children's attendance.

${ }^{7}$ Movva (http://movva.tech) delivers nudges to engage parents in their children's education across Brazil and Ivory Coast (as of 2019). One of the authors (Guilherme) is Movva's co-founder and chairman.

${ }^{8}$ See section 3.1 for a detailed discussion.
} 
assignment at two levels: within classrooms and across schools, including a pure control group.

Before our experiment began, parents were quite inaccurate about their children's school effort: the correlation between beliefs about absences and actual absences in math classes, reported in children's scorecards, was only 0.21 (no different across treatment arms). The intervention did what we set it out to: by the end of the school year, the correlation between beliefs and absences reported by teachers through the platform was up to 0.39 in the information group - a $45 \%$ increase in accuracy relative to control parents within each classroom. In contrast, in the salience group, parents were no more accurate about their children's absences at the end of the school year - if anything, the correlation between beliefs and absences was $21 \%$ lower in that group, consistent with the idea that these messages introduce noise, resulting in a flatter relationship between beliefs and actual absences relative to the control group.

Using administrative data on educational outcomes, we find that the informational intervention has large impacts on attendance (2.1 percentage points, or about 5 additional classes a year; a nearly $1 / 5$ reduction in absenteeism), math GPA and standardized test scores (0.09 standard deviation; equivalent to leapfrogging 1 quarter ahead in school) and grade promotion rates (3.2 percentage points; a $1 / 3$ reduction in grade repetition), in line with previous findings (Bergman, 2021; Berlinski et al., 2016; Rogers and Feller, 2016). We find that treated parents ask their children systematically more about school, incentivize studying to a greater extent, and have higher aspirations about their children's making it to college, and that children in treated households report engaging in academic and reading activities to a greater extent.

Strikingly, most of the effects of information are driven by salience: messages without child-specific information improve outcomes by $89-126 \%$ relative to those in the information group. What is more, we show that the effects of salience are even higher than those of information among students with lower attendance at baseline - presumably, those whose parents would benefit the most from information.

How can it be that children improve by as much in both treatment arms if parents become more accurate about attendance levels in one condition, but no more so in the other? We document that an important mechanism might be information acquisition triggered by salience effects. We find that treated parents become more accurate about changes in math GPA over time, relative to the control group, consistent with both interventions mobilizing parents to acquire themselves decision-relevant information. This is the case even though text messages did not communicate child-specific grades; in fact, even child-specific information does not make parents more accurate about GPA levels. ${ }^{9}$ In this context, updating beliefs in the right direction - even if only coarsely - is enough to improve learning outcomes by the same magnitude as interventions that deliver information on grades directly to parents (e.g. Berlinski et al., 2016). To that effect, we find that, just as in Dizon-Ross

\footnotetext{
${ }^{9}$ This is also not merely an artifact of school effort being correlated with grades, since parents' accuracy about student attendance moves in different directions across treatment conditions.
} 
(2019), while child-specific information increases inequality across children - in particular, it makes educational outcomes worse for low-effort children relative to control students within the same classroom -, salience messages do precisely the same.

Are salience effects only relevant in the short-run, e.g. because parents stop paying attention over time? If anything, our results suggest the opposite is true: at least within the 4-month horizon of our study, the effects of salience messages not only persist, but even increase over time: the gap between the salience group and the pure control group increases between the third and the fourth quarters both with respect to math attendance and GPA - despite no mechanical reason for compounding, since outcomes are computed within each quarter.

Results are robust to a series of alternative explanations. Randomly varying the saturation of parents assigned to the information treatment across different schools, we rule out that salience effects are driven by spillovers from the informational intervention. Assigning a subset of parents to finer-grain information (which frames child-specific school effort relative to the classroom median, along the lines of Rogers and Feller, 2016) also has statistically identical effects to those of salience messages, ruling out that results are driven by the intervention not being 'informative enough'. Last, assigning an SMS nudge program to a different sample of parents (targeting them directly with weekly suggestions of activities to do with their children, without ever involving teachers), we rule out that results are driven by the fact that, in the main experiment, teachers had to fill in a platform each week with information about their students.

Our findings are consistent with parents setting investments in their children's education subject to attentional constraints. An additional experiment provides further evidence to support that mechanism: we find that salience effects significantly increase with the frequency of nudging (the effect size of 3 nudges per week on math attendance is nearly 2-fold that of child-specific information), and that nudges that are not subject-specific improve outcomes across both math and Portuguese classes, while the effects of math-specific information or math-specific salience messages are confined to math attendance and grades.

Together, these results suggest that the effects of informational interventions could be obtained at lower cost - and even magnified - by interventions that manipulate attention, raising the salience of the decision they target. This insight may well extend beyond education: just like parents who receive information about their child's school effort react to the salience of monitoring, employers may react to the salience of firing low-performing employees in face of information about their performance (as in Rockoff et al., 2012), clients with late payments may react to the salience of enforcement in face of information about how default affects their future access to credit (as in Bursztyn et al., 2019), and customers may react to the salience of purchasing a good in face of information about its benefits (as in Allcott and Taubinsky, 2015). ${ }^{10}$

\footnotetext{
${ }^{10}$ In Bursztyn et al. (2019), where the largest reduction in default rates is caused by messages highlighting the consequences of default for future access to credit, authors point out that they "(...) cannot directly assess the extent to which this treatment provides new information as opposed to bringing customers'
} 
More broadly, our findings relate to an active literature connecting salience to belief updating (e.g. Bordalo et al., 2012, 2019; Enke et al., 2019; Hanna et al., 2014), extending that logic to the effects of informational interventions themselves. They also qualify the interpretation of previous results about the effects of informational interventions, particularly in the context of communication with parents (Bergman, 2021; Dizon-Ross, 2019; Jensen, 2010). Last, while a recent literature posits that the effects of information can be non-trivial when it redirects attention (Golman et al., 2017; Golman and Loewenstein, 2018; Loewenstein et al., 2014), this paper not only provides first-hand evidence for this mechanism outside the lab, but also shows that it can be quantitatively important.

\section{Education in Brazil and São Paulo State}

Like most Latin American countries, while Brazil has achieved significant progress over the last 20 years in making basic education universal (over $98 \%$ of $7-14$ year-olds are enrolled), it still struggles with educational quality. ${ }^{11}$ To that point, the eight Latin-American countries that took the 2015 PISA exam scored at the very bottom of the 65 participating countries, and were outscored even by those with much lower per capita income. Brazilian 15 yearold students scored 121 points below the OECD average in math, what is equivalent to a two-year lag in math skills. ${ }^{12}$

Education in Brazil is supervised by government offices across municipal, state and federal levels. Municipalities are responsible for early childhood education and primary schools, State governments are responsible for middle schools and high schools, and the federal government is responsible for college education (besides a few special secondary education programs ran by federal institutes) and for regulating private educational institutions at all levels.

São Paulo is the wealthiest and most populous Brazilian State, and its educational system encompasses the largest number of students in the country. According to the Educational Census from the Brazilian Ministry of Education, enrollment in São Paulo State amounted to 5.3 million primary and middle school students in 2015. Among those, 700,000 were ninth graders, $63 \%$ of which served by schools directly administered by the State authority. Despite being a relatively wealthy State - accruing to $40 \%$ of country's GDP -, São Paulo features high inequality in access to education: while wealthy families typically enroll their children in higher-quality private schools, public schools typically

\footnotetext{
attention to something they already knew" (p. 1644, emphasis added). In Allcott and Taubinsky (2015), authors recognize that "[i]t is thus not unreasonable to assume that (...) the conditional average treatment effect on willingness-to-pay from our information treatments equal the average marginal bias from imperfect information and inattention" (p. 2503, emphasis added).

${ }^{11} 2015$ National Household Survey (PNAD), Brazilian Institute for Geography and Statistics (IBGE). Primary school enrollment is mandatory in the country for children between ages 6 and 14 .

${ }^{12}$ The Programme for International Student Assessment (PISA) is an ongoing triennial survey that assesses the extent to which 15 year-old students approaching the end of middle-school have acquired key knowledge and skills that are essential for productive engagement in modern societies. Around 540,000 students took the assessment in 2015, a representive assessment of about 29 million students across 72 participating countries.
} 
serve students from disadvantaged backgrounds. In our sample, over $50 \%$ of households earn less than 3 minimum wages (about 900 USD as of September, 2017), within the income range of slum dwellers in the State capital. As such, public school students tend to perform particularly poorly: in 2015, São Paulo State's public middle-school students scored 4.7 out of 10 in the National Index for the Development of Basic Education (Ideb) - which averages math and language standardized test scores, penalizing that average by grade repetition rates -, falling short of its already extremely modest target (5.0) for middle-school students in the State.

Poor educational outcomes emerge as a combination of poor infrastructure, low teacher value-added, and low family engagement in students' school life. Across OECD countries, $20 \%$ of students report that they had skipped a day of school or more in the two weeks prior to the PISA test. In Brazil, that figure was 48\%. Strikingly, according to the 2015 National Survey of Students' Health, about 1 in every 4 parents do not know whether their child skipped classes, about 1 in every 3 parents do not systematically ask their child about problems in school, and about 1 in every 2 parents do not regularly ask about homework. Consistent with those statistics, in focus groups, public school teachers often cite low family engagement as the leading cause of students' poor school performance.

Engaging parents in this setting is hard: before the pandemic, the leading communication technology between schools and parents was still handwritten notes sent through students themselves, who may not face the right incentives to ensure the message gets through. Even though basically every parent could be reached via phone, cost control measures by Education Secretariats to prevent excessive spending by schools have made it such that their land lines often carry heavy restrictions on calls to mobile phones. ${ }^{13}$ Above and beyond communication constraints, information on students' effort or performance in school is often not readily available to be shared. In most States, no real-time digital information systems are in place to track students' attendance or school behavior. Teachers keep daily records on paper, but typically only upload such information into centralized school systems at the end of the school year.

\section{Empirical strategy}

This section introduces our empirical strategy. We start with a conceptual framework in subsection 3.1 to set the ground for the design of our experiment. Informed by that framework, subsection 3.2 describes the experimental design to isolate the salience effects of informational interventions. We describe the platform that teachers fill in weekly in subsection 3.3, followed by a summary of the outcomes we draw upon, from administrative sources to survey data, in subsection 3.4. Next, subsection 3.5 presents descriptive statistics of our sample, including a discussion about selection into the study and balance

\footnotetext{
${ }^{13}$ Less than $30 \%$ of Brazilian households own landlines, while $93.4 \%$ of them own mobile phones, according to the 2015 National Household Survey (PNAD). While mobile phone penetration is high in Brazil, that of internet and smartphone apps is not: about $55 \%$ of active lines are not systematically connected to the internet (Regional Study Center to Information Society Development, CETIC).
} 
across treatment conditions. Last, subsection 3.6 describes the equations we estimate, our treatment of standard errors, and how we deal with multiple comparisons.

\subsection{Conceptual Framework}

The ideal experiment to study this research question would compare parents who receive child-specific information to other parents whose beliefs about their children's school effort are manipulated while their attention is held fixed. Such experiment is, however, not feasible; information disclosure presumably always attracts attention (Golman and Loewenstein, 2018; Loewenstein et al., 2014). Hence, to study this question, what we do instead is compare parents who receive information to other parents whose attention is manipulated while their beliefs about their children's behavior are held fixed. This alternative comparison approximates the ideal experiment by isolating the mechanism of interest, along the lines of Ludwig et al. (2011).

How could one implement this mechanism experiment outside the lab? What we do in our context is to randomly assign parents to either school messages that contain childspecific information or to school messages that try to direct their attention to the behaviors reported on - without, however, conveying child-specific information. The idea is that, by comparing the two groups of parents, the experiment allows us to capture the additional effects of information on parent's beliefs and behavior above and beyond those that operate through the salience mechanism (if any).

Concretely, salience messages emphasize that the dimensions of student effort we weekly report on in the information group (attendance, punctuality and homework completion) are important (e.g. "It is important that Nina attends math classes / arrives on time in math classes / hands in math homework everyday"). We match the school behavior addressed by the salience and information messages every week.

Framing salience messages in this way might raise concerns, in that claiming that a behavior is important might change preferences or beliefs above and beyond making that dimension top-of-mind. The reason why we think this is the appropriate framing is threefold. First, informational interventions presumably do the exact same thing: being targeted by a message from the school likely makes recipients regard this dimension as important potentially affecting their preferences and beliefs just as much. ${ }^{14}$

Second, alternative framings would only imperfectly approximate those salience effects. For instance, a reminder (e.g. "You can learn about your children's attendance by asking their school") is presumably not surprising at all, and would be unlikely to draw attention comparably to the informational intervention. ${ }^{15}$ Alternatively, a message offering parents

\footnotetext{
${ }^{14}$ In our experiment, we can test directly if parents' beliefs are affected by the salience intervention; in particular, do salience messages lead parents to infer that their children are putting in low effort at school? Section 4 shows that is not the case: salience messages do not systematically affect the slope of the relationship between parent's beliefs and student attendance at end line.

${ }^{15}$ In fact, as Bursztyn et al. (2019) documents, simple reminders might not approximate well the effects of informational interventions. Moreover, reminders might just as well change recipients' preferences or beliefs above and beyond making that dimension top-of-mind.
} 
the opportunity to receive attendance information over SMS conditional on their reply is indeed likely to make attendance salient. Having said that, such message would induce at least some parents to actually reply, making it unfeasible to disentangle the effects of the child-specific information they requested from those of salience without resorting to deception (by denying some parents access to the piece of information advertised in the original message). This is so because of selection in who takes up the information offer, preventing one from merely restricting the sample to those who do not reply. To avoid deception, the task of introducing additional variation to affect parents' likelihood of replying to the text message would once again bring about the challenge of intervening without affecting their preferences or beliefs directly - a challenge that has no obviously satisfying fix.

Third, the idea that we could send salience messages to all treated parents, and childspecific content in addition to the information group, would fail to cleanly separate the effects of information from those of salience. The reason is that, in the presence of inattention, additional messages would likely induce larger treatment effects even in the absence of child-specific information. This is exactly what we document in Section 6: in an additional experiment, effect sizes on attendance and grades increase with the frequency of messaging. Incidentally, other studies have documented that message length also matters for the effects of informational interventions (e.g. ?). For those reasons, we send exactly the same number of messages across treatment conditions and carefully design messages to have approximately the same number of characters in each case.

\subsection{Experimental Design}

All details of the experimental design and a pre-analysis plan were pre-registered at the AEA RCT Registry on June 26, 2016 (AEARCTR-0001379). ${ }^{16}$

\subsubsection{Within-classroom randomization}

In the experiment, across 287 schools in São Paulo, Brazil, encompassing 19,300 ninth graders, math teachers had to fill in a platform weekly with information about their students' behavior (attendance, tardiness and homework completion). Within each classroom, we randomly assigned parents to different messages, shared by the platform weekly over text messages (SMS): some parents received child-specific information, some received salience messages emphasizing the importance of attending to the child's school behavior, while others received no message at all (the control group). The assignment was held fixed over the course of the experiment. Messages were designed to be simple and clear, and to have as close as possible number of characters across treatment arms. Comparing information and salience students to control students allows estimating the extent to which

\footnotetext{
${ }^{16}$ See Supplementary Appendix I for the pre-analysis plan in full, including an account of deviations from pre-registration. A preliminary version of this paper was circulated under the title "What Is It About Communicating With Parents?".
} 
the effects of child-specific information are driven by salience, as discussed in the previous subsection.

We restricted communication to student effort in math classes. While standardized tests cover both math and Portuguese, the Education Secretariat thought that math teachers tend to keep more accurate records, and would have an easier time using the online platform relative to Portuguese teachers. The particular dimension of student effort targeted by information and salience messages alternated weekly, rotating across three dimensions: attendance, punctuality and homework completion. We decided to rotate across those dimensions for three reasons: (1) because teachers already measure them weekly (although only on paper; data entry into the Secretariat's system only takes place at the end each quarter, or even at the end of the school year in some cases), (2) because the Education Secretariat thought it was important to inform parents about all of them (rather than just about attendance), and (3) because we thought it would be less likely that teachers' usage of the platform would die out over time if they had to report on a different behavior every week (making it seem less like just replicating the work they already do on paper). The exact wording of the salience messages varied slightly every cycle, in an attempt to prevent spam-avoiding behavior by parents, and in line with the goals of the mechanism experiment discussed in the previous subsection. For the full script of messages sent for each treatment arm, see Supplementary Appendix A.

Parents of all treatment arms only received text messages if the teacher filled in the platform that week. This was true even for the salience arm, in order to avoid confounding treatment effects with potential differences in teachers' compliance across conditions. ${ }^{17}$ Perfect compliance with randomization protocols was ensured since our implementing partner (Movva) had full control over enrollment (data on all participants had to be entered by teachers into their system prior to the start of the experiment, and assignment was conditional on enrollment) and over the messages ultimately sent to parents.

\subsubsection{Identification concerns and two-level randomization}

There are a number of potential concerns with inferring salience effects based on experimental design outlined in the previous subsection. First, if parents already had reasonably accurate information about their children's school effort, or if parents found the information conveyed through the text messages too coarse to update their prior beliefs, then we might find no treatment effects of information to start with - making it unfeasible to understand the extent to which those effects are driven by salience.

In the context of our experiment, both concerns are unfounded: Section 4 shows that parents are dramatically inaccurate about their children's attendance at baseline, and that information makes them substantially more accurate at end line relative to the control group. Having said that, we did not know which would be the case by the time we designed

\footnotetext{
${ }^{17}$ Teachers had until Sunday of each week to fill in information with respect to the past 3 weeks (see the next subsection); parents received the message assigned to them always on the following Tuesday, according to their treatment status.
} 
and pre-registered the study. For this reason, we included an additional informational intervention in a sub-sample of schools (randomly assigned; see below), in which parents were targeted by more informative messages - framing information on student behavior relative to the median of their classmates (e.g. "most students in Nina's class missed less than 3 classes in the previous 3 weeks"), analogous to Rogers and Feller (2016). ${ }^{18}$ The platform automatically computed each classroom median behavior once teachers submitted information on all their students, each week. Comparing the effects of salience messages to those of relative information allows us to estimate the relevance of salience effects in face of a more demanding counterfactual.

\section{i. Control: No messages}

ii. Child-specific information: Messages with child-specific information about attendance, punctuality and homework completion

iii. Salience: Messages highlighting the importance of school attendance, punctuality and homework completion

iv. Relative information: Messages with child-specific information about attendance, punctuality and homework completion framed relatively to their classmates' median behavior

Sample messages by treatment arm

Child-specific information Salience Relative Information

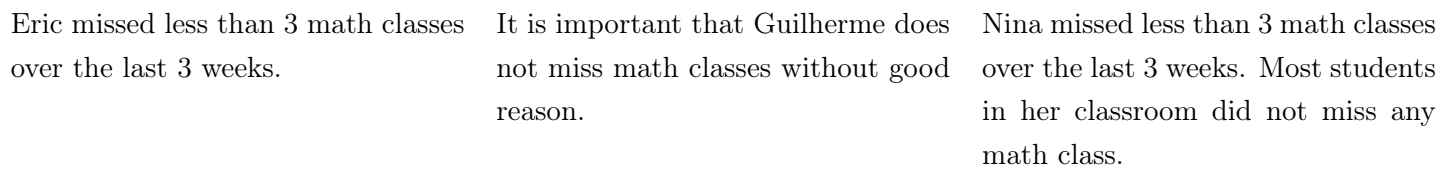

A second concern is spillover effects within classroom. If the interventions causally improve treated students' educational outcomes, a variety of mechanisms could lead control students within each classroom to indirectly benefit from those. In particular, control students' learning outcomes could improve because of their interactions with now highereffort peers (e.g. Bennett and Bergman, 2021; Sacerdote, 2011), because their parents change behavior due to their interactions with treated parents (who presumably change behavior in response to information or salience messages), or because teachers increase effort in response to higher-achieving pupils (perhaps even specifically towards control students, to ensure they do not fall behind in the classroom). In the presence of spillovers, using within-classroom control students as a counterfactual would lead us to under-estimate

\footnotetext{
${ }^{18}$ Rogers and Feller (2016) sends parents information about their child's attendance relative to their classroom's modal behavior. Using child-level information as the comparison group, findings point out that relative information has significantly higher impacts on students' educational outcomes in US schools. We use median behavior instead since it is presumably much easier to understand; to that point, the mode of the distribution had to be explained graphically in Rogers and Feller (2016), a feature that technically cannot be combined with text messages.
} 
treatment effects. Incidentally, spillovers might also lead us to under-estimate differences between the effects of information and salience messages, specifically if parents in the salience group talk to other parents about the messages, and infer child-specific information from those conversations thanks to the information treatment.

To deal with those concerns, our design randomizes the interventions at two levels. First, across schools - randomly assigned to different sub-samples, each associated with a specific saturation of the information and salience interventions. ${ }^{19}$ Those include a pure control group (schools where no student is assigned to either information or salience messages) and a no information group (schools where students are only assigned to salience or control). Second, within classroom, randomizing students across treatment arms en suite with the saturation assignment at the school level. ${ }^{20}$ Comparing students assigned to the information and the salience groups to those in the pure control group allows us to estimate treatment effects parsing out potential spillover effects on control students within each classroom. In turn, comparing students assigned to the salience intervention across the no information group and the regular sample allows us to estimate salience effects while parsing out potential spillover effects from the information treatment on those students. Importantly, other than pure control schools, neither school principals nor teachers were aware of differences in assignment between schools, or of child-specific assignments within schools. ${ }^{21}$

While relying on the pure control group as a counterfactual allows estimating the effects of interest while parsing out spillovers, it brings about additional concerns. Teachers in pure control schools did not have to fill in the platform (in order to avoid deception, or poor compliance once teachers eventually realized that information was not being delivered to parents). As such, having to input information into the platform could have induced teachers in the regular sample to change effort relative to pure control schools (e.g. if enough of them think that the school principal or parents might monitor them to a greater extent now that data on student effort is available at high frequency). If that were the case, one would over-estimate treatment effects of both information and salience messages when using the pure control group as a counterfactual - potentially compromising the external validity of our findings, particularly when it comes to the effects of salience messages as one considers the policy version with no data entry by teachers.

To deal with this concern, we include an additional sub-sample of schools in which

\footnotetext{
${ }^{19}$ Whenever there are multiple ninth-grade classrooms in a given school, we include all of them in the experiment.

${ }^{20}$ We stratified randomization in two steps. In the first step, we stratified the assignment of schools to sub-samples based on three school-level variables: their average math scores in the first quarter (measured through the Education Secretariat's internal assessment), their average student absenteeism rate, and their share of parents enrolled to participate in the study. In the second step, we stratified the assignment of students to treatment arms within classroom based on their first quarter math scores (in the Education Secretariat's internal assessment). Not all students take this test (which is not mandatory). For students with missing values, we predict their score based on a simple linear regression using all baseline covariates, stratifying assignment based on predicted scores.

${ }^{21}$ Students in pure control schools were enrolled through the same process as those in other sub-samples. What is more, principals of all schools, even in the pure control group, were allowed to use the platform to send monthly communication to parents about school events; see Section 3.3.
} 
parents are assigned only to either nudges or to a control group. ${ }^{22}$ Nudges - which are also delivered to parents weekly over SMS - do not require any inputs by teachers. Instead, their content draws inspiration in READY4K (York et al., 2019), sharing weekly suggestions of activities for parents to do with their children. Comparing students assigned to nudges to those in the pure control group allows us to estimate salience effects parsing out potential effects on teacher behavior due to the teacher platform.

We excluded those schools from the possibility of sending monthly communication to parents (a feature used to convince schools in all other sub-samples to participate in the study; see Section 3.3) since, in some schools, math teachers also handled this activity (delegated by principals) - as the goal of this sub-sample was to shut down the possibility of teacher effects. That decision, however, had a cost: the Education Secretariat required us to work on a different region of the State whenever the communication platform was not made available to principals. As a result, students in that sub-sample are not statistically identical to those in our other sub-samples; in particular, schools in that region had relatively lower grades at baseline. To deal with those baseline differences, we take advantage of the fact that our program only started at the second half of the school year, comparing educational outcomes of different sub-samples before and after the program was introduced. The differences-in-differences estimator identifies the causal effects of nudges relative to the pure control group under the assumption that student outcomes would have not have changed differentially across sub-samples over time in the absence of nudges. We show evidence for the validity of this identification strategy in subsection 5.5.2.

The figure below summarizes our two-level randomization design. Sub-samples A through $\mathrm{C}$ allow estimating the effects of the informational intervention and the extent to which those are driven by salience; sub-sample D allows estimating the effect of salience messages without potential spillovers from information; and sub-sample E allows estimating salience effects in the absence of teacher effects. ${ }^{23}$

\footnotetext{
${ }^{22}$ The saturation within those schools assigned $2 / 3$ of students to nudges and $1 / 3$ to the control group, reflecting power calculations that had the subjects assigned to nudges involved in multiple comparisons.

${ }^{23}$ The design choice for sub-samples A through D reflects power calculations accounting for the hypothesis of interest. In the case of sub-sample E, the sample reflects the demands of the Education Secretariat.
} 


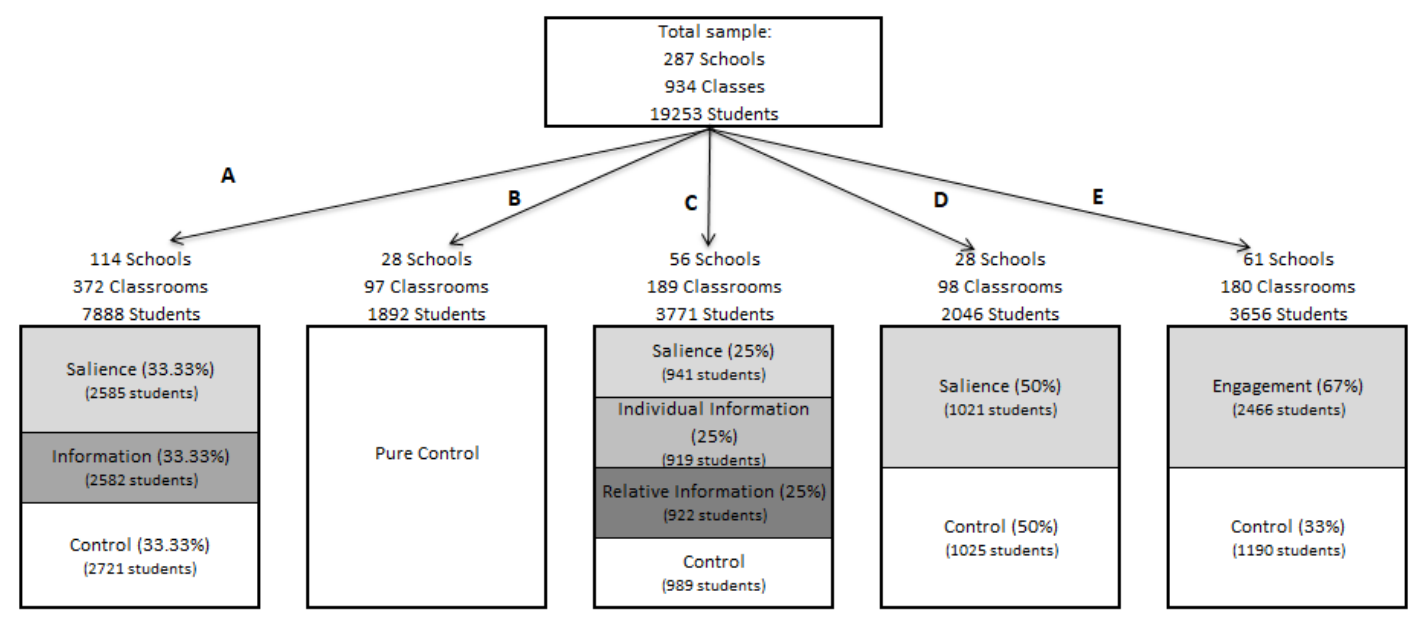

\subsubsection{Timeline}

The school year in Brazil runs from February to December and is divided in four quarters, with a winter break in July. The timeline of the experiment was as follows. Parents were surveyed at baseline in mid-June, 2016, towards the end of the second quarter. All parents in our sampled schools (including pure control ones) who consented to participate in the study filled in basic characteristics of the child and their primary caregiver, followed by a baseline phone survey. Schools and students were then randomized into the different treatment arms, and teachers (other than in pure control and nudge schools) were trained to fill in the platform, by the end of June.

Teachers started entering student data into the platform immediately after the winter break. In turn, parents started receiving messages 3 weeks after classes resumed, since messages in the information group always describe student effort over the 3 previous weeks. Communication lasted until the first week of December, when final exams took place. Standardized tests took place immediately before, at the very end of November. Students were surveyed as part of preparation activities for these tests, the week before that. Parents were surveyed at end line immediately after the end of SMS communication, during the second week of December, 2016.

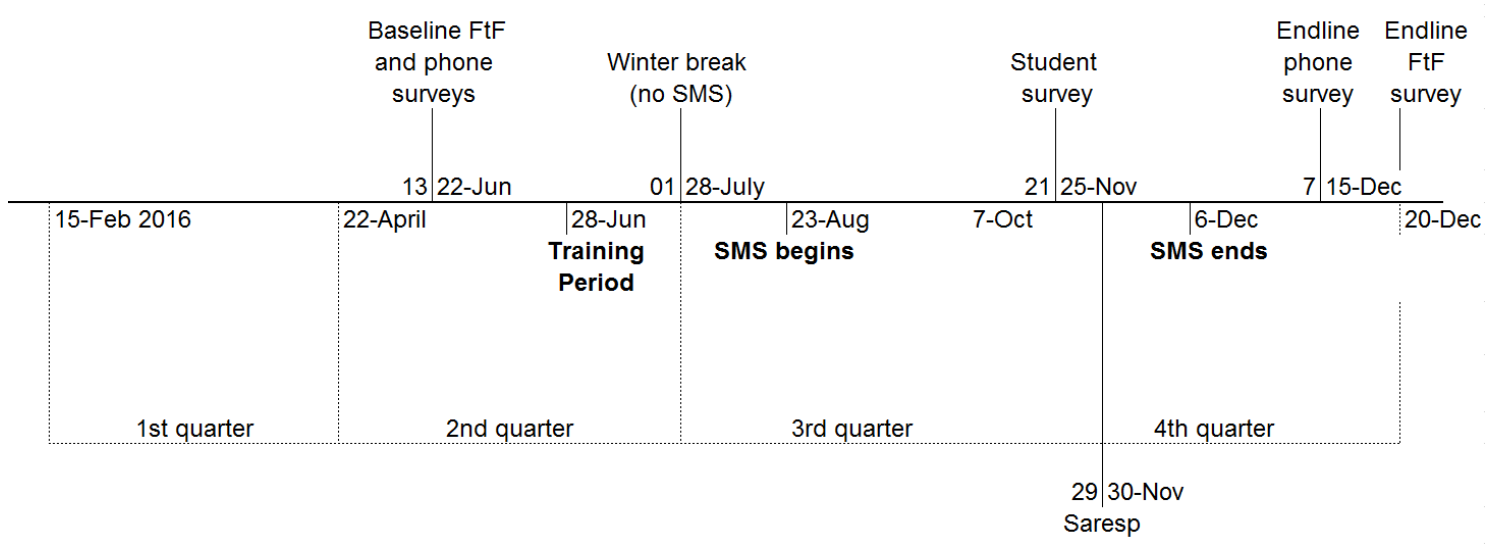




\subsection{Teacher platform}

We created an online data entry platform specifically for the study, designed in a simple and intuitive way such that schools could easily manage it. ${ }^{24}$ As discussed in the previous subsection, math teachers from treatment schools were oriented to fill in the platform every week with that week's dimension of students' behavior: attendance, punctuality or homework completion, following the scale shown below, reflecting each student behavior on that dimension over the past three weeks. ${ }^{25}$

Scale by dimension of student behavior

\begin{tabular}{|c|c|c|}
\hline Attendance & Punctuality & Homework completion \\
\hline 1. Missed more than 5 classes & 1. Was late in more than 5 classes & 1. Did not complete any of the assignments \\
\hline 2. Missed 3 to 5 classes & 2. Was late 3 to 5 classes & 2. Completed less than half of the assignments \\
\hline 3. Missed less than 3 classes & 3. Was late for less than 3 classes & 3. Completed more than half of the assignments \\
\hline 4. Did not miss any class & 4. Was not late in any class & 4. Completed all the assignments \\
\hline
\end{tabular}

Scales across different dimensions were congruent - low (high) numbers meant low (high) effort across all dimensions -, and the relevant scale for each week was always visible in the platform, to minimize concerns with measurement error. The system required teachers to fill in information on all students in the classroom each week. Teachers were reminded to fill in the platform weekly over SMS. Teachers who failed to fill it in at any given week received an SMS alert, noting that they had not entered student data that week and encouraging them to do so in the following week. Principals received motivational messages over SMS encouraging them to engage their teachers in the program, as well as SMS alerts in case teachers' compliance in the school was below an acceptable threshold. As a result, average compliance was high - roughly two thirds of teachers filled in the platform in any given week (see Appendix C). ${ }^{26}$

As mentioned, to incentivize schools to collect parents' phone numbers and baseline characteristics, we offered all schools (other than those in sub-sample E, where nudges were randomly assigned) access to the platform such that they could send parents (infrequent)notifications about school events - limited to one notification per month. Once an event was scheduled in the platform (using the principal's credentials), the system would send the SMS notification to parents one week before, and an SMS reminder one day prior to the event.

\footnotetext{
${ }^{24} 60 \%$ of Brazilian schools have access to internet, although typically only with very limited bandwidth - often below 4 mbps, shared across staff and all student computers, if any. The online platform consumed very little data, and could be accessed by principals and teachers from any computer or smartphone, even outside of the school.

${ }^{25}$ Students have around six math classes per week.

${ }^{26}$ Despite some differences in data entry rates across the different sub-samples of schools where teachers had to enter student data into the platform, results are robust to bounding procedures that account for potential selection in unobservable student characteristics; see Appendix E.
} 


\subsection{Data and outcomes}

We rely on four different data sources to collect our outcomes of interest. First, face-to-face survey data. At baseline (mid-June), we surveyed all parents who consented to participate in the program on their socio-economic characteristics and those of their children. This dataset comprises 15,597 observations, giving us access to a wide range of controls: primary caregiver's family tie with the student, their income bracket and educational achievement, and their (and their child's) gender, race and age. At end line (end of November), we surveyed students face-to-face on their perceptions about their parents' engagement in their school life, their time allocation between leisure and study, their values and aspirations, and their social and emotional skills. This dataset comprises 9,539 observations, reflecting the fact that take-up of this final survey was optional (although strongly encouraged by schools).

Second, phone surveys, collected via robot calls (Interactive voice response units, IVR) and incentivized with airtime credit. At both baseline (mid-June) and end line (December), we surveyed parents to elicit their parenting practices, beliefs about their child's math attendance and grades, and their demand for child-specific information on those dimensions. Response rates of phone surveys were $23.2 \%$ at baseline and $25.8 \%$ at end line, typical of that mode of data collection. Nevertheless, the sampling pool is large enough that we still have a large number of observations to detect relevant treatment effects on parents' beliefs and behaviors. The exact number of observations varies by outcome variable, since non-response increases throughout the call. As such, phone survey outcomes range from 4,064 to 4,471 observations at baseline, and from 3,868 to 4,974 observations at end line. Non-response was not differential across treatment arms (see Appendix B).

Third, administrative data from São Paulo State's Education Secretariat: quarterly data on students' attendance and GPA in math and Portuguese classes, standardized test scores in math and Portuguese (from the System of School Performance Evaluation of the State of São Paulo, Saresp - a State-wide mandatory exam for 9th grade public school students), and grade promotion status, across all sub-samples. Attendance is recorded in percentage points (0-100). GPA ranges from 0 to 10 (only integers), with a passing grade set at 5 points for all disciplines (failing one or more disciplines leads to grade repetition). This dataset comprises 22,850 observations. It includes even students whose caregivers did not opt in to participate in the program, allowing us to analyze the extent of selection into the program based on students' characteristics.

Fourth, weekly data on platform scores (rotating across attendance, punctuality and homework completion, all with respect to the 3 previous weeks) for all sub-samples but pure control schools and sub-sample E. ${ }^{27}$ This dataset features at least one week of attendance data for 12,641 students, at least one week of punctuality data for 12,208 students, and at least one week of homework completion data for 12,025 students.

\footnotetext{
${ }^{27}$ Teachers' average compliance rate across sub-samples and weeks was roughly $66 \%$; see Appendix C.
} 


\subsection{Descriptive statistics, balance and selection}

Table 1 presents the sample means of students' and primary caregivers' baseline characteristics by treatment arm, along with p-values of ANOVA tests of equality of means across groups. Panel A displays student's characteristics and Panel B, those of caregivers.

[Table 1]

The table shows that $48 \%$ of students in our sample are girls and $40 \%$ are brown or black - a little over the State average (35.6\%, according to the 2010 Census) since white families are typically wealthier in Brazil, and wealthy families typically send their children to private schools. In fact, $59 \%$ of primary caregivers in our sample earn less than 3 minimum wages (about USD 750 at the time), within the range of low socioeconomic status in the State. Students in our sample average 14.7 years old. Their math and Portuguese 1st-quarter grades average 5.9 and 6.2, respectively (in a 0 to 10 scale, with a passing grade of 5). $76 \%$ of primary caregivers are mothers, and those are, on average, at their early 40s. $69 \%$ of them have no education beyond middle school; as such, $2 / 3$ of participating students are at least as advanced in school as their parents ever were.

The sample is balanced across treatment arms: out of 17 variables, only age features statistically significant differences across groups, at the $10 \%$ level - which is expected to happen just by chance - and numerically irrelevant. To that point, F-tests document that baseline characteristics are not jointly different across groups, when it comes to either students' or caregivers' characteristics.

Receiving messages from the school as part of parents' participation in the study borne no costs; parents just had to provide consent and a valid phone number, either directly at parent-teacher meeting towards the end of the second quarter, or indirectly, by filling in a paper form that students took home when parents were absent from the school meeting. Over $66 \%$ of the 23,398 parents invited to participate signed up for the program.

Table 2 analyzes selection in opt-in. For parents who did not sign up, we have access to only a few student characteristics from the Secretariat of Education administrative records: their gender, age, math and Portuguese 1st-quarter attendance and grades, and their family's Bolsa Família's beneficiary status (known to schools because a high-enough attendance rate is part of the transfer's conditionality).

[Table 2]

The table shows that parents who signed up for the program are from relatively betteroff households: their children had statistically higher attendance and grades, and they were less likely to be Bolsa Família beneficiaries. Since any educational intervention that requires parents' consent is expected to have imperfect compliance, we focus throughout on the average treatment effect on the treated. Having said that, Appendix B shows that our results are robust to re-weighting observations by their inverse probability of opt-in. 


\subsection{Estimation}

To estimate the effects of the informational intervention and the extent to which those are driven by salience, we estimate the following equation:

$$
Y_{s c i}=\alpha+\beta_{1} \text { info }_{s c i}+\beta_{2} \text { salience }_{s c i}+\beta_{3} \operatorname{control}_{s \notin\{B\}, c i}+\sum_{k=1}^{K} \gamma_{k} X_{s c i k}+\theta_{s}+\varepsilon_{s c i},
$$

where $Y_{s c i}$ denotes the outcome of interest for student $i$ in classroom $c$ of school $s$; info $_{s c i}=1$ for students whose parents were assigned to child-specific messages, and 0 otherwise; $_{\text {salience }} s c i=1$ for students whose parents were assigned to salience messages, and 0 otherwise; $\operatorname{control}_{s \notin\{B\}, c i}=1$ for the control group (other than in pure control schools), and 0 otherwise - with pure control schools as the omitted category. Next, $X_{s c i}$ is a matrix of student characteristics, including their gender, age and race, their baseline attendance and GPA, and their parents' gender, age, race, income and education; $\theta_{s}$ stands for randomization stratum fixed-effects; and $\varepsilon_{s c i}$ is the error term.

Coefficients are estimated using Ordinary Least Squares (OLS). We cluster standarderrors at the classroom level, allowing for arbitrary correlation among residuals of students under the same teacher. We are interested in testing $\beta_{1}=\beta_{2}$.

When we estimate treatment effects on platform scores (Section 5.1), we omit the within-classroom control category instead, as those outcomes were not collected in pure control schools. When it comes to treatment effects on administrative educational outcomes (Section 5.2), we start by estimating equation 1 only within sub-samples A and B. In robustness checks, we augment this specification with an indicator variable for students whose parents were assigned to child-specific information framed relative to their classroom median, when including sub-sample $\mathrm{C}$, and allow the salience coefficient to vary in subsample D (where no parent is assigned to child-specific information).

Following our pre-analysis plan, treatment effects on administrative educational outcomes are analyzed individually. In contrast, when it comes to platform scores, measures of parental engagement, and students' socio-emotional skills, we handle family-wise error rates from multiple comparisons by computing standardized summary measures, following Kling et al. (2007).

\section{Effects on parent's accuracy about student effort}

This section tests whether the informational intervention indeed makes parents more accurate about their children's school effort, while the salience intervention does not. Subsection 4.1 starts by describing the distribution of parents' beliefs about student attendance and grades at baseline, followed by statistical tests of treatment effects on parent's accuracy in subsection 4.2 . 


\subsection{Baseline beliefs}

Parents' beliefs about student attendance and grades were elicited (non-incentivized) through our baseline phone survey. When it comes to attendance, parents were asked to provide their best estimate of how many times their child had missed math classes over a typical three-week period. Their answers were then compared to administrative records on students' attendance over the first quarter. ${ }^{28}$ Parents had to choose which bracket best approximated their estimate: no absences; 1 to 2 absences; 3 to 5 absences; or more than 5 absences. ${ }^{29}$ Parents were also asked to give their best estimate of their child's 1st-quarter math grade. Again, parents had to choose which bracket best approximated their estimate: below average (0-5); adequate (5-6); good (7-8); or very good (9-10).

Figure 1 showcases the distribution of parents' beliefs at baseline, contrasted with actual student attendance and grades.

\section{[Figure 1]}

The figure shows that only about $1 / 3$ of parents choose the correct bracket for either their children's baseline attendance or GPA in math classes. On average, parents are overoptimistic about their children's attendance: similarly to Bergman (2021), most parents think that their child misses fewer classes than they actually do. While over $40 \%$ of respondents think their child has missed no classes over the last 3 weeks, this is true for only about $15 \%$ of the students. This sets the stage for the typical moral hazard story, whereby information has parents monitor children more intensely (in face of lower monitoring costs), increasing student effort, and ultimately improving learning outcomes as a result. The next subsection provides direct evidence that parents indeed update their beliefs in response to the informational intervention - but not in response to the salience intervention.

\subsection{Treatment effects on parents' accuracy about effort levels}

Throughout this subsection, we restrict attention to parents' accuracy about student attendance in math classes, since the intervention did not convey information about their GPA. We defer the discussion of treatment effects on parents' accuracy about student GPA until Section 6.2, in the context of information-seeking behavior by parents.

Following Dizon-Ross (2019), we compute the correlation between parents' beliefs and children's actual absences at end line, across the different experimental conditions. If parents were perfectly accurate, that correlation would be equal to 1. At baseline, however, the correlation between parents' beliefs about their children's absences in math classes over

\footnotetext{
${ }^{28}$ We asked about the 3 previous weeks to frame the question consistently with the information respondents would (potentially) receive over text messages. Since attendance data from the Education Secretariat comprises the entire span of the 1st quarter, we scale it down proportionately to generate its three-week equivalent.

${ }^{29}$ See Supplementary Appendix J for the full script.
} 
the previous 3 weeks and children's actual absences in that period was only $0.22 .{ }^{30}$ What is more, even if parents were accurate at baseline, student effort cannot simply be inferred from children's previous school standing (made available through scorecards shared by schools at the end of each quarter): the correlation between 2nd-quarter math GPA and mean platform scores entered by teachers for control students over the course of the 3rd and 4th quarters is only 0.54 for homework completion, 0.32 for attendance and 0.24 for punctuality.

At the end line, we compute that correlation using children's actual absences reported by teachers through the platform, since that was the content parents in the information treatment actually received. We ask parents to provide their best estimate of how many times their child had missed math classes over the 4th quarter. Parents' beliefs are discretized just as in Bergman (2021); they had to choose which bracket best approximated their estimate: $0 ; 1-2 ; 3-5 ; 6-8$; or more than 8 absences. In turn, teachers reported on each student's attendance every 3 weeks, specifying how many classes they missed over that interval (missed 0, 1-2; 3-5; 5 or more). We compute actual absences as the average of teachers' reports over the 4 th quarter, such that the exercise compares parents' beliefs to the exact information conveyed through the child-specific information treatment without requiring additional computation. ${ }^{31}$

Figure 2 documents end-line correlations within each treatment arm through local polynomial regressions, residualizing beliefs and actual absences with respect to all characteristics of students and their caregivers that we observe. ${ }^{32}$

\section{[Figure 2]}

The figure shows that, similarly to the baseline correlation, the end-line relationship between parents' beliefs and children's actual absences remains much flatter than the 45degree line in the control group. In turn, in the information group, Panel A shows that such relationship is steeper: treated parents of low-absenteeism children become more optimistic about their attendance relative to those in the control group, while the opposite is true at the high-end of the absenteeism distribution.

Reassuringly, Panel B documents that the same is not the case for the salience intervention: its local polynomial regression line basically coincides with that of the control group over the entire range of actual absences.

\footnotetext{
${ }^{30}$ We have access to children's actual absences over the 1st quarter - not over the 3 weeks prior to the baseline survey. Since a school quarter lasts 9 weeks, we divide that figure by 3 to compute our actual absences' indicator. Measurement error due to the coarse categories made available for parents to express their estimates, or due to systematic time trends in absences over that 9-week period, should be statistically identical across treatment arms.

${ }^{31}$ Measurement error due to the coarse categories made available for parents to express their estimates, or due to differences in the scales of beliefs and actual absences in this exercise, should be statistically identical across treatment arms - and, hence, should not affect our estimates of treatment effects. See Appendix D for additional details.

${ }^{32}$ We restrict the $\mathrm{X}$-axis to the $[0,3]$ interval in both panels since very few observations are in the $(3,4]$ range, rendering non-parametric estimates infeasible.
} 
Table 3 documents that those patterns hold in a regression framework. Columns 1 and 3 restrict attention to the information and the control groups (both within-classroom and pure control), while columns 2 and 4, to the salience and control groups (both withinclassroom and pure control). Columns 1 and 2 document that the correlation between parents' beliefs and children's actual absences is not statistically different across groups at baseline, and columns 3 and 4 estimate treatment effects of information and salience on that correlation, respectively. ${ }^{33}$

[Table 3]

Columns 3 and 4 show that, at the end line, information increases the correlation between parent's beliefs and children's actual absences from 0.31 to 0.42 (column 3; significant at the $5 \%$ level). In turn, salience decreases it (by roughly $20 \%$ of the control average, in column 4), although the effect is not precisely estimated. In sum, the informational intervention does make parents more accurate, while the salience intervention does not.

\section{$5 \quad$ Effects on educational outcomes}

Having shown that the interventions affect parents' beliefs as intended, this section documents treatment effects on educational outcomes. We present the effects of the interventions on platform scores in subsection 5.1, and on administrative outcomes in subsection 5.2. Subsection 5.3 follows by estimating heterogeneous treatment effects of child-specific and salience messages with respect to student effort (captured through the data entered by teachers into the platform), to shed light on the nature of conditional impacts documented in the literature. Next, subsection 5.5.3 estimates dynamic treatment effects, followed by robustness exercises in subsection 5.5.

\subsection{Treatment effects on platform outcomes within the classroom}

On the first time teachers entered student attendance data on into the platform, only $34.6 \%$ of students had not missed any math classes in the 3 previous weeks; in fact, $20.7 \%$ of them had missed 5 classes or more over that period. Homework completion was also underwhelming: only $46.2 \%$ of students handed in all assignments in the 3 weeks prior to the first time teachers reported on that dimension; $13 \%$ had not handed in assignments at all. In turn, tardiness was much less of a problem: roughly $80 \%$ of students were never late in any particular week when this dimension was reported on by teachers.

We estimate the effects of child-specific information and salience messages on students' attendance, punctuality and homework completion in math classes, as entered by teachers into the platform. To do that, we stack the data in a panel structure, and estimate the effects of interest absorbing classroom fixed-effects and controlling for a linear time trend

\footnotetext{
${ }^{33}$ The number of observations differs across columns 1-2 and 3-4 because of differences in response rates across the baseline and end-line phone surveys; non-response is not systematically different across treatment arms; see Appendix B.
} 
(to account for systematic variation in student behavior as the school year draws to an end). To avoid the issue of multiple comparisons in face of the different dimensions of student effort, we compute a summary measure of platform scores (following Kling et al., 2007), which takes the value of the dimension reported at each week, standardized with respect to the mean and standard deviation of the control group. Table 4 presents the results in column (1), as well as treatment effects on each of its components in columns (2) through (4).

[Table 4]

Column 1 presents treatment effects on the summary measure of student effort. Salience messages improve effort by 0.019 standard deviation (significant at the $5 \%$ level). Since effort increases over the course of the school year, this effect size is equivalent to skipping nearly 3 weeks ahead relative to control students. In turn, information does not significantly increase student effort. Analyzing the effects on its components, treatment effects on the summary measure are mostly driven by effects on attendance (column 2), which increases by 0.031 standard deviation in response to salience messages (significant at the $1 \%$ level) - an effect size nearly 3-fold that of child-specific information. For the other components (columns 3 and 4), the estimates for information and salience effects are very similar and not statistically different from zero, and we cannot reject that the effect sizes of the interventions are statistically identical in all four columns (at the 10\% significance level).

\subsection{Treatment effects on administrative outcomes}

Next, we estimate the effects of child-specific information and salience messages on students' 4th-quarter attendance in math classes, 4th-quarter math GPA, math standardized test scores, and their likelihood of advancing to high school. ${ }^{34}$ Table 5 presents the results.

[Table 5]

Average 4th-quarter attendance in pure control schools is already reasonably high. Students attend $87.5 \%$ of math classes in those schools; after all, $75 \%$ or higher attendance is a requirement for grade promotion, and $85 \%$ or higher, a conditionality for Bolsa Família payments. Nevertheless, information significantly increases it by 2.1 percentage points (significant at the 1\% level), an effect size equivalent to five additional classes (roughly, a full extra week of math) over the course of the school year. Information also increases math GPA by 0.071 standard deviation (significant at the $5 \%$ level), an effect size similar to that of other SMS informational interventions (e.g. Berlinski et al., 2016). While math GPA is computed from tests graded by the teacher herself, child-specific information also significantly increases standardized test scores attributed by third-party graders, to an even

\footnotetext{
${ }^{34}$ The analyses restrict attention to students who were still in school by the end of the year, and who had taken the standardized test, in each case. Supplementary Appendix B documents that our results are not driven by selection.
} 
greater extent ( 0.107 standard deviation, significant at the $5 \%$ level). This is a large effect size, equivalent to treated students finishing up the school year 1 school quarter ahead of the control group. ${ }^{35}$ Those learning gains particularly benefit students on the margin of failing math class, as child-specific information leads to a significant and sizeable increase in the likelihood of advancing to high school: 2.6 percentage points (significant at the 5\% level), a nearly $1 / 3$ reduction in grade repetition relative to pure control schools.

Strikingly, we find that salience accounts for the lion's share of the effects of the informational intervention. Not only do salience messages also significantly improve all educational outcomes, but also, their effect sizes are always statistically identical to those of child-specific information (at the $10 \%$ level). This is not a matter of statistical precision: the ratio of salience coefficients to those of child-specific information is never below $89 \%$. Moreover, as in the case of platform scores (Section 5.1), salience effect sizes are sometimes larger - up to $126 \%$ of those of child-specific information. ${ }^{36}$

Table 5 also shows that the interventions have large spillovers on control students within the classroom: students whose parents were assigned not to receive messages within classrooms where other parents were treated also improve systematically relative to the pure control group, by as much or only slightly less than those assigned to child-specific information or salience messages. While our research design cannot pin down the specific nature of spillovers - potentially a combination of peer effects, parent interactions and teacher effects -, Section 5.5 provides extensive evidence that the absence of differences between the information and salience groups is not driven by such second-order effects of the informational intervention.

Figure 3 plots the densities of math standardized test scores within each treatment arm to show that the lack of differences between the average effects of child-specific information and salience messages does not mask different patterns for their distributional effects.

[Figure 3]

The figure shows that the distributions of standardized test scores of students whose parents were assigned to child-specific information or salience messages are equally shifted to the right relative to that of pure control students. A Kolmogorov-Smirnov test rejects the hypothesis that the salience and pure control test score distributions are the same (at the $10 \%$ level), and fails to reject equality of the child-specific information and salience distributions $(\mathrm{p}=0.94)$.

Since administrative outcomes other than standardized test scores have discrete ranges (e.g. math GPA can only take integer values between 0 and 10), another way to analyze distributional effects is estimating heterogeneous treatment effects according to students' baseline educational standing. Table 6 replicates the analyses separately for students below and above the median 1st-quarter math attendance.

\footnotetext{
${ }^{35}$ Based on comparing the average performance in SARESP of ninth graders and that of high-school freshmen, and dividing the difference in averages by 4 to compute expected quarterly learning.

${ }^{36}$ For both child-specific information and salience messages, treatment effects are concentrated on boys; see Appendix G.
} 
[Table 6]

The table shows that, as in the main analyses, salience effect sizes are never statistically lower than those of child-specific information. Quite the contrary, salience effects are actually higher than those of child-specific information among below-median attendance students (significant at the 5\% level for math GPA and grade promotion). Among those students, the effect of salience messages is almost two-fold that of information on math GPA (nearly 0.12 s.d.), and nearly $50 \%$ higher when it comes grade promotion. In effect, the effect of salience messages on the likelihood of advancing to high school among students with below-median attendance is 3 -fold that among above-median students $(\mathrm{p}=0.02)$. Those patterns are striking, as intuition suggests that these students would be the ones most likely to benefit from informational interventions in face of parent-child moral hazard.

In sum, results suggest that salience interventions can do just as well as child-specific information on average, and even better among students with lower attendance at baseline.

\subsection{Conditional impacts}

Dizon-Ross (2019) documents that higher accuracy leads to higher inequality: the informational intervention decreases misallocation of educational investments, with parents increasing (decreasing) investments in high-(low-)performing children, relative to the control group. Is it also the case when it comes to our informational intervention? How about when it comes to salience messages? This subsection documents heterogeneity in treatment effects on educational outcomes with respect to student effort, as captured through platform scores.

We interact treatment indicators with the average score entered by teachers into the platform for each student over the course of the experiment, estimating different regressions for each dimension of student effort. We are interested in whether the effects of childspecific information and salience messages vary systematically with average platform scores. In Dizon-Ross (2019), parents of low-performing children reduce educational investments relative to the control group, while the opposite is true for parents of high-performing children. In our regression, that would be equivalent to a negative coefficient for the treatment indicator, and a positive coefficient for its interaction with average platform scores.

Appendix F documents heterogeneous treatment effects on educational outcomes conditional with respect to student attendance, punctuality and homework completion. Because teachers did not fill in the platform in pure control schools, estimates are relative to the within-classroom control group, absorbing classroom fixed-effects. As one would expect, higher attendance, punctuality and homework completion positively and systematically correlate with better educational outcomes in Tables F.1-F.3. Although large spillovers from the interventions on within-classroom control students make treatment effects hard to detect, the Appendix documents interesting patterns for conditional impacts. For nearly all outcomes across attendance, punctuality and homework completion, the coefficient of 
child-specific information is negative, and that of its interaction with average platform scores, positive, consistent with parents 'doubling down' on students who are already doing well as in Dizon-Ross (2019). Having said that, the exact same patterns also hold when it comes to salience messages: its coefficient and that of its interaction with average platform scores have the same sign as those of child-specific information across all columns in each table. In some cases, such conditional impacts are even larger and more precisely estimated when it comes to salience messages, as in the case of treatment effects on 4th-quarter math attendance conditional on student punctuality.

In our experiment, conditional impacts manifest mostly as negative treatment effects on low-effort students targeted by the interventions, relative to low-effort students in the control group. For instance, we estimate that the informational intervention decreases the likelihood of advancing to high school by 9.6 p.p. for students who are always late, and increase it by 0.5 p.p. for those who are never late. ${ }^{37}$ Symmetrically, we estimate that salience messages decrease the likelihood of advancing to high school by 6.8 p.p. for students who are always late, and increase it by 0.8 p.p. for those who are never late. ${ }^{38}$

How is it possible that the two interventions alike induce conditional impacts with respect to student effort, when only child-specific information makes parents more accurate about effort levels? Such patterns are consistent with two (non-mutually exclusive) potential mechanisms - both distinct from parents re-optimizing in face of frictionless belief updating. First, it could be that low-effort students react differentially to higher parental engagement, which increases in response to both child-specific information and salience messages, regardless of parents' underling beliefs (see Section 6.1). Second, it could be that both interventions lead parents to acquire information independently - along the lines of "learning through noticing" (Hanna et al., 2014) -, changing educational investments in response to updated beliefs about their children's school performance. In fact, we show that, in both treatment conditions, parents become more accurate about changes in math GPA over time (see Section 6.2). We return to this discussion in Section 6.

\subsection{Dynamic treatment effects}

This subsection estimates dynamics treatment effects, taking advantage of the fact that we have access to quarterly data on math attendance and GPA from the Education Secretariat administrative records. We can test whether those outcomes did not vary systematically across treatment and control parents before the onset of the interventions, and whether treatment effects systematically increase or decrease over time.

This is particularly of interest for the effects of salience messages. Although we show that those messages do not affect parents' accuracy about student attendance at end line, it could still be that parents initially react to salience messages because they (wrongly) infer information from those. Specifically, if parents assigned to the salience intervention

\footnotetext{
${ }^{37}$ Respectively, $-0.130+(0.0338 \times 1)=-0.0962$ and $-0.130+(0.0338 \times 4)=0.0052$, since teachers rate student effort in each dimension from 1 to 4 .

${ }^{38}$ Respectively, $-0.0931+(0.0252 \times 1)=-0.0679$ and $-0.0931+(0.0252 \times 4)=0.0077$.
} 
think that they are getting messages because their children are putting in low effort at school, they might disproportionately react to the intervention. As time goes by, however, as more and more parents realize that this interpretation is unwarranted, they would eventually stop reacting to salience messages, leading their effects to fade out over time. This alternative story - which is consistent with no differential accuracy at end line and better learning outcomes - would have important implications for the interpretation and generalizability of our findings. This subsection allows us to test this hypothesis.

Figure 4 displays how math attendance (Panel A) and math GPA (Panel B) vary quarterly within each treatment arm.

\section{[Figure 4]}

Panel A displays a downward trend for math attendance over the course of the school year for all groups. The interventions, however, are able to partly mitigate that trend over the third and fourth quarters. Differences between groups become significant only in the 3rd quarter, and persist into the 4th quarter. Most importantly, differences between the salience and pure control groups increase over time: salience effect size increases from 1.3 to 2.1 percentage points from one quarter to the next. In Panel B, grades display an upward trend over the second half of the school year for all groups, but particularly so for those targeted by the interventions. As in the case of attendance, differences between the salience and pure control groups increase over time: salience effect sizes of increases from 0.092 to 0.104 standard deviations between quarters. ${ }^{39}$ In both cases, there is no mechanical reason for effect sizes to increase over time (e.g. compounding), since attendance and GPA figures are computed within each quarter.

\subsection{Robustness checks}

This subsection assesses the robustness of our findings to the remaining identification concerns discussed in Section 3.2.2. Subsection 5.5.1 explores whether conclusions change when child-specific information is framed relative to classmates' median behavior. Next, subsection 5.5.2 investigates whether results are driven by spillovers from the informational intervention on students whose parents were assigned to salience messages. Last, subsection 5.5.3 documents whether results are driven by teacher effects because of data entry into the platform.

\subsubsection{Are child-specific messages informative enough?}

Is child-specific information really unnecessary, or did our experiment convey too little information to improve educational outcomes above and beyond the effects of making student effort top-of-mind? As Rogers and Feller (2016) argues, while it might reasonably low-cost

\footnotetext{
${ }^{39}$ The slight difference between the salience effect size on 4th-quarter Math GPA in Table 5 and Figure 4 stems from the diff-in-diff specification in the latter, which nets out baseline differences across the salience and pure control groups.
} 
for a parent to acquire information on their child's school behavior, it might be much more costly to figure out what is the relevant benchmark against which to compare it. This subsection considers a more demanding counterfactual for salience effects, estimating the effects of framing child-specific information each week against the backdrop of classmates' median behavior.

Table 7 shows the results of a regression that also includes sub-sample C, where students were randomly assigned into either control, salience, child-specific information, or relative information. As discussed in Section 3.6, we augment equation 1 with an indicator variable equal to 1 for children whose parents received child-specific information framed relative to the classroom median, and 0 otherwise.

\section{[Table 7]}

The table shows that, similar to Rogers and Feller (2016), effect sizes of framing childspecific information in relative terms tend to be larger than those of not doing so. That is the case for math attendance and GPA, and notably for standardized test scores (an effect size of 0.141 standard deviations, about $50 \%$ larger than that of information itself). The exception is grade promotion, for which its effect size is actually lower, less than $60 \%$ that of child-specific information alone.

Most importantly, when it comes to the comparison between salience and relative information, the only instance for which their effects are statistically different is exactly grade promotion - for which it is the effect size of salience that is higher (significant at the $10 \%$ level). Even when it comes to standardized test scores, salience effects are still over two thirds of the effect size of relative information, and they are statistically indistinguishable.

While results suggest that the finer child-specific information is, the higher its potential to improve learning outcomes - at some point, possibly above and beyond the impacts of salience messages -, they also suggest that salience is still likely to play a major role behind its effects. In any case, the informational intervention we use throughout the paper matches the typical structure of school-parents communication campaigns in developing countries (as in Berlinski et al., 2016, which also finds a 0.09 effect size of an text-message information program on students' standardized test scores).

\subsubsection{Are results driven by spillovers from child-specific information?}

As discussed in Section 3.2, even with a pure control group, it could still be the case that the salience and information treatments interact within treated schools. This is a specific form of contamination across treatments that does not affect control students. It could happen if parents in the salience treatment ask other parents about messages, and infer from some of those conversations information about their own child's school behavior thanks to the information treatment. To test this hypothesis, this subsection investigates whether salience effects are lower in sub-sample D, where students were assigned to either salience messages or control - but not to child-specific information. 
Concretely, we estimate the following equation:

$$
\begin{array}{r}
Y_{s c i}=\alpha+\beta_{1} \text { info }_{s c i}+\beta_{2} \text { salience }_{s c i}+\beta_{3} \text { control }_{s \notin B, c i} \\
+\beta_{4} \text { salience }_{s c i} \times 1\{s \in D\}+\varphi 1\{s \in D\}+\sum_{k=1}^{K} \gamma_{k} X_{s c i k}+\theta_{s}+\varepsilon_{s c i},
\end{array}
$$

where $1\{s \in D\}=1$ if the school belongs to sub-sample D (50\% salience, $50 \%$ control), and 0 otherwise. We are interested in testing $\beta_{4} \leq 0$.

Table 8 shows the results of estimating equation 2, allowing salience effects to vary in schools where the informational intervention is absent. Panel A estimates differential treatment effects of salience messages within the no-information sub-sample through an interaction term, and Panel B estimates treatment effects of salience messages restricting attention to that sub-sample and the pure control group.

\section{[Table 8 ]}

We find overwhelming evidence that salience effects are not driven by spillovers from the informational intervention. If anything, salience effects are actually larger in the absence of child-specific information, although differential effects are mostly statistically insignificant at conventional significance levels. ${ }^{40}$

\subsubsection{Are results driven by teacher effects?}

As discussed in Section 5.2, spillover effects from the interventions on control students within the classroom are substantial: those students experience almost as large effects on math attendance and GPA, and statistically identical effects on standardized test scores and grade promotion rates. Since we rely on pure control schools as a counterfactual where teachers did not have to enter data about student effort each week into the platform -, an important concern is whether our results are driven by differences in teacher behavior across different sub-samples. If that were the case, then attributing most of the effects of informational interventions to salience would be misleading, and our findings would not generalize in contexts where teachers are not responsible for high-frequency data entry.

There are two ways to address that concern. The first is to note that, even within classroom, our interventions improve educational outcomes even relative to the withinclassroom control group: that is the case for the summary measure of platform scores (significant at the 5\% level), and marginally so for 4 th quarter math attendance and math GPA ( $\mathrm{p}=0.161$ and $\mathrm{p}=0.137$, respectively; see Table 5$)$. The second is to resort to our additional experiment, in which we randomly assigned some students to nudges (sub-sample E; see Section 3.2.2).

\footnotetext{
${ }^{40}$ The frequency at which teachers filled in the platform weekly was slightly higher in sub-sample D than in other sub-samples (statistically significant at the $1 \%$ level; see Appendix B). Results are robust to bounding treatment effects to account for selection; see Appendix E.
} 
In those schools, we randomly assigned participants to either control or nudges, reaching parents directly without child-specific information or the need to involve teachers at all. Nudges shared weekly suggestions of activities for parents to do with their children, also through weekly SMS. ${ }^{41}$ Messages are not linked to curricular activities; rather, those try to bring parents closer to their children's school life by having them ask about school, discuss future plans, and share how they dealt with similar issues back in the day. Nudges are structured around bi-weekly sequences, inspired by READY4K! (York et al., 2019) (see Supplementary Appendix A for sample sequences).

We estimate treatment effects of nudges relative to pure control schools, precisely because of large spillovers within classroom. The main identification challenge, as discussed in section 3.2.2, is that students within sub-sample E were not statistically identical at baseline to those of our main sample. The reason is that the Education Secretariat required us to work in a different region whenever the teacher platform was not made available for skills (for logistical reasons linked to training), and students had relatively lower 1st-quarter math grades in that other region.

Even though we can control for a wide array of students' and parents' characteristics, one may still worry that students of different profiles could have evolved differentially over time due to unobservable factors that cannot be controlled for. To deal with this concern, we take advantage of the fact that our program was ran only during the second half of the school year, and use a differences-in-differences strategy to compare the evolution of the different sub-samples, before and after the program was introduced. We restrict attention to math attendance and GPA, for which we have quarterly data.

The differences-in-differences estimator identifies the causal effects of nudges under the assumption that educational outcomes would not have changed differentially across nudge schools and pure control schools in the absence of the intervention. While the identification assumption cannot be tested, we can test whether outcomes across those groups varied differentially over the first two quarters - before the onset of the program.

We estimate the following equation:

$$
\begin{array}{r}
Y_{s c i t}=\alpha+\beta_{1}\left(\text { nudge }_{s c i} \times \text { Post }_{t}\right)+\beta_{2}\left(\text { control }_{s \in E, c i} \times \text { Post }_{t}\right) \\
+\theta \text { Post }_{t}+\gamma_{1} \text { nudge }_{s c i}+\gamma_{2} \text { control }_{s \in E, c i}+\varepsilon_{s c i t}
\end{array}
$$

where $Y_{\text {scit }}$ denotes the outcome of interest for student $i$ in classroom $c$ at school $s$ on quarter t; nudge $_{s c i}=1$ for students assigned to nudges, and 0 otherwise; $\operatorname{control}_{s \in E, c i}=1$ for students assigned to the control group within sub-sample E, and 0 otherwise; Post $_{t}=1$ if $t \geq 3$, and 0 otherwise; and $\varepsilon_{\text {scit }}$ stands for the error term. We are interested in testing $\beta_{1}=0$. We can also investigate within-classroom spillovers in the absence of teacher effects by testing $\beta_{2}=0$.

Table 9 estimates the effects of nudges on math attendance (column 1) and math GPA

\footnotetext{
${ }^{41}$ The program, Eduq + , is powered by edtech Movva (http://movva.tech).
} 
(column 2) using equation 3. Columns 3 and 4 estimate a placebo exercise, restricting attention to the first two quarters - before the onset of the intervention -, and setting Post $_{t}=1$ if $t=2$, and 0 otherwise, to test for differential pre-trends between the nudge and pure control groups.

[Table 9]

Columns 1 and 2 show that nudges have significant impacts on both outcomes, increasing math attendance by 1.5 p.p. and math GPA by 0.12 s.d. relative to the pure control group (both significant at the 1\% level). Strikingly, nudges' effect size on learning is $50 \%$ larger than that of salience messages alone, suggesting that non-specific and more engaging content can capture parents' attention to a greater extent (see Section 6.3). Last, columns 3 and 4 document no differential pre-trends between the nudge and pure control groups with respect to either attendance or GPA.

Figure 5 allows treatment effects to vary more flexibly over the course of the school year, estimating non-parametric effects of nudges on math attendance (Panel A) and math GPA (Panel B) relative to the pure control group with the first quarter as the reference period.

\section{[Figure 5]}

Both panels confirm that differences between the nudge and pure control groups only arise after the onset of the intervention. They also confirm the patterns we document for dynamic treatment effects of salience messages (Section 5.4), as the effects of nudges do not systematically decay between the $3 \mathrm{rd}$ and 4 th quarters. Together, our findings rule out that the effects of salience messages are driven by teacher effects.

\section{Mechanisms}

This section turns to the mechanisms behind treatment effects. We start by estimating treatment effects on parents' behavior and aspirations, and on students' time use in subsection 6.1. Next, subsection 6.2 documents treatment effects on parents' information-seeking behavior, by studying their accuracy with respect to end-line math GPA - as the informational intervention never conveyed child-specific information on grades. Last, subsection 6.3 turns to attentional constraints, providing direct evidence that the frequency of messaging and their content's specificity affect the depth and breadth of their impacts on learning outcomes.

\subsection{Parental engagement and students' time use}

Why is it that the interventions improve student's educational outcomes? To study this question, we take advantage of end-line survey data on parents' behavior and aspirations, and on students' time use. Students were asked 12 questions about how often (never, almost 
never, sometimes, almost always, or always) their parents typically engage in different activities. We pre-registered that we would compute 3 summary measures of parental engagement based on those questions (standardizing their components and averaging across them within summary measure; Kling et al., 2007): academic activities (comprising help with homework, help with organizing school materials, participation in school meetings, and conversations with teachers); motivation (comprising words of incentives to attend school, to be on time, to study, and to read); and dialogue(comprising conversations about homework, about grades, about the day at school, and about classes). We also estimate treatment effects on parents' aspirations, an indicator variable equal to 1 if the student states at end line that their parents believe s/he would make it to college, and 0 otherwise. Table 10 presents treatment effects on the summary measures of parental engagement and aspirations.

\section{[Table 10]}

We find that both child-specific information and salience messages lead parents to ask their children significantly more about school and to incentivize studying to a greater extent than those in the control group. Moreover, both significantly induce higher aspirations about their children's making it to college. Across all columns, the effects of information and salience are statistically indistinguishable at conventional significance levels.

Next, students were asked how many hours per day (0, 15 minutes, 30 minutes, 1 hours, 2 hours, more than 2 hours) they spend on a range of different activities. We preregistered we would compute 3 summary measures of students' time use based on those questions (standardizing their components and averaging across them within summary measure; Kling et al., 2007): academic activities (studying at home on weekdays; studying at home on weekends; studying at home the day before an exam); reading (reading a book; reading the newspaper; reading magazines); and other activities (watching TV; browsing the internet or on social media; and helping with house chores). Table 11 presents treatment effects on those measures of students' behavior.

\section{[Table 11]}

Students whose parents were assigned to either child-specific information or salience messages report engaging in academic and reading activities to a significantly greater extent than those in pure control school. Once again, across all columns, the effects of information and salience are statistically indistinguishable at conventional significance levels.

As discussed in Section 5.3, the fact that parents' and students' behaviors respond alike to child-specific information and salience messages could explain why we find conditional impacts on educational outcomes with respect to student performance even if parents in the salience group could not condition responses on more accurate beliefs about their children's attendance, punctuality and homework completion. That could be the case if low-effort students responded differentially to higher parental engagement, resulting in worse grades 
and likelihood of advancing to high school relative to low-effort students in the control group. We unfortunately do not have statistical power to test this hypotheses directly, by estimating heterogeneous treatment effects on student time use with respect to student effort, because of the large within-classroom spillovers of the interventions.

\subsection{Information acquisition}

Why does parental engagement and student behavior react just as much to salience messages as they do to child-specific information? This subsection documents that such patterns are consistent with treatment effects on parents' information-seeking behavior, analyzing how the accuracy of parents' beliefs about their children's math GPA changes in response to the interventions.

At the baseline phone survey, parents were asked to provide their best estimate of their child's 2nd-quarter math grade. Parents had to choose one out of four categories: below average (0-4); adequate (5-6); good (7-8); or very good (9-10). At the end-line phone survey, we asked parents to guess their children's math GPA directly (open-ended, between 0 and 10). We build a 4-point scale variable for end-line beliefs equivalent to the baseline variable.

We compute the correlation between parents' beliefs and children's math GPA at end line, across the different experimental conditions. If parents were perfectly accurate, that correlation would be equal to 1 . Figure 6 shows, however, that this correlation is not only much lower in the control group, but also, no higher in the information group (Panel A) or the salience group (Panel B) - perhaps unsurprisingly, as none of our interventions conveyed child-specific information about grades. Next, we compute the correlation between changes in parents' beliefs and that in children's math GPA between baseline and end line, across the different experimental conditions. While in the control group that correlation is nearly zero - parents seem to have very limited awareness of whether their children are improving or deteriorating throughout the school year -, it is systematically higher in both the information group (Panel C) and the salience group (Panel D). All in all, both interventions lead parents to coarsely update beliefs: they come to understand that their children's grades are going up or down, even if they are still not any better in guessing by how much, relative to the control group.

[Figure 6]

Table 12 shows that these patterns hold in a regression framework. Columns 1, 3 and 5 restrict attention to the information and the control groups (both within-classroom and pure control), while columns 2, 4 and 6, to the salience and control groups (both withinclassroom and pure control). Columns 1 and 2 document that the correlation between parents' beliefs and children's actual math GPA is not statistically different across groups at baseline; columns 3 and 4 estimate treatment effects of information and salience on that correlation; and columns 5 and 6 estimate treatment effects of information and salience 
on the correlation between changes in parent's beliefs between baseline and end line and changes in math GPA between the 2 nd and 4 th quarters. ${ }^{42}$

[Table 12 ]

Columns 3 and 4 confirm that neither child-specific information nor salience messages make parents systematically more accurate about their children's 4th-quarter math GPA. In turn, both interventions make parents a lot more accurate about changes in math GPA over time: child-specific information increases the correlation between changes in beliefs and actual changes in math GPA by $2 / 3$ (significant at the $1 \%$ level, column 5 ), and salience messages, by nearly $50 \%(\mathrm{p}$-value $=0.125$, column 6$)$.

Results suggest that both interventions lead parents to acquire information independently. While accuracy gains among parents targeted by child-specific information could be partly explained by the fact that student attendance and math GPA are positively correlated, our results suggest that roughly $70 \%$ of those gains are actually due to salience effects; after all, parents in the salience group do not become more accurate about student effort, but do so when it come to changes in math GPA between baseline and end line. These results are also not an artifact of salience messages making parents merely less optimistic about their children's educational outcomes: our results show that is not the case for math attendance or GPA levels neither for changes in math GPA over time; moreover, Figure D.1 shows that while most parents were in fact too optimistic with respect to their children's baseline attendance in math classes, the same was not the case with respect to baseline math GPA - parents were roughly equally distributed across optimistic, accurate and pessimistic before the intervention.

Last, Appendix H presents additional evidence on parents' information-seeking behavior, estimating heterogeneous treatment effects by parents' willingness to receive information (WTR), stated at baseline. Chassang et al. (2012) posits that subjects with higher demand for the intervention should be precisely the ones who exert higher effort within the setting of the randomized control trial. We document that, in our setting, that seems to be the case regardless of the intervention: effect sizes of child-specific information are actually larger among parents with low WTR, who might only independently acquire information when primed by the salience effects of the intervention.

All in all, our findings are consistent with inattention and "learning through noticing" (Hanna et al., 2014). As discussed in Section 5.3, this mechanism could explain why we find conditional impacts on educational outcomes with respect to student performance even if parents in the salience were no more accurate with respect to student attendance reported by teachers through the platform.

\footnotetext{
${ }^{42}$ The number of observations differs across columns 1-2, 3-4 and 5-6 because of differences in response rates across the baseline and end-line phone surveys, and in the number of subjects who answered both surveys; non-response is not systematically different across treatment arms; see Appendix B.
} 


\subsection{Attentional constraints}

Last, while the previous results provide strong support for attentional constraints as the main driver of the impacts we document, this subsection provides direct evidence of parents' inattention. To do that, we turn to communication features of our intervention, exploring random variation in (1) the specificity of the content of messages sent to parents (framed around math classes, or otherwise), and (2) the frequency of messaging.

First, we study the extent to which subject-specific salience messages have effects confined to that subject. Due to working memory limitations and heuristics such as associativeness (Kahneman, 2011), the fact that child-specific information was restricted to school behavior within math classes suggests its effects should be lower when it comes to attendance and learning outcomes in Portuguese classes. In contrast, nudges should affect math and Portuguese attendance and grades to a much more similar extent, as their content was designed to be not subject-specific. ${ }^{43}$ Table 13 estimates treatment effects on students' 4th-quarter Portuguese attendance, GPA and standardized test scores (columns $1-3) \cdot{ }^{44}$

\section{[Table 13]}

While estimated treatment effects of both interventions are positive across all columns, effect sizes are much smaller and less precisely estimated than their counterparts for math classes. In particular, the effect of both child-specific information and salience messages on Portuguese standardized tests scores is less than half their effects on math standardized test scores.

This is not merely because it is harder to improve learning outcomes in Portuguese classes relative to math classes, as the evidence on the effects of nudges illustrates next. Figure 7 documents treatment effects of nudges on math and Portuguese 4th-quarter attendance (Panel A) and GPA (Panel B), using a differences-in-differences estimator (as in subsection 5.5.2).

\section{[Figure 7]}

Panel A shows (restricting attention at first to the left-hand-side column of both panels, which portrays effect sizes of one nudge per week) that nudges have significant effects on attendance in Portuguese classes, which increases by 1.4 p.p. relative to pure control schools. That effect size is twice as large as that of math-specific information or salience messages. One nudge per week also increases Portuguese GPA relative to the pure control group - a 0.09 effect size (significant at the 10\% level), $50 \%$ larger than that of salience messages.

\footnotetext{
${ }^{43}$ It could of course be the case that it is harder to affect learning in Portuguese than in math. But even if that were the case, non-specific nudges would still provide the appropriate benchmark for salience effects when content is not domain specific.

${ }^{44}$ As grade promotion depends on grades being greater than or equal to 5 across all subjects, we cannot assess the extent of spillovers within student for that outcome.
} 
Second, we study the extent to which salience effects increase with the frequency of messaging. Under attentional constraints, effects sizes should increase with the frequency of communication if additional messages make it more likely that children's school life becomes top-of-mind. To study that question, we take advantage of an additional experiment conducted in a companion paper (Bettinger et al., 2019). In that paper, we randomize several features of communication with parents within sub-sample E (see Section 3.2.2), including the number of nudges parents receive each week. Parents assigned to receive 1 message per week receive a weekly SMS with a suggested activity for them to do with their child. Those assigned to 2 messages per week also receive a weekly SMS with a motivating fact that prequels the activity with some simple foundations for why the latter should support children's learning. Those assigned to 3 messages per week also receive a weekly SMS with a growth message, after the activity, incentivizing parents to do it regularly.

Figure 7 displays effect sizes of 1,2 and 3 nudges per week on students' math and Portuguese 4th-quarter attendance (Panel A) and GPA (Panel B) using a differencesin-differences estimator. It documents that effect sizes substantially increase with the frequency of nudges, for both math and Portuguese. With 3 nudges per week, math attendance increases by 2.7 p.p., $50 \%$ more than with 1 nudge per week. The same pattern holds for math GPA, and when it comes to Portuguese attendance and grades: with 3 nudges per week, the treatment effect of nudges on Portuguese GPA (0.15 standard deviation, significant at the $1 \%$ level) is nearly two-fold that of 1 nudge per week. Interestingly, from 2 to 3 nudges per week, there are already some signs of saturation effects; in particular, the effect size of 3 nudges per week is nearly identical to that of 2 nudges per week on math attendance, and exactly identical when it comes to math GPA. Saturation is also consistent with limited attention, as additional messages are not expected to draw additional attention when the decision domain is already top-of-mind.

Together, results not only demonstrate that attentional constraints are the key driver behind why child-specific information improves educational outcomes, but also corroborate the claim that nudges can magnify the effects of informational interventions by drawing on additional features to manipulate subjects' attention.

\section{Concluding Remarks}

While interventions that inform parents about their children's school effort tend to have large impacts on educational outcomes, we show that alternative interventions that draw parents' attention to student effort without making them more accurate can improve learning outcomes by just as much. We find that salience effects are not short-lived, and that they are not driven by interactions with information or by teacher effects. Our findings are consistent with the effects of child-specific messages being driven by salience. In particular, the extent to which educational outcomes improve in response to salience messages depends on student effort just as much as in the information group - even though the former set of parents had no direct inputs for belief updating. All in all, results are consistent with 
belief updating in the presence of attentional constraints.

Our findings contribute to a booming literature that investigates cost-effective interventions to improve educational outcomes in developing countries. ${ }^{45}$ While different strategies have been rigorously evaluated - from cash transfers (Baird et al., 2011; Barrera-Osorio et al., 2011; Behrman et al., 2009; Mo et al., 2013; Schultz, 2004) to scholarships (Blimpo, 2014; Friedman et al., 2011; Kremer et al., 2009; Li et al., 2014) to increasing the quantity and quality of teachers (Chin, 2005; Duflo et al., 2015; Urquiola, 2006; Urquiola and Verhoogen, 2009) and school grants (Das et al., 2013; Lucas and Mbiti, 2014; Newman et al., 2002; Pop-Eleches and Urquiola, 2013; Pridmore and Jere, 2011) -, only a few have been shown to improve student outcomes through easily scalable interventions. We provide direct evidence that interventions that manipulate attention can induce at least as large effects as informational interventions, and at a lower cost. The effects of more frequent messaging are up to 2-fold those of weekly messages with child-specific information, and nudges (especially at higher frequency) have significant impacts across both math and Portuguese learning outcomes, while the effects of math-specific messages are mostly confined to that subject.

In the context of the growing body of evidence that suggests that parents play a crucial role in shaping their children's behavior and school performance (e.g. Barnard, 2004; Houtenville and Conway, 2008; Nye et al., 2006), our results qualify the findings of experimental evaluations of school communication with parents (e.g. Bergman, 2019, 2021; Bergman and Chan, 2019; Berlinski et al., 2016; Castleman and Page, 2015; Dizon-Ross, 2019; Gallego et al., 2018; Jensen, 2010; Kraft and Dougherty, 2013; Rogers and Feller, 2016; York et al., 2019), suggesting that most of their effects could actually be driven by salience. ${ }^{46,47}$ More broadly, our findings suggest that the effects of informational interventions across a multiplicity of domains could be obtained at lower cost - and even magnified - by interventions that manipulate attention, raising the salience of the decision they target.

Having said that, in practice, not all informational interventions might be replicated simply with messages that try to make the decision domain top-of-mind. For information concerning fixed states of the world, which require no updating, or for information that is easily available, understanding the extent to which the effects of informational interventions are driven by salience becomes less relevant. Alternatively, for information that might be

\footnotetext{
${ }^{45}$ As Ludger et al. (2015) and others document, students in developing countries learn much less than students of the same age or grade in OECD countries. In those countries, the focus has recently shifted from merely increasing school enrollment to improving learning (Glewwe and Muralidharan, 2015).

${ }^{46}$ Differences in parental inputs are viewed as an important cause of intergenerational inequality (Becker and Tomes, 1979), and family socio-economic status is a key factor behind variation in children's educational achievement (Woessmann and Hanushek, 2011). While poor and rich families differ across many dimensions, few seem as easy to address as their differential monitoring of children's school performance.

${ }^{47}$ Our study also contributes to the still scarce literature on behavioral educational interventions. Recent papers study interventions that tackle parents' inertia and routine, (Avvisati et al., 2013; Banerji et al., 2013; Benhassine et al., 2015; Harackiewicz et al., 2002; Kraft and Rogers, 2015), including text messages, email reminders, and letters targeted at parents and students (Castleman and Page, 2015; Hoxby et al., 2013; Jensen, 2010). While the field of behavioral economics has been successfully applied to many areas, Education has received comparatively less attention so far (Lavecchia et al., 2014).
} 
prohibitively costly for individuals to acquire independently, such as major-specific returns to college education (Hastings et al., 2015), salience might not be very effective in changing behavior, as individuals might not come by the decision-relevant information even if they actively search for it.

Moreover, manipulating attention is not trivial. Yeager et al. (2019) shows that an online growth mindset intervention in US high schools improves math grades relative to a comparable online intervention that does not address beliefs about intelligence. Bursztyn et al. (2019) shows that while text messages sent by an Indonesian bank appealing to moral values significantly reduce default, other messages from the bank (even those mentioning payment reminders) do not. In those studies, even though belief updating is relevant and information could be acquired independently by participants, messages that do not address educational beliefs (in the former) or the moral implications of default (in the latter) might have failed to capture subjects' attention to the same extent as other interventions. As in any policy evaluation, the devil is the details; ultimately, designing effective and scalable interventions requires careful piloting and evaluation.

Last, when the effects of informational interventions are driven by salience, what can we conclude about their welfare implications? The answer ultimately depends on how salience affects the underlying decision process: if it expands consideration sets (such that decision-makers attend to a broader set of alternatives), it must weakly increase welfare; in contrast, if it leads to early stopping in a sequential sampling model subject to satisficing (such that decision-makers might end up with a lower-value alternative), it could lead to lower welfare (Benkert and Netzer, 2018). While it seems hard to make the case that improving educational outcomes could make children or parents worse off, in other domains, there might be no guarantee that behavior change triggered by informational interventions actually improves welfare - a point conceptually made in Loewenstein et al. (2014) and intimately connected to the ambiguity of the welfare effects of nudges pointed out by Benkert and Netzer (2018). Additional research is needed to understand how salience affects the underlying decision process and, ultimately, welfare in each case. 


\section{References}

Allcott, H. and Taubinsky, D. (2015). Evaluating behaviorally-motivated policy: Experimental evidence from the lightbulb market. American Economic Review, 105(8):25012038.

Ambuehl, S., Bernheim, B. D., and Lusardi, A. (2017). A method for evaluating the quality of financial decision making, with an application to financial education.

Avvisati, F., Gurgand, M., Guyon, N., and Maurin, E. (2013). Getting parents involved: A field experiment in deprived schools. Review of Economic Studies, 81(1):57-83.

Baird, S., McIntosh, C., and Özler, B. (2011). Cash or condition? Evidence from a cash transfer experiment. The Quarterly Journal of Economics, 126(4):1709-1753.

Banerji, R., Berry, J., and Shotland, M. (2013). The impact of mother literacy and participation programs on child learning: Evidence from a randomized evaluation in india. Cambridge, MA: Abdul Latif Jameel Poverty Action Lab (J-PAL).

Barnard, W. M. (2004). Parent involvement in elementary school and educational attainment. Children and youth services review, 26(1):39-62.

Barrera-Osorio, F., Bertrand, M., Linden, L. L., and Perez-Calle, F. (2011). Improving the design of conditional transfer programs: Evidence from a randomized education experiment in colombia. American Economic Journal: Applied Economics, 3(2):167195.

Becker, G. S. and Tomes, N. (1979). An equilibrium theory of the distribution of income and intergenerational mobility. Journal of Political Economy, 87(6):1153-1189.

Behrman, J. R., Parker, S. W., and Todd, P. E. (2009). Schooling impacts of conditional cash transfers on young children: Evidence from mexico. Economic development and cultural change, 57(3):439-477.

Benhassine, N., Devoto, F., Duflo, E., Dupas, P., and Pouliquen, V. (2015). Turning a shove into a nudge? A "labeled cash transfer" for education. American Economic Journal: Economic Policy, 7(3):86-125.

Benkert, J.-M. and Netzer, N. (2018). Informational requirements of nudging. Journal of Political Economy, 126(6):2323-2355.

Bennett, M. and Bergman, P. (2021). Better together? social networks in truancy and the targeting of treatment. Journal of Labor Economics, 39(1):1-36.

Bergman, P. (2019). How behavioral science can empower parents to improve children's educational outcomes. Behavioral Science 85 Policy, 5(1):52-67. 
Bergman, P. (2021). Parent-child information frictions and human capital investment: Evidence from a field experiment. Journal of Political Economy, 129(1):199-222.

Bergman, P. and Chan, E. W. (2019). Leveraging technology to engage parents at scale: Evidence from a randomized controlled trial. The Journal of Human Resources.

Berlinski, S., Busso, M., Dinkelman, T., and Martinez, C. (2016). Reducing parent-school information gaps and improving education outcomes: Evidence from high frequency text messaging in chile. Unpublished Manuscript.

Bettinger, E., Cunha, N., Lichand, G., and Madeira, R. (2019). The nuts and bolts of nudging parental engagement.

Blimpo, M. P. (2014). Team incentives for education in developing countries: A randomized field experiment in benin. American Economic Journal: Applied Economics, 6(4):90109.

Bordalo, P., Gennaioli, N., and Shleifer, A. (2012). Salience theory of choice under risk. The Quarterly Journal of Economics, 127(3):1243-1285.

Bordalo, P., Gennaioli, N., and Shleifer, A. (2019). Memory, attention, and choice.

Bursztyn, L. and Coffman, L. C. (2012). The schooling decision: Family preferences, intergenerational conflict, and moral hazard in the brazilian favelas. Journal of Political Economy, 120(3):359-397.

Bursztyn, L., Fiorin, S., Gottlieb, D., and Kanz, M. (2019). Moral incentives in credit card debt repayment: Evidence from a field experiment. Journal of Political Economy, 127(4):1641-1683.

Bursztyn, L., González, A. L., and Yanagizawa-Drott, D. (2018). Misperceived social norms: Female labor force participation in saudi arabia.

Castleman, B. L. and Page, L. C. (2015). Summer nudging: Can personalized text messages and peer mentor outreach increase college going among low-income high school graduates? Journal of Economic Behavior \& Organization, 115:144-160.

Chassang, S., Padro-i Miquel, G., and Snowberg, E. (2012). Selective trials: a principalagent approach to randomized control trials. American Economic Review, 102(4):12791309 .

Chin, A. (2005). Can redistributing teachers across schools raise educational attainment? Evidence from Operation Blackboard in India. Journal of development Economics, 78(2):384-405.

Cunha, F. and Heckman, J. (2007). The technology of skill formation. 
Das, J., Dercon, S., Habyarimana, J., Krishnan, P., Muralidharan, K., and Sundararaman, V. (2013). School inputs, household substitution, and test scores. American Economic Journal: Applied Economics, 5(2):29-57.

Dizon-Ross, R. (2019). Parents' beliefs about their children's academic ability: Implications for educational investments. American Economic Review, 109(8):2728-65.

Duflo, E., Dupas, P., and Kremer, M. (2015). School governance, teacher incentives, and pupil-teacher ratios: Experimental evidence from kenyan primary schools. Journal of Public Economics, 123:92-110.

Enke, B., Schwerter, F., and Zimmerman, F. (2019). Associate memory and belief formation.

Friedman, W., Kremer, M., Miguel, E., and Thornton, R. (2011). Education as liberation?

Gabaix, X., Laibson, D., Moloche, G., and Weinberg, S. (2006). Costly information acquisition: Experimental analysis of a boundedly rational model. American Economic Review, 96(4):1043-1068.

Gallego, F., Malamud, O., and Pop-Eleches, C. (2018). Parental monitoring and children's internet use: The role of information, control, and cues.

Glewwe, P. and Muralidharan, K. (2015). Improving school education outcomes in developing countries: evidence, knowledge gaps, and policy implications. University of Oxford, Research on Improving Systems of Education (RISE).

Golman, R., Hagmann, D., and Loewenstein, G. (2017). Information avoidance. Journal of Economic Literature, 55(1):96-135.

Golman, R. and Loewenstein, G. (2018). Information gaps: A theory of preferences regarding the presence and absence of information. Decision, 5(3):143-164.

Hanna, R., Mullainathan, S., and Schwartzstein, J. (2014). Learning through noticing: Theory and evidence from a field experiment. The Quarterly Journal of Economics, 129(3):1311-1353.

Harackiewicz, J. M., Barron, K. E., Pintrich, P. R., Elliot, A. J., and Thrash, T. M. (2002). Revision of achievement goal theory: Necessary and illuminating.

Hastings, J., Nielson, C., and Zimmerman, S. (2015). The effects of earning disclosure on college enrollment decisions.

Heckman, J. J. and Mosso, S. (2014). The economics of human development and social mobility. Annu. Rev. Econ., 6(1):689-733.

Houtenville, A. J. and Conway, K. S. (2008). Parental effort, school resources, and student achievement. Journal of Human resources, 43(2):437-453. 
Hoxby, C., Turner, S., et al. (2013). Expanding college opportunities for high-achieving, low income students. Stanford Institute for Economic Policy Research Discussion Paper, (12-014).

Jensen, R. (2010). The (perceived) returns to education and the demand for schooling. The Quarterly Journal of Economics, 125(2):515-548.

Kahneman, D. (2011). Thinking Fast and Slow. Farrar, Straus and Giroux.

Kling, J. R., Liebman, J. B., and Katz, L. F. (2007). Experimental analysis of neighborhood effects. Econometrica, 75(1):83-119.

Kraft, M. A. and Dougherty, S. M. (2013). The effect of teacher-family communication on student engagement: Evidence from a randomized field experiment. Journal of Research on Educational Effectiveness, 6(3):199-222.

Kraft, M. A. and Rogers, T. (2015). The underutilized potential of teacher-to-parent communication: Evidence from a field experiment. Economics of Education Review, $47: 49-63$.

Kremer, M., Miguel, E., and Thornton, R. (2009). Incentives to learn. The Review of Economics and Statistics, 91(3):437-456.

Lavecchia, A. M., Liu, H., and Oreopoulos, P. (2014). Behavioral economics of education: Progress and possibilities.

Lee, D. (2009). Training, wages, and sample selection: Estimating sharp bounds on treatment effects. The Review of Economic Studies, 76(3):1071-1102.

Li, T., Han, L., Zhang, L., and Rozelle, S. (2014). Encouraging classroom peer interactions: Evidence from chinese migrant schools. Journal of Public Economics, 111:29-45.

Loewenstein, G., Sunstein, C., and Golman, R. (2014). Disclosure: Psychology changes everything. Annual Review of Economics, 6:391-419.

Lucas, A. M. and Mbiti, I. M. (2014). Effects of school quality on student achievement: Discontinuity evidence from kenya. American Economic Journal: Applied Economics, 6(3):234-263.

Ludger, W. et al. (2015). Universal Basic Skills What Countries Stand to Gain: What Countries Stand to Gain. OECD Publishing.

Ludwig, J., Kling, J., and Mullainathan, S. (2011). Mechanism experiments and policy evaluations. Journal of Economic Perspectives, 25(3):17-38.

Mo, D., Zhang, L., Yi, H., Luo, R., Rozelle, S., and Brinton, C. (2013). School dropouts and conditional cash transfers: Evidence from a randomised controlled trial in rural china's junior high schools. The Journal of Development Studies, 49(2):190-207. 
Newman, J., Pradhan, M., Rawlings, L. B., Ridder, G., Coa, R., and Evia, J. L. (2002). An impact evaluation of education, health, and water supply investments by the bolivian social investment fund. The World Bank Economic Review, 16(2):241-274.

Nye, C., Turner, H., Schwartz, J., and Nye, C. (2006). Approaches to parent involvement for improving the academic performance. Campbell Systematic Reviews, 4.

Pop-Eleches, C. and Urquiola, M. (2013). Going to a better school: Effects and behavioral responses. The American Economic Review, 103(4):1289-1324.

Pridmore, P. and Jere, C. (2011). Disrupting patterns of educational inequality and disadvantage in malawi. Compare: A Journal of Comparative and International Education, 41(4):513-531.

Rockoff, J., Staiger, D., Kane, T., and Taylor, E. (2012). Information and employee evaluation: Evidence from randomized intervention in public schools. American Economic Review, 102(7):3184-3213.

Rogers, T. and Feller, A. (2016). Reducing student absences at scale. Unpublished paper.

Sacerdote, B. (2011). Peer Effects in Education: How Might They Work, How Big Are They And How Much Do We Know Thus Far?, volume 3, chapter 4, pages 249-277.

Schultz, T. P. (2004). School subsidies for the poor: evaluating the mexican progresa poverty program. Journal of development Economics, 74(1):199-250.

Urquiola, M. (2006). Identifying class size effects in developing countries: Evidence from rural bolivia. The Review of Economics and Statistics, 88(1):171-177.

Urquiola, M. and Verhoogen, E. (2009). Class-size caps, sorting, and the regressiondiscontinuity design. The American Economic Review, 99(1):179-215.

Woessmann, L. and Hanushek, E. A. (2011). The economics of international differences in educational achievement. Handbook of the Economics of Education, 3:89-200.

Yeager, D., Hanselman, P., Walton, G., Murray, J., Crosnoe, R., Muller, C., Tipton, E., Schneider, B., Hulleman, C., Hinojosa, C., Paunesku, D., Romero, C., Flint, K., Roberts, A., Trott, J., Iachan, R., Buontempo, J., Yang, S., Carvalho, C., Hahn, R., Gopalan, M., Mhatre, P., Ferguson, R., Duckworth, A., and Dweck, C. (2019). A national experiment reveals where a growth mindset improves achievement. Nature, (572):364-369.

York, B. N., Loeb, S., and Doss, C. (2019). One step at a time: The effects of an early literacy text-messaging program for parents of preschoolers. Journal of Human Resources, 54(3):537-566. 


\section{Figures}

Figure 1: Parents' accuracy wrt their child's baseline math attendance

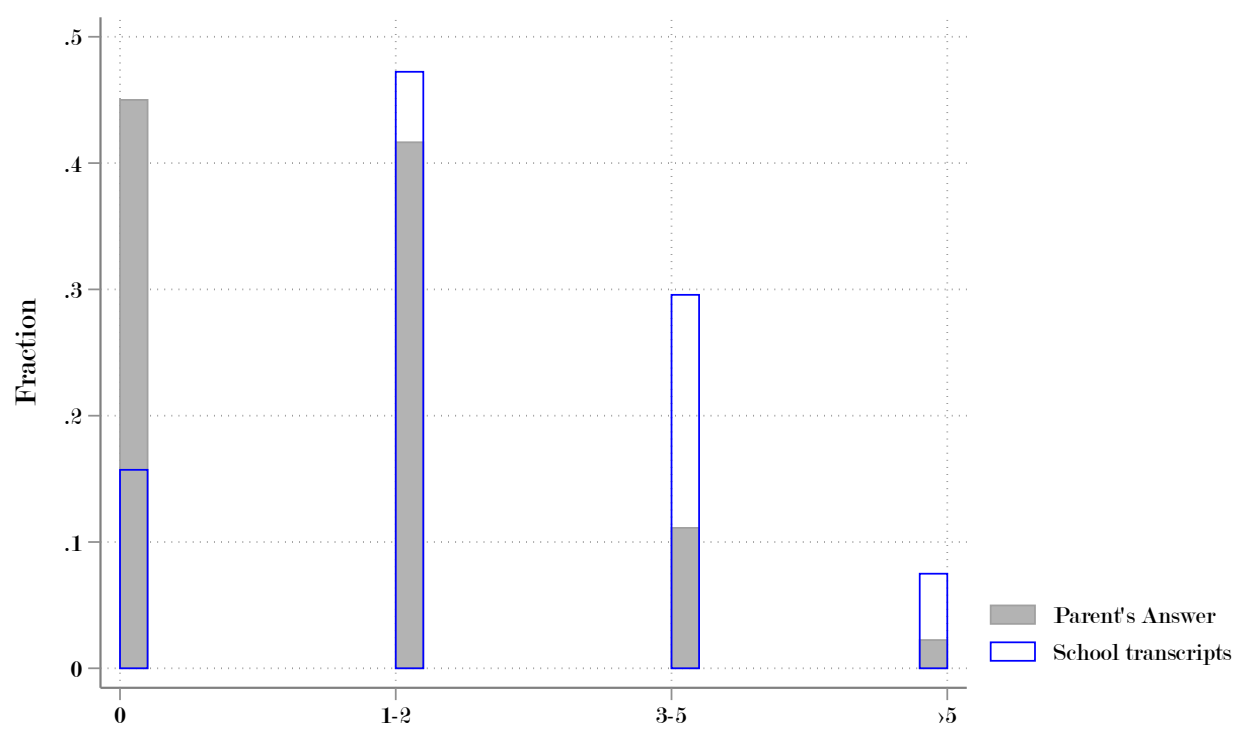

Absences in a 3 week period

Note: This Figure displays the distribution of parents' beliefs about their child's attendance and recorded attendance. Parents were asked at baseline to give their best estimate on how many times their child missed math classes on a period of three weeks. Data was then crossed with administrative records. Four categories were available for parents' answers on attendance (missed 0; 1-2; 3-5; more than 5). Administrative data registers data on attendance on a quarterly basis (period of $\sim 9$ weeks) and was divided by 3 to validate parents' answers. 
Figure 2: Parents' beliefs vs. actual student absenteeism (platform data)

Panel A: Information vs. Control

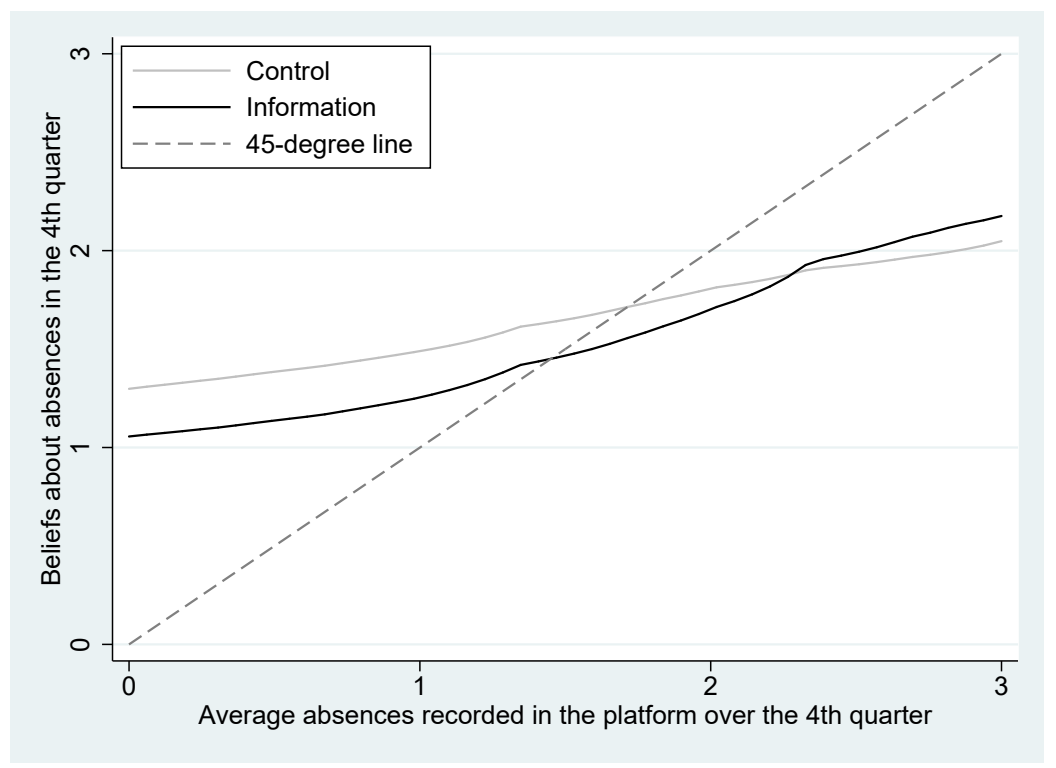

Panel B: Salience vs. Control

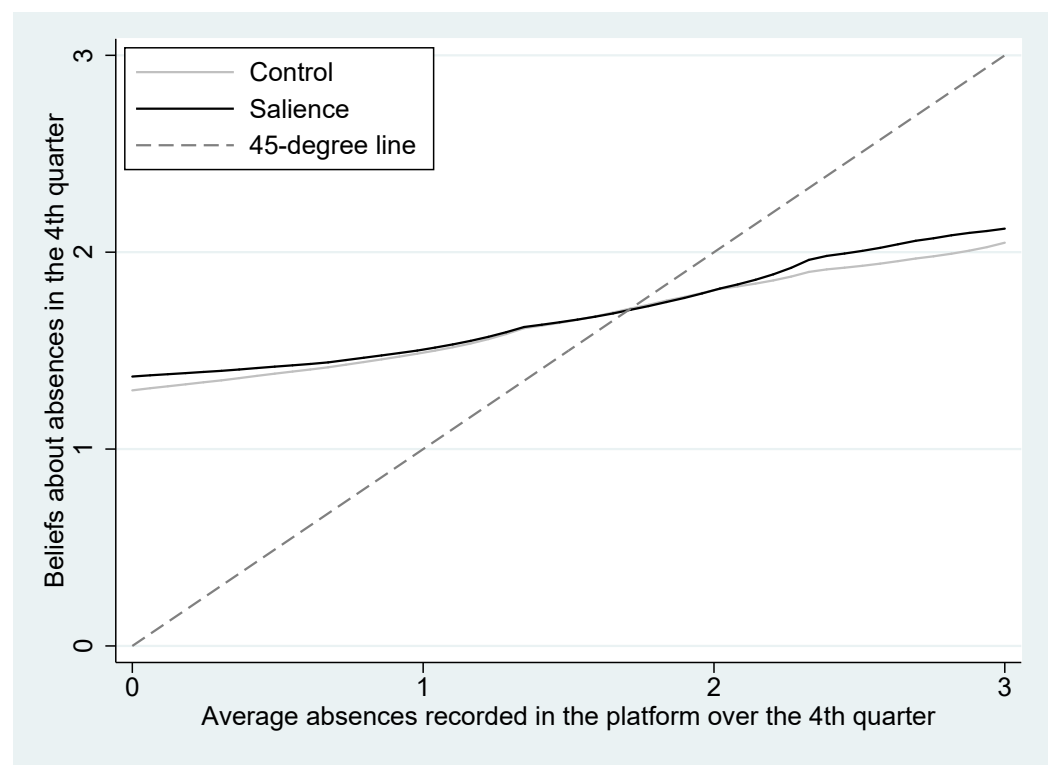

Note: Non-parametric relationship between parents' end-line beliefs about their child's absences in math classes and actual absences. At the end-line survey, parents were asked to provide their best estimate of how many times their child missed math classes over the past quarter. Parents could pick an answer from five categories (0 absences; $1-2 ; 3-5 ; 6-8$; or more than 8 ). In this figure, we compute actual absences from the data entered by teachers into the platform ' since this is the data parents in the information group are targeted with. Teachers reported information on each student's attendance every 3 weeks, specifying how many classes they missed over that interval (missed 0, 1-2; 3-5; 5 or more). Both panels show parents' beliefs on the Y-axis, and the average of teachers' reports over the 4th quarter on the X-axis. Panel A plots a local polynomial regression for that relationship within the information group and the control group. Panel B plots a local polynomial regression for that relationship within the salience group and the control group. Both local polynomial regressions use a bandwidth of 0.6. We restrict the $\mathrm{X}$-axis to the $[0,3]$ interval in both panels since very few observations are in the $(3,4]$ range, rendering non-parametric estimates infeasible. 
Figure 3: Distributional Effects

Math standardized test scores

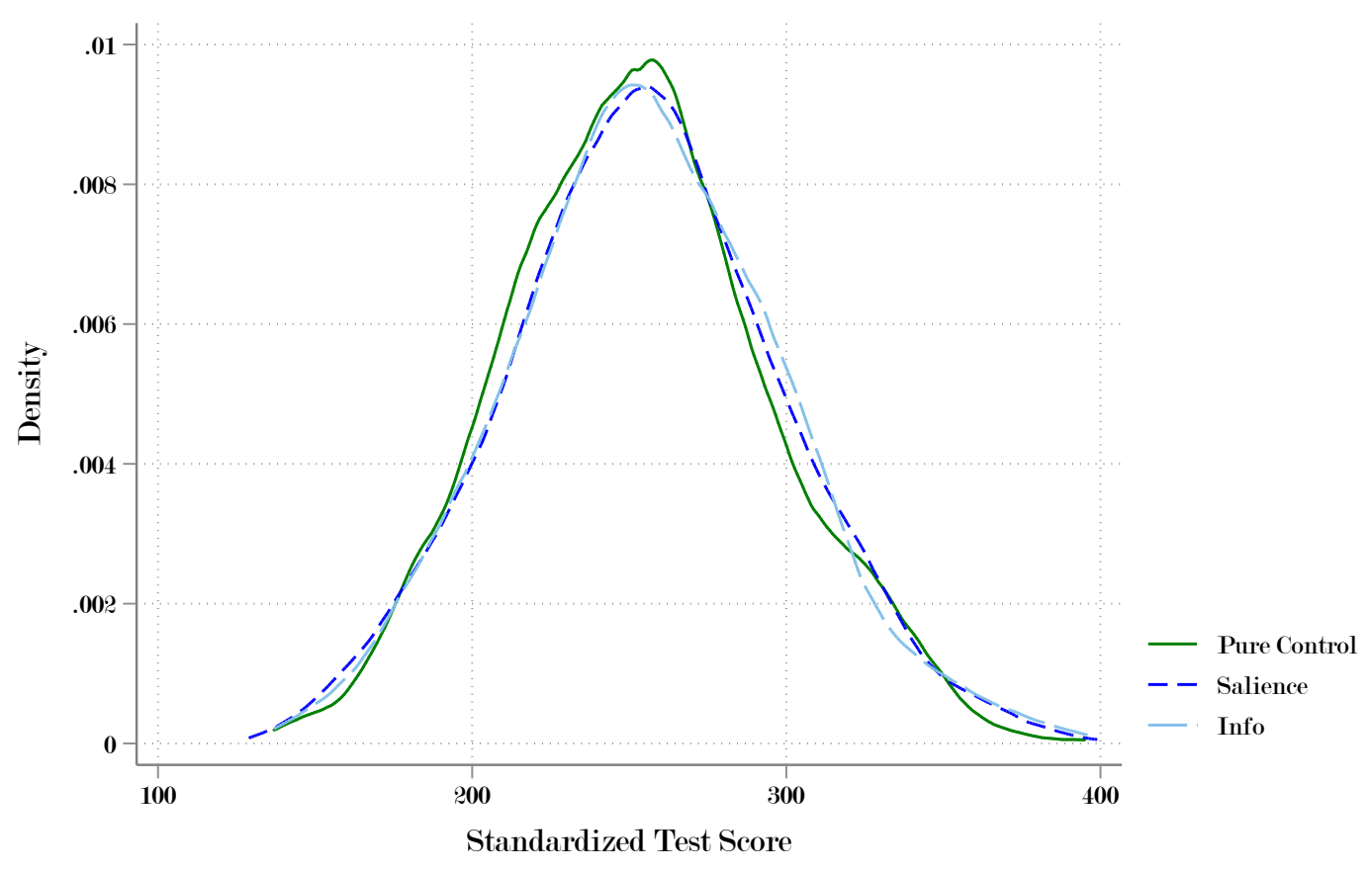

p-value control-saliency=0.08; p-value saliency-info=0.94

Note: Effect of child-specific information and salience messages across the distribution of students' math standardized test scores for each treatment arm. Data used are from administrative records. The standardized test (Saresp) has a 400-point scale, where zero is the minimum score. P-values reported for Kolmogorov-Smirnov tests of the hypothesis that pairs of distributions are not statistically different. 
Figure 4: Are effects short-lived? Salience and information effects over time

Panel A: Effect on attendance over time

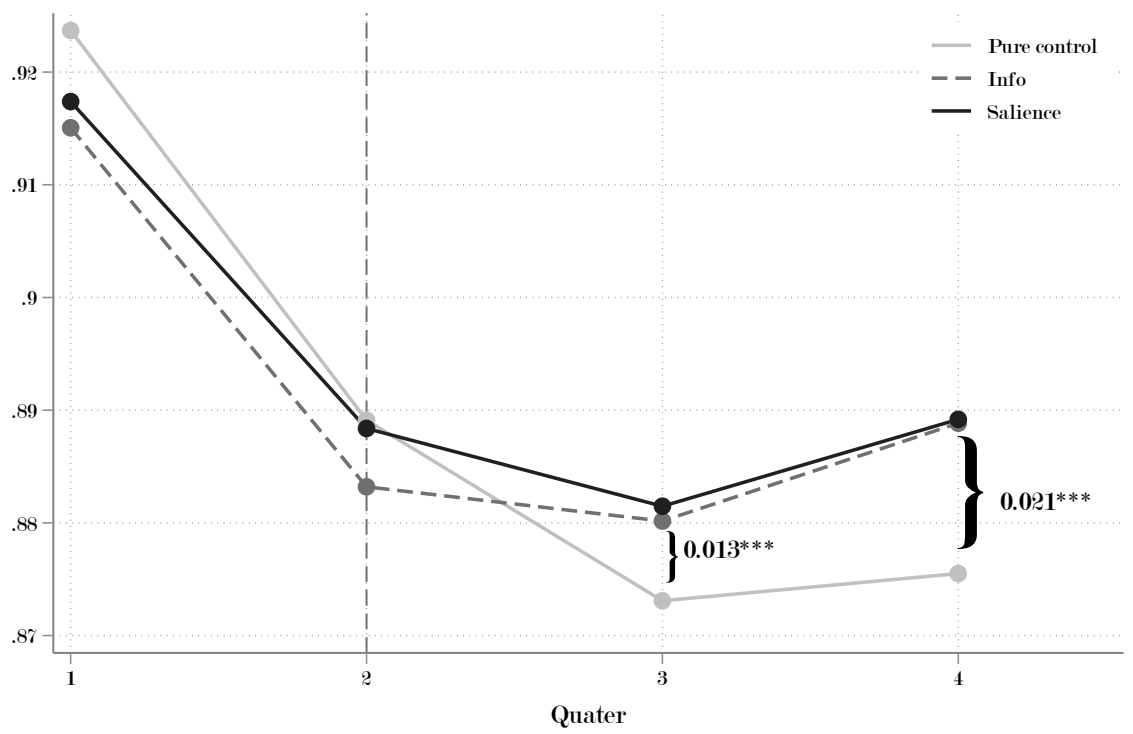

Panel B: Effect on GPA over time

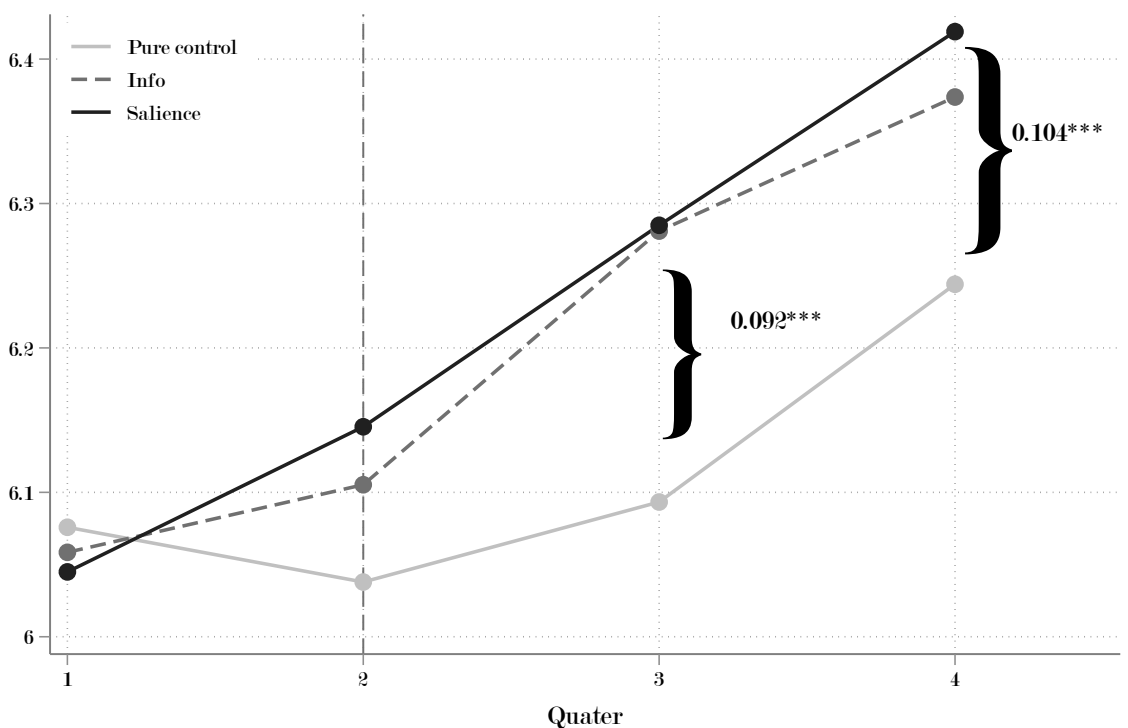

Note: Panels A and B show the attendance and GPA averages for the pre- and post-intervention period, for treatment and control groups. Attendance is recorded in percentage points (0-1 interval). GPA is in a 0-10 scale (integer increments), with 5 as the passing grade. The intervention started at the beginning of the third quarter (as shown by the vertical dashed line) and lasted until the end of the fourth quarter. Attendance and GPA are available for each of the four quarters, as part of students' transcripts. Braces highlight the differences between the salience and pure control groups at each quarter, from a model estimated with student controls, strata fixed effect and standard errors clustered at the classroom level, as specified by equation 1. Student controls include gender, age, race, baseline grades and attendance, and caregivers' controls include gender, age, race, family income and education. Coefficients for GPA are in standard deviations, where GPA was normalized relative to the distribution of the comparison group (pure control). Significance levels are denoted by $*$ if $\mathrm{p}<0.1, * * \mathrm{p}<0.05$ and $* * *$ if $\mathrm{p}<0.01$. 
Figure 5: Differences-in-differences coefficients of nudges, by quarter

Panel A: Attendance (p.p.)

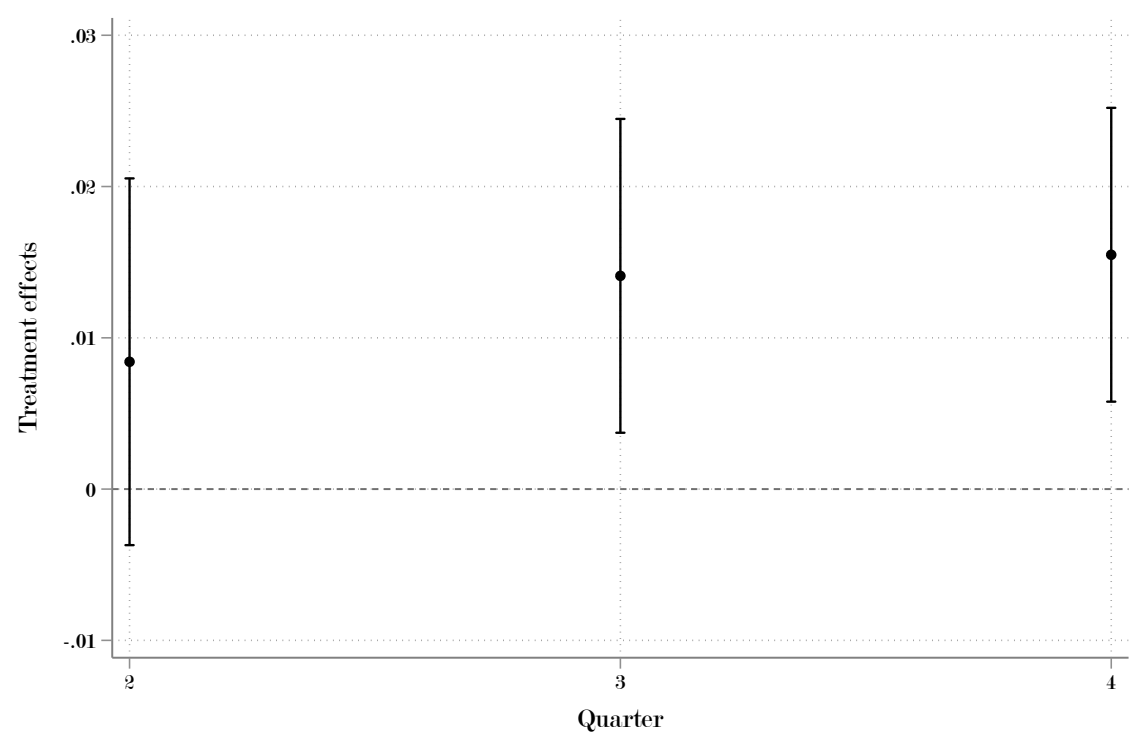

Panel B: GPA (s.d.)

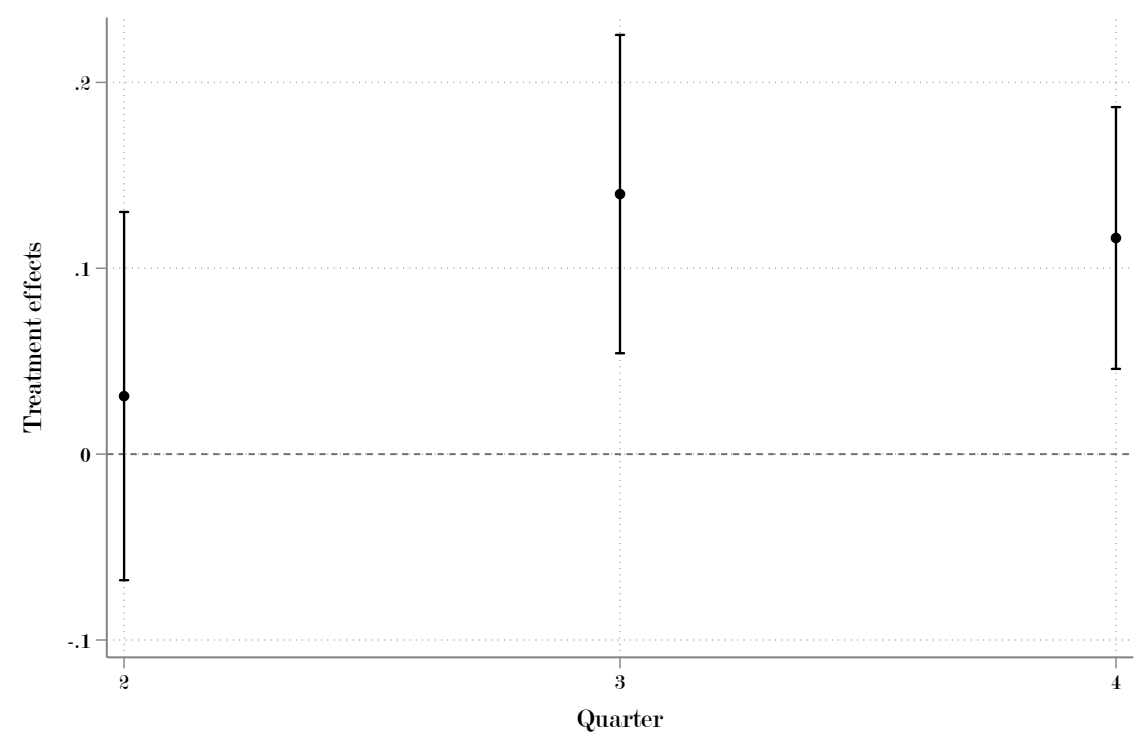

Note: Panels A and B show quarter-specific differences-in-differences estimates from equation 3 for the nudge program by quarter, with the first quarter as the reference period. Math GPA was normalized relative to the distribution of the comparison group (pure control). $90 \%$ confidence interval with standard errors clustered at the classroom level. 
Figure 6: Parents' beliefs vs. actual math GPA

Panel A: Information vs. Control (levels) Panel B: Salience vs. Control (levels)
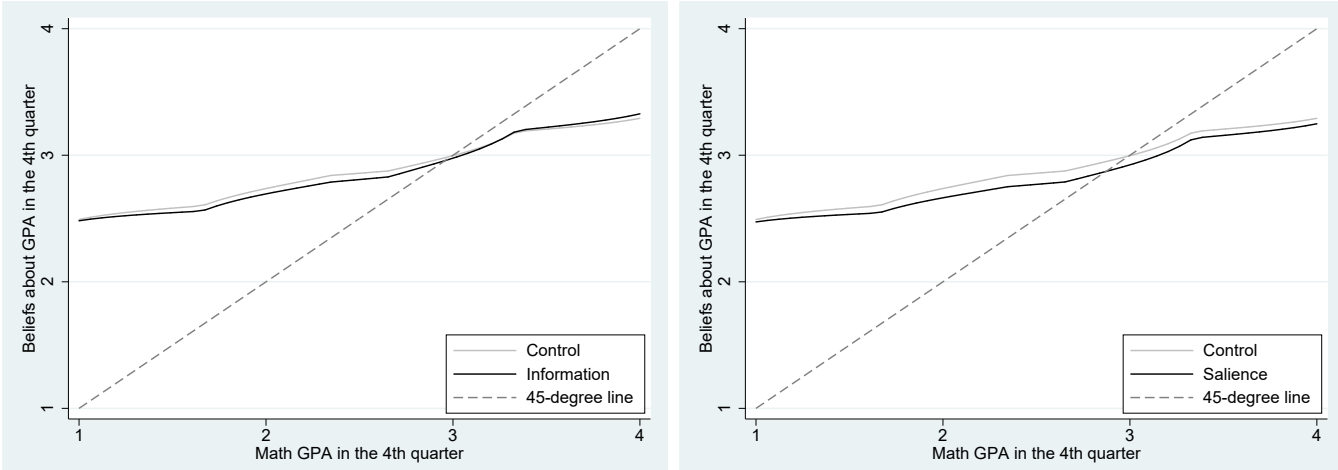

Panel C: Information vs. Control (changes)

Panel D: Salience vs. Control (changes)
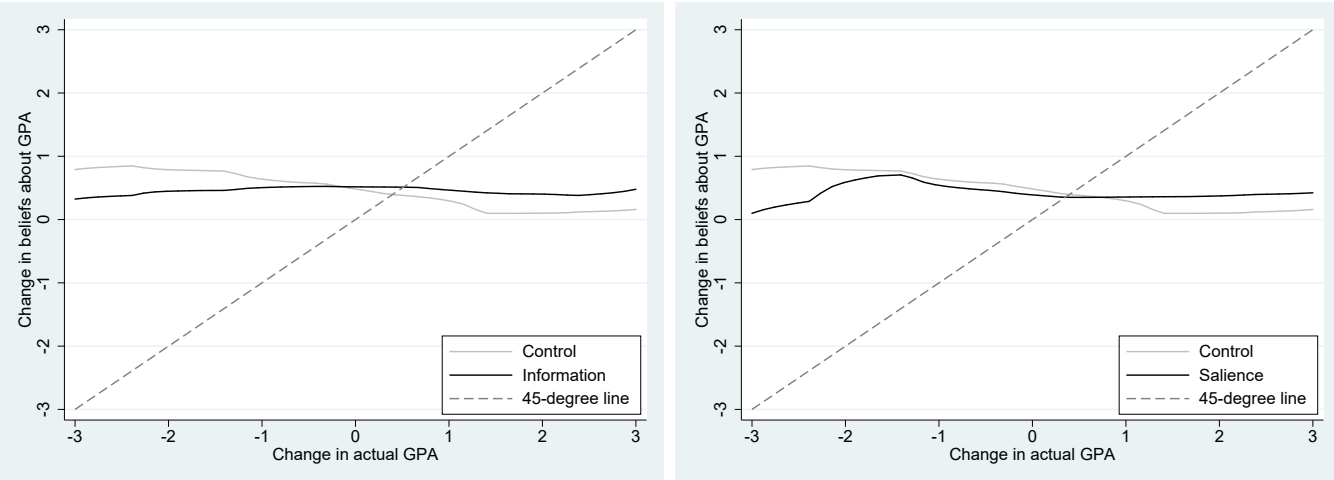

Note: Non-parametric relationship between parents' end-line beliefs about their children's GPA and actual math GPA (Panels A and B) and that between changes in parents' beliefs between baseline and end line and changes in math GPA between the 2nd and 4th quarters (Panels C and D). At baseline, parents were asked to provide their best estimate of their child's first quarter math grade, choosing among four brackets: $0-4 ; 5-6 ; 7-8$; or $9-10$. At end line, parents were asked to provide their best estimate of their child's 4thquarter math GPA, an integer between 0 and 10. We adjust end-line beliefs and actual math GPA's to the 4-point scale of baseline beliefs. The control group across all panels includes both within-class control students and the pure control group. All local polynomial regressions use a 0.6 bandwidth. 
Figure 7: Effect sizes as a function of the number of nudges per week

Panel A: Effect on attendance

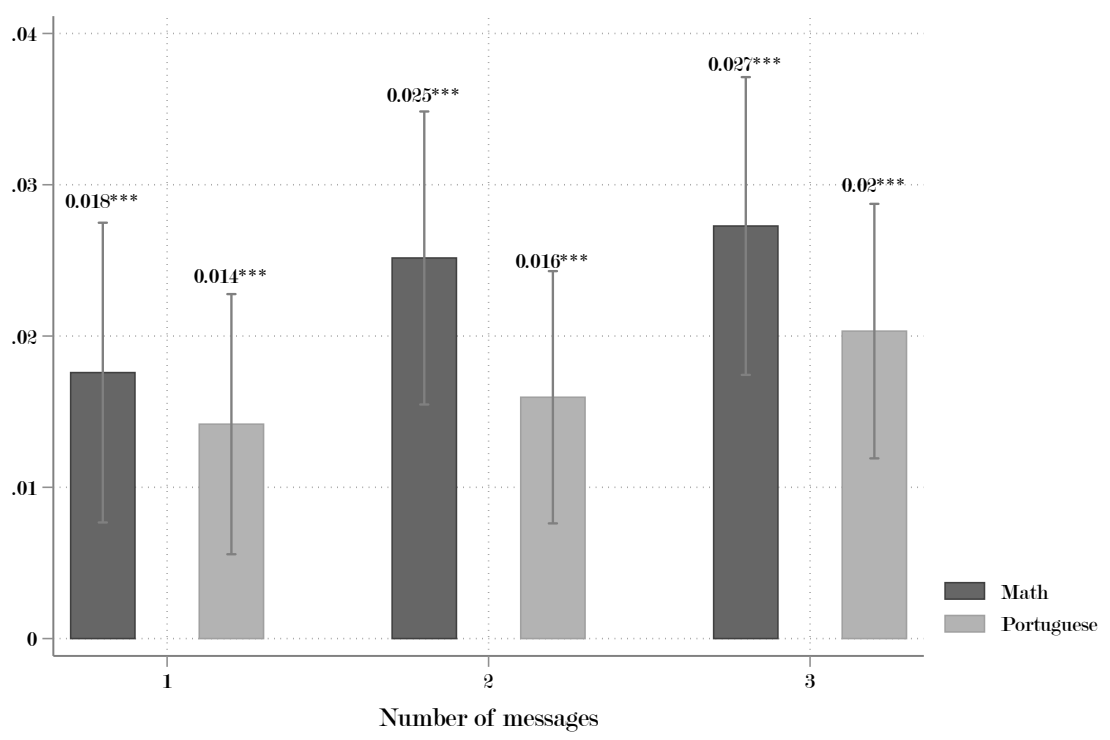

Panel B: Effect on GPA

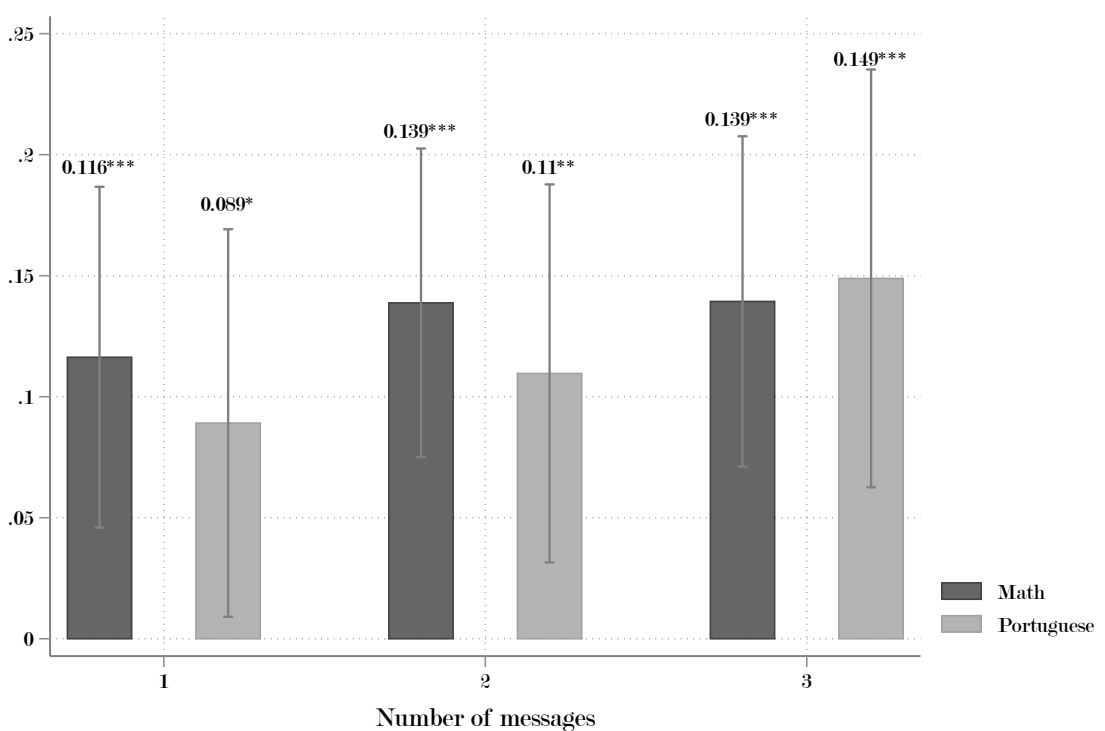

Note: Treatment effects of nudges to parents on attendance in math classes (Panel A) and math GPA (Panel B), estimated through differences-in-differences, with the first quarter as reference period. The sample includes sub-sample $\mathrm{E}$ and the pure control group. Effect sizes for different treatment intensities: one, two or three nudges per week. GPA was normalized relative to the distribution of the comparison group (pure control). Students' controls include gender, age, race, baseline grades and attendance, and caregivers' controls include gender, age, race, family income and education. All estimates are from OLS regressions, with standard errors clustered at the classroom level. * if $\mathrm{p}<0.1,{ }^{* *} \mathrm{p}<0.05$ and $* * *$ if $\mathrm{p}<0.01$. 


\section{Tables}

Table 1: Descriptive statistics and balance

\begin{tabular}{|c|c|c|c|c|c|c|}
\hline & \multicolumn{4}{|c|}{ Sub-sample means } & \multirow[t]{2}{*}{$\begin{array}{c}\text { ANOVA test } \\
\text { p-value }\end{array}$} & \multirow[t]{2}{*}{$\begin{array}{c}\text { Number of } \\
\text { observations }\end{array}$} \\
\hline & $\begin{array}{c}\text { Pure } \\
\text { Control } \\
\end{array}$ & $\begin{array}{c}\text { Control } \\
\text { within classroom }\end{array}$ & Salience & $\begin{array}{l}\text { Child-specific } \\
\text { information }\end{array}$ & & \\
\hline \multicolumn{7}{|c|}{ Panel A: Student characteristics } \\
\hline Female & 0.48 & 0.50 & 0.51 & 0.51 & 0.14 & 15589 \\
\hline Age & 14.71 & 14.72 & 14.71 & 14.75 & 0.03 & 15595 \\
\hline Brown & 0.34 & 0.35 & 0.34 & 0.35 & 0.48 & 15592 \\
\hline Black & 0.06 & 0.05 & 0.06 & 0.06 & 0.45 & 15592 \\
\hline Portuguese GPA (0-10) & 6.18 & 6.19 & 6.13 & 6.13 & 0.36 & 15437 \\
\hline Math GPA $(0-10)$ & 5.94 & 5.99 & 5.92 & 5.90 & 0.25 & 15453 \\
\hline Portuguese attendance & 0.91 & 0.92 & 0.92 & 0.91 & 0.68 & 15480 \\
\hline Math attendance & 0.91 & 0.91 & 0.91 & 0.91 & 0.30 & 15440 \\
\hline \multicolumn{7}{|c|}{ Panel B: Adult responsible for student } \\
\hline Mother & 0.78 & 0.76 & 0.76 & 0.76 & 0.28 & 15597 \\
\hline Age & 40.43 & 40.25 & 40.34 & 40.42 & 0.86 & 15461 \\
\hline Brown & 0.34 & 0.34 & 0.34 & 0.34 & 0.65 & 15593 \\
\hline Black & 0.07 & 0.06 & 0.07 & 0.07 & 0.80 & 15593 \\
\hline Middle school incomplete & 0.32 & 0.30 & 0.31 & 0.31 & 0.66 & 15591 \\
\hline Middle school complete & 0.30 & 0.26 & 0.28 & 0.27 & 0.17 & 15591 \\
\hline High School & 0.31 & 0.33 & 0.30 & 0.31 & 0.13 & 15591 \\
\hline Earns less than $1 \mathrm{MW}(\sim \$ 250)$ & 0.17 & 0.18 & 0.17 & 0.18 & 0.63 & 15593 \\
\hline Earns between 1 - $3 \mathrm{MW}$ & 0.42 & 0.45 & 0.45 & 0.46 & 0.41 & 15593 \\
\hline
\end{tabular}

Note: Conditional means net of randomization strata fixed effects and p-values computed using randomization strata fixed effects. Standard errors clustered at the classroom level. Variables are computed for four sub-samples. The table reports the following variables for students: age, gender, race and Portuguese and math attendance and grades. The table also reports the following variables for primary caregivers: age, gender, race, education (indicator variables for incomplete middle school, complete middle school, and high school), and income (indicator variables for less than one minimum wage, and between one and three minimum wages). Data on students' age, gender, attendance and GPA are from administrative records, and data on students' race and on caregivers' characteristics are from the face-to-face baseline survey, restricted to those who consented to participate in SMS program. 
Table 2: Selection at opt-in

\begin{tabular}{|c|c|c|c|c|}
\hline & \multicolumn{2}{|c|}{ Sub-sample mean } & \multirow[t]{2}{*}{ Diff. } & \multirow[t]{2}{*}{ Observations } \\
\hline & Opt-out & Opt-in & & \\
\hline Female & 0.45 & 0.50 & $\begin{array}{l}0.05^{* * *} \\
{[0.01]}\end{array}$ & 23372 \\
\hline Age & 14.92 & 14.73 & $-0.19^{* * *}$ & 23398 \\
\hline Portuguese GPA ( $\max 10)$ & 5.39 & 6.16 & $\begin{array}{l}0.77^{* * *} \\
{[0.03]}\end{array}$ & 22687 \\
\hline Math GPA $(\max 10)$ & 5.09 & 5.94 & $\begin{array}{l}0.84^{* * *} \\
{[0.03]}\end{array}$ & 22691 \\
\hline Portuguese attendance & 0.88 & 0.91 & {$\left[0.04^{* * *}\right.$} & 22850 \\
\hline Math attendance & 0.87 & 0.91 & $\begin{array}{l}0.04^{* * *} \\
{[0.00]}\end{array}$ & 22753 \\
\hline Cash transfer beneficiary & 0.19 & 0.16 & $\begin{array}{l}-0.03^{* * *} \\
{[0.01]}\end{array}$ & 23029 \\
\hline
\end{tabular}

Note: Differences in student characteristics between those whose primary caregivers consented to participate in the SMS program and all others (refusals or those who could not be reached by the school to ask for consent). Data from administrative records on students' age, gender, 1st-quarter math and Portuguese attendance and GPA, and whether their household is a Bolsa-Família (Brazil's flagship conditional cash transfer) beneficiary. Column 3 reports differences in means between the two groups for each variable. $*$ if $\mathrm{p}<0.1,{ }^{* *} \mathrm{p}<0.05$ and ${ }^{* * *}$ if $\mathrm{p}<0.01$. 
Table 3: Parents' accuracy about attendance levels

\begin{tabular}{lcccc}
\hline & $(1)$ & $(2)$ & $(3)$ & $(4)$ \\
& \multicolumn{2}{c}{ Baseline beliefs } & \multicolumn{2}{c}{ End-line beliefs } \\
\cline { 2 - 5 } Actual absences & $0.211^{* * *}$ & $0.186^{* * *}$ & $0.271^{* * *}$ & $0.267^{* * *}$ \\
& {$[0.025]$} & {$[0.024]$} & {$[0.043]$} & {$[0.043]$} \\
Child-specific information & -0.016 & & $-0.273^{* * *}$ & \\
& {$[0.050]$} & & {$[0.060]$} & \\
Salience & & 0.033 & & 0.063 \\
& & {$[0.050]$} & & {$[0.064]$} \\
Actual absences x Information & -0.011 & & $0.121^{* *}$ & \\
& {$[0.035]$} & & {$[0.057]$} & \\
Actual absences x Salience & & -0.047 & & -0.055 \\
& & {$[0.034]$} & & {$[0.058]$} \\
\hline Observations & 3,085 & 3,174 & 2,136 & 2,032 \\
Classroom FE & No & No & No & No \\
Student-level controls & Yes & Yes & Yes & Yes \\
R-squared & 0.112 & 0.120 & 0.167 & 0.126 \\
\hline
\end{tabular}

Note: Correlation between parents' baseline and end-line beliefs about their children's school attendance and actual attendance within each period. At the baseline survey, parents were asked to provide their best estimate of how many times their child had missed math classes over the past three weeks, choosing among four brackets: 0 absences; $1-2 ; 3-5$; or more than 5. Since administrative data on students' 1 st-quarter absences were only available for the whole quarter ( $\sim 9$ weeks), in columns $(1)$ and $(2)$ actual absences are computed by dividing that indicator by 3 . At the end-line survey, parents were asked to provide their best estimate of how many times their child missed math classes over the past quarter, choosing among five brackets: 0 absences; $1-2 ; 3-5 ; 6-8$; or more than 8 . We compute actual absences from the data entered by teachers into the platform, since this is the data parents in the information group are targeted with. Teachers reported on each student's attendance every 3 weeks, specifying how many classes they missed over that interval (missed $0,1-2 ; 3-5 ; 5$ or more). In columns (3) and (4), actual absences are the average of teachers' reports over the 4th quarter. Columns (1) and (3) include only students in the child-specific information and control groups (both within-class and pure control). Columns (2) and (4) include only students in the salience and control groups (both within-class and pure control). Regressions include indicator variables for students in the information and salience groups and an interaction term between actual absences and the indicator for child-specific information (Columns 1 and 3) or actual absences and the indicator for salience messages (Columns 2 and 4). Students' controls include gender, age, race, baseline grades and attendance, and caregivers' controls include gender, age, race, family income and education. All columns are OLS regressions, with standard errors clustered at the classroom level. $*$ if $\mathrm{p}<0.1,{ }^{* *} \mathrm{p}<0.05$ and $* * *$ if $\mathrm{p}<0.01$ 
Table 4: Effects on platform scores, within classroom

\begin{tabular}{|c|c|c|c|c|}
\hline & (1) & (2) & $\begin{array}{c}(3) \\
\text { Components }\end{array}$ & (4) \\
\hline & Summary measure & Attendance & Punctuality & Homework \\
\hline Child-specific information & $\begin{array}{c}0.0108 \\
{[0.00953]}\end{array}$ & $\begin{array}{c}0.0115 \\
{[0.0126]}\end{array}$ & $\begin{array}{c}0.000930 \\
{[0.0123]}\end{array}$ & $\begin{array}{c}0.0199 \\
{[0.0131]}\end{array}$ \\
\hline Salience & $\begin{array}{l}0.0189^{* *} \\
{[0.00895]}\end{array}$ & $\begin{array}{c}0.0312^{* * *} \\
{[0.0118]}\end{array}$ & $\begin{array}{l}0.00883 \\
{[0.0117]}\end{array}$ & $\begin{array}{c}0.0163 \\
{[0.0122]}\end{array}$ \\
\hline Linear time trend (weeks) & $\begin{array}{c}0.00703^{* * *} \\
{[0.000472]}\end{array}$ & $\begin{array}{l}0.0163 * * * \\
{[0.000742]}\end{array}$ & $\begin{array}{c}-0.00386^{* * *} \\
{[0.000708]}\end{array}$ & $\begin{array}{l}0.0103^{* * *} \\
{[0.000679]}\end{array}$ \\
\hline p-value diff. [Info] -[Salience] & 0.408 & 0.125 & 0.536 & 0.784 \\
\hline Observations & 158,018 & 53,453 & 52,389 & 52,176 \\
\hline Classroom FE & Yes & Yes & Yes & Yes \\
\hline Student-level controls & Yes & Yes & Yes & Yes \\
\hline R-squared & 0.231 & 0.274 & 0.359 & 0.381 \\
\hline
\end{tabular}

Note: Treatment effects of child-specific information and salience messages on different students' outcomes recorded by the teachers. The sample includes students that opted-in the study and whose parents answered the survey. Observations for students are stacked at the week-level. In columns (2) to (4), the dependent variables are: number of classes attended in the week (column 2), number classes attended on time (punctuality, column 3), and the number of completed homeworks (column 4). Each of those variables are normalized relative to the distribution of the comparison group (pure control). In column 1, we calculate a summary measure by averaging across the other three components, following Kling et al. (2007). Students' controls include gender, age, race, baseline grades and attendance, and caregivers' controls include gender, age, race, family income and education. We also control for classroom fixed-effects and a linear weekly time trend. All columns are OLS regressions, with standard errors clustered at the classroom level. ${ }^{*}$ if $\mathrm{p}<0.1,{ }^{* *} \mathrm{p}<0.05$ and ${ }^{* * *}$ if $\mathrm{p}<0.01$.

Table 5: Effects on attendance, grades and grade promotion

\begin{tabular}{lcccc}
\hline & $\begin{array}{c}(1) \\
\text { Math } \\
\text { Attendance } \\
(\text { p.p. })\end{array}$ & $\begin{array}{c}\text { Math } \\
\text { GPA } \\
\text { (std.) }\end{array}$ & $\begin{array}{c}(3) \\
\text { Promotion } \\
\text { Rate } \\
\text { Ch.p. }\end{array}$ & $\begin{array}{c}\text { Math } \\
\text { Standardized } \\
\text { Test (std.) }\end{array}$ \\
\cline { 2 - 5 } Salience & $0.021^{* * *}$ & $0.071^{* *}$ & $0.026^{* *}$ & $0.107^{* *}$ \\
& {$[0.006]$} & {$[0.032]$} & {$[0.012]$} & {$[0.047]$} \\
Control within classroom & $0.021^{* * *}$ & $0.090^{* * *}$ & $0.032^{* * *}$ & $0.095^{* *}$ \\
& {$[0.006]$} & {$[0.032]$} & {$[0.012]$} & {$[0.047]$} \\
& $0.018^{* * *}$ & $0.070^{* *}$ & $0.030^{* *}$ & $0.085^{*}$ \\
Control mean & {$[0.006]$} & {$[0.031]$} & {$[0.012]$} & {$[0.047]$} \\
p-value diff. [Info] -[Salience] & 0.896 & 0.221 & 0.219 & 0.596 \\
\hline Observations & 12,577 & 12,577 & 12,577 & 12,577 \\
Randomization strata FE & Yes & Yes & Yes & Yes \\
Student-level controls & Yes & Yes & Yes & Yes \\
R-squared & 0.21 & 0.62 & 0.10 & 0.34 \\
\hline
\end{tabular}

Note: Treatment effects of child-specific information and salience messages on the following administrative outcomes: 4th-quarter attendance in math classes (Column 1); 4th-quarter math GPA (Column 2); grade promotion rate (=1 if the student advanced to high school, and 0 otherwise; Column 3 ), and math standardized test scores (Column 4). GPA and standardized test were normalized relative to the distribution of the pure control group. Students' controls include gender, age, race, baseline grades and attendance, and caregivers' controls include gender, age, race, family income and education. We also control for randomization strata fixed-effects. All columns are OLS regressions, with standard errors clustered at the classroom level. ${ }^{*}$ if $\mathrm{p}<0.1,{ }^{* *} \mathrm{p}<0.05$ and ${ }^{* * *}$ if $\mathrm{p}<0.01$. 


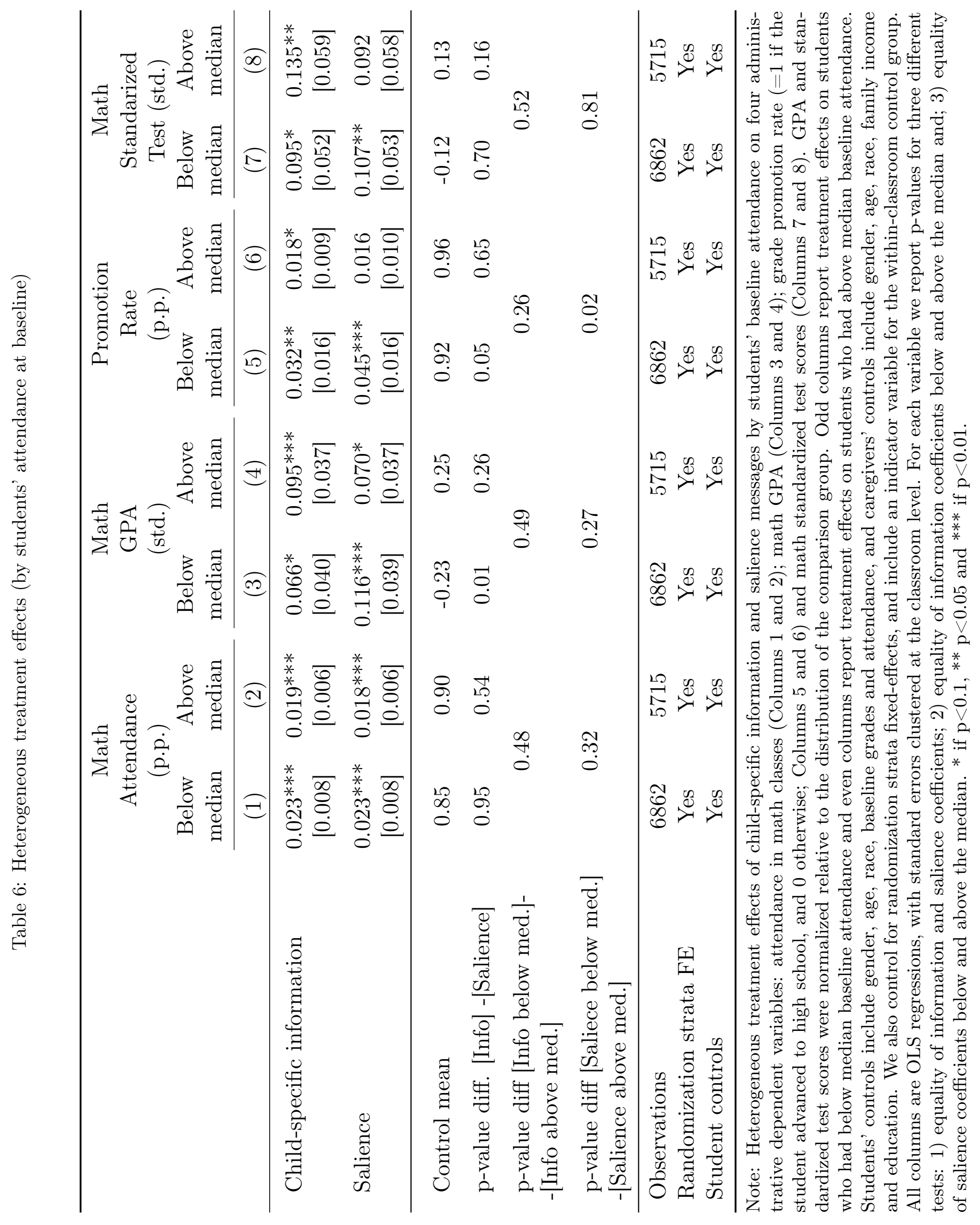


Table 7: Effects of framing child-specific information relatively to the classroom median

\begin{tabular}{lcccc}
\hline & $\begin{array}{c}(1) \\
\text { Math } \\
\text { Attendance } \\
(\text { p.p. })\end{array}$ & $\begin{array}{c}\text { Math } \\
\text { GPA } \\
\text { (std.) }\end{array}$ & $\begin{array}{c}\text { Promotion } \\
\text { Rate } \\
(\mathrm{p} . \mathrm{p} .)\end{array}$ & $\begin{array}{c}(4) \\
\text { Math } \\
\text { Standardized } \\
\text { Test (std.) }\end{array}$ \\
\cline { 2 - 5 } Child-specific information & $\begin{array}{c}0.021^{* * *} \\
{[0.006]}\end{array}$ & $\begin{array}{c}0.069^{* *} \\
{[0.032]}\end{array}$ & $\begin{array}{c}0.029^{* *} \\
{[0.012]}\end{array}$ & $\begin{array}{c}0.097^{* *} \\
{[0.047]}\end{array}$ \\
& $0.022^{* * *}$ & $0.078^{*}$ & 0.017 & $0.141^{* *}$ \\
Relative information & {$[0.007]$} & {$[0.041]$} & {$[0.014]$} & {$[0.058]$} \\
& $0.021^{* * *}$ & $0.090^{* * *}$ & $0.032^{* * *}$ & $0.095^{* *}$ \\
Salience & {$[0.006]$} & {$[0.032]$} & {$[0.012]$} & {$[0.047]$} \\
\hline Control mean & 0.875 & 0.000 & 0.938 & -0.000 \\
p-value diff. [Rel. info] -[Salience] & 0.770 & 0.690 & 0.086 & 0.252 \\
\hline Observations & 12577 & 12577 & 12577 & 12577 \\
Randomization strata FE & Yes & Yes & Yes & Yes \\
Student controls & Yes & Yes & Yes & Yes \\
\hline
\end{tabular}

Note: The table displays treatment effects of child-specific information, child-specific relative information, and salience messages on the following administrative outcomes: 4th-quarter attendance in math classes (Column 1); 4th-quarter math GPA (Column 2); grade promotion rate (=1 if the student advanced to high school, and 0 otherwise; Column 3), and math standardized test scores (Column 4). Parents in the relative information treatment receive not only child-specific information but comparisons of their children to other students in their class. GPA and standardized test scores were normalized relative to the distribution of the pure control group. Students' controls include gender, age, race, baseline grades and attendance, and caregivers' controls include gender, age, race, family income and education. We also control for randomization strata fixed-effects, and include an indicator variable for the within-classroom control group. All columns are OLS regressions, with standard errors clustered at the classroom level. ${ }^{*}$ if $\mathrm{p}<0.1,{ }^{* *} \mathrm{p}<0.05$ and ${ }^{* * *}$ if $\mathrm{p}<0.01$. 
Table 8: Differential effects of salience in sub-sample without informational intervention

\begin{tabular}{|c|c|c|c|c|}
\hline & $\begin{array}{c}\text { (1) } \\
\text { Math } \\
\text { Attendance } \\
\text { (p.p.) }\end{array}$ & $\begin{array}{c}(2) \\
\text { Math } \\
\text { GPA } \\
\text { (std.) }\end{array}$ & $\begin{array}{c}(3) \\
\text { Promotion } \\
\text { Rate } \\
\text { (p.p.) }\end{array}$ & $\begin{array}{c}(4) \\
\text { Math } \\
\text { Standardized } \\
\text { Test (std.) }\end{array}$ \\
\hline \multicolumn{5}{|l|}{ Panel A: Full sample } \\
\hline Child-specific information & $\begin{array}{c}0.021^{* * *} \\
{[0.006]}\end{array}$ & $\begin{array}{c}0.070^{* *} \\
{[0.032]}\end{array}$ & $\begin{array}{c}0.026^{* *} \\
{[0.012]}\end{array}$ & $\begin{array}{c}0.108^{* *} \\
{[0.047]}\end{array}$ \\
\hline Salience & $\begin{array}{c}0.017^{* * *} \\
{[0.006]}\end{array}$ & $\begin{array}{c}0.070^{* *} \\
{[0.033]}\end{array}$ & $\begin{array}{c}0.027^{* *} \\
{[0.012]}\end{array}$ & $\begin{array}{c}0.101^{* *} \\
{[0.048]}\end{array}$ \\
\hline Salience x No-information sub-sample & $\begin{array}{c}0.001 \\
{[0.004]}\end{array}$ & $\begin{array}{l}0.049^{*} \\
{[0.029]}\end{array}$ & $\begin{array}{c}0.004 \\
{[0.009]}\end{array}$ & $\begin{array}{c}0.015 \\
{[0.042]}\end{array}$ \\
\hline Observations & 12577 & 12577 & 12577 & 12577 \\
\hline Randomization strata FE & Yes & Yes & Yes & Yes \\
\hline Student controls & Yes & Yes & Yes & Yes \\
\hline \multicolumn{5}{|l|}{ Panel B: Sample B and D } \\
\hline Salience x No-information sub-sample & $\begin{array}{c}0.034^{* * *} \\
{[0.006]}\end{array}$ & $\begin{array}{c}0.172^{* * *} \\
{[0.042]}\end{array}$ & $\begin{array}{c}0.059^{* * *} \\
{[0.012]}\end{array}$ & $\begin{array}{l}0.106^{*} \\
{[0.056]}\end{array}$ \\
\hline Observations & 3760 & 3541 & 3675 & 3455 \\
\hline Randomization strata FE & Yes & Yes & Yes & Yes \\
\hline Student controls & Yes & Yes & Yes & Yes \\
\hline
\end{tabular}

Note: Treatment effects of salience messages separately for schools where some parents were assigned to childspecific information, and those where none was. Panel A estimates differential treatment effects of salience messages within the no-information sub-sample through an interaction term, and Panel B estimates treatment effects of salience messages restricting attention to that sub-sample and the pure control group. Treatment effects on 4th-quarter attendance in math classes (Column 1); 4th-quarter math GPA (Column 2); grade promotion rate (=1 if the student advanced to high school, and 0 otherwise; Column 3 ), and math standardized test scores (Column 4). GPA was normalized relative to the distribution of the pure control group. Students' controls include gender, age, race, baseline grades and attendance, and their caregivers' controls include gender, age, race, family income and education. We also control for randomization strata fixed-effects, and include an indicator variable for the within-classroom control group. All columns are OLS regressions, with standard errors clustered at the classroom level. ${ }^{*}$ if $\mathrm{p}<0.1, * * \mathrm{p}<0.05$ and $* * *$ if $\mathrm{p}<0.01$. 
Table 9: Treatment effects of nudges: Differences-in-differences

\begin{tabular}{lcccc}
\hline & $(1)$ & $(2)$ & $(3)$ & $(4)$ \\
\hline & \multicolumn{2}{c}{ All quarters } & Placebo (first 2 quarters) \\
\cline { 2 - 5 } & Math & Math & Math & Math \\
& Attendance & GPA & Attendance & GPA \\
& (p.p.) & (std.) & (p.p.) & (std.) \\
\hline Nudges x Post & $0.0151^{* * *}$ & $0.116^{* * *}$ & 0.00842 & 0.0312 \\
& {$[0.00591]$} & {$[0.0427]$} & {$[0.00735]$} & {$[0.0600]$} \\
Nudges & 0.00621 & $-0.162^{* * *}$ & 0.00130 & $-0.180^{* * *}$ \\
Post & {$[0.00604]$} & {$[0.0610]$} & {$[0.00635]$} & {$[0.0673]$} \\
& $-0.0333^{* * *}$ & 0.00420 & $-0.0389^{* * *}$ & -0.0206 \\
\hline Observations & {$[0.00416]$} & {$[0.0252]$} & {$[0.00499]$} & {$[0.0388]$} \\
Student-level controls & 14,775 & 14,586 & 7,347 & 7,376 \\
R-squared & Yes & Yes & Yes & Yes \\
\hline & 0.072 & 0.060 & 0.074 & 0.062 \\
\hline
\end{tabular}

Note: Treatment effects of nudge messages to parents that do not require any input from teachers on: 4th-quarter attendance in math classes (Columns 1 and 3) and 4th-quarter math GPA (Columns 2 and 4). GPA was normalized relative to the distribution of the pure control group. The sample includes sub-sample $\mathrm{E}$ and the pure control group. We also excluded parents assigned to 2 or 3 nudges per week. Observations are stacked at the quarter-level. In Columns (1) and (2), we estimate treatment effects using all four available quarters. In Columns (3) and (4), we estimate placebos using only the first two available quarters. All estimates use the first quarter as period of reference. Regressions include interactions between a post-treatment time dummy and treated students, and between the post-treatment dummy and within-classroom control group dummy (the pure control is the reference group). We also include in the regression indicator variables for the post-treatment period and for the treatment and within-classroom control groups, and student-level controls. Students' controls include gender, age, race, baseline grades and attendance, and caregivers' controls include gender, age, race, family income and education. All columns are OLS regressions, with standard errors clustered at the classroom level. ${ }^{*}$ if $\mathrm{p}<0.1,{ }^{* *} \mathrm{p}<0.05$ and $* * *$ if $\mathrm{p}<0.01$. 
Table 10: Effects on parental engagement

\begin{tabular}{|c|c|c|c|c|}
\hline & $\begin{array}{l}\quad(1) \\
\text { Academic } \\
\text { activities }\end{array}$ & $\begin{array}{c}(2) \\
\text { Motivation }\end{array}$ & $\begin{array}{c}(3) \\
\text { Dialogue }\end{array}$ & $\begin{array}{c}(4) \\
\text { Aspirations }\end{array}$ \\
\hline Child-specific information & $\begin{array}{l}0.092^{*} \\
{[0.051]}\end{array}$ & $\begin{array}{l}0.075^{*} \\
{[0.042]}\end{array}$ & $\begin{array}{c}0.147^{* * * *} \\
{[0.044]}\end{array}$ & $\begin{array}{c}0.092^{* *} \\
{[0.036]}\end{array}$ \\
\hline Salience & $\begin{array}{c}0.064 \\
{[0.050]}\end{array}$ & $\begin{array}{c}0.096 * * \\
{[0.041]}\end{array}$ & $\begin{array}{c}0.122^{* * * *} \\
{[0.043]}\end{array}$ & $\begin{array}{c}0.095^{* * *} \\
{[0.036]}\end{array}$ \\
\hline p-value diff. [Info] -[Salience] & 0.263 & 0.382 & 0.374 & 0.891 \\
\hline $\begin{array}{l}\text { Observations } \\
\text { Randomization strata FE } \\
\text { Student controls }\end{array}$ & $\begin{array}{l}9539 \\
\text { Yes } \\
\text { Yes }\end{array}$ & $\begin{array}{l}9539 \\
\text { Yes } \\
\text { Yes }\end{array}$ & $\begin{array}{l}9539 \\
\text { Yes } \\
\text { Yes }\end{array}$ & $\begin{array}{l}9539 \\
\text { Yes } \\
\text { Yes }\end{array}$ \\
\hline \multicolumn{5}{|c|}{$\begin{array}{l}\text { Note: Treatment effects of child-specific information and salience messages on parental engagement. } \\
\text { Variables are based on students' end-line survey. They were asked to state how often their parents } \\
\text { engage in certain activities (never, almost never, sometimes, almost always, always). Out of the } 12 \\
\text { questions, factor analysis was performed to create } 3 \text { variables of parental behavior: academic activ- } \\
\text { ities (help with homework, help to organize school material, participate in school-parent meetings, } \\
\text { talk to the teachers); motivation (incentivize to not miss school, to not be late, to study and to } \\
\text { read); dialogue (ask about homework, ask about grades, ask about day in school and classes). We } \\
\text { also created a dummy variable for parents' aspirations that indicates whether students answered } \\
\text { that their parents expect them to go to college or not. Variables were normalized relative to the } \\
\text { distribution of the comparison group (pure control). Students' controls include gender, age, race, } \\
\text { baseline grades and attendance, and caregivers' controls include gender, age, race, family income } \\
\text { and education. We also control for randomization strata fixed-effects, and include an indicator } \\
\text { variable for the within-classroom control group. All columns are OLS regressions, with standard } \\
\text { errors clustered at the classroom level. } * \text { if } p<0.1, * * p<0.05 \text { and } * * * \text { if p }<0.01 \text {. }\end{array}$} \\
\hline
\end{tabular}


Table 11: Effects on students' time use

\begin{tabular}{lccc}
\hline & $\begin{array}{c}(1) \\
\text { Academic } \\
\text { activities }\end{array}$ & $\begin{array}{c}(2) \\
\text { Reading }\end{array}$ & $\begin{array}{c}(3) \\
\text { Other } \\
\text { activities }\end{array}$ \\
\cline { 2 - 4 } Child-specific information & $\begin{array}{c}0.151^{* * *} \\
{[0.051]}\end{array}$ & $\begin{array}{c}0.116^{*} \\
{[0.065]}\end{array}$ & $\begin{array}{c}-0.108^{* *} \\
{[0.054]}\end{array}$ \\
Salience & $\begin{array}{c}0.123^{* *} \\
{[0.050]}\end{array}$ & $\begin{array}{c}0.113^{*} \\
{[0.060]}\end{array}$ & $\begin{array}{c}-0.110^{* *} \\
{[0.052]}\end{array}$ \\
\hline p-value diff. [Info] -[Salience] & 0.344 & 0.946 & 0.933 \\
\hline Observations & 9539 & 9539 & 9539 \\
Randomization strata FE & Yes & Yes & Yes \\
Student controls & Yes & Yes & Yes \\
\hline
\end{tabular}

Note: Treatment effects of child-specific information and salience messages on students' time-use. Variables are based on the end-line survey. Students were requested to answer how many hours per day $(0,15$ minutes, 30 minutes, 1 hour, 2 hours, more than 2 hours) they spend in each of the following activities: i. studying at home on weekdays; ii. studying at home on weekends; iii. studying at home the day before a test; iv. reading a book; v. reading the newspaper; vi. reading magazines; vii. watching TV; viii. navigating on the internet or social media; and ix. helping with housework. Factor analysis was performed to create three variables of student behavior: academic activities (items i, ii and iii); reading activities (items iv, v and vi) and other activities (items vii, viii and ix). Variables were normalized relative to the distribution of the comparison group (pure control). Students' controls include gender, age, race, baseline grades and attendance, and caregivers' controls include gender, age, race, family income and education. We also control for randomization strata fixed-effects, and include an indicator variable for the within-classroom control group. All columns are OLS regressions, with standard errors clustered at the classroom level. ${ }^{*}$ if $\mathrm{p}<0.1, * * \mathrm{p}<0.05$ and $* * *$ if $\mathrm{p}<0.01$. 
Table 12: Parents' accuracy about math GPA levels and changes

\begin{tabular}{|c|c|c|c|c|c|c|}
\hline & \multicolumn{2}{|c|}{ Baseline beliefs } & \multicolumn{2}{|c|}{ End-line beliefs } & \multicolumn{2}{|c|}{ Change in beliefs } \\
\hline & $(1)$ & $(2)$ & $(3)$ & $(4)$ & $(5)$ & (6) \\
\hline Actual GPA & $\begin{array}{l}-0.050 \\
{[0.048]}\end{array}$ & $\begin{array}{l}-0.017 \\
{[0.051]}\end{array}$ & $\begin{array}{c}0.265^{* * *} \\
{[0.030]}\end{array}$ & $\begin{array}{c}0.253^{* * *} \\
{[0.039]}\end{array}$ & & \\
\hline Changes in actual GPA & & & & & $\begin{array}{c}0.156^{* * *} \\
{[0.036]}\end{array}$ & $\begin{array}{c}0.157^{* * *} * \\
{[0.039]}\end{array}$ \\
\hline Child-specific information & $\begin{array}{c}0.051 \\
{[0.085]}\end{array}$ & & $\begin{array}{l}-0.055 \\
{[0.104]}\end{array}$ & & $\begin{array}{c}0.052 \\
{[0.044]}\end{array}$ & \\
\hline Salience & & $\begin{array}{c}0.031 \\
{[0.080]}\end{array}$ & & $\begin{array}{c}0.014 \\
{[0.091]}\end{array}$ & & $\begin{array}{c}0.008 \\
{[0.043]}\end{array}$ \\
\hline Actual GPA x Information & $\begin{array}{l}-0.011 \\
{[0.032]}\end{array}$ & & $\begin{array}{c}0.020 \\
{[0.037]}\end{array}$ & & & \\
\hline Actual GPA x Salience & & $\begin{array}{l}-0.013 \\
{[0.030]}\end{array}$ & & $\begin{array}{l}-0.018 \\
{[0.036]}\end{array}$ & & \\
\hline Changes in actual GPA $x$ Information & & & & & $\begin{array}{c}0.104^{* * *} \\
{[0.052]}\end{array}$ & \\
\hline Changes in actual GPA x Salience & & & & & & $\begin{array}{c}0.073 \\
{[0.054]}\end{array}$ \\
\hline Baseline level & & & & & $\begin{array}{c}-1.216^{* * *} \\
{[0.025]}\end{array}$ & $\begin{array}{c}-1.195 * * * \\
{[0.025]}\end{array}$ \\
\hline Observations & 2,815 & 2,878 & 2,296 & 2,178 & 1,160 & 1,140 \\
\hline Classroom FE & No & No & No & No & No & No \\
\hline Student-level controls & Yes & Yes & Yes & Yes & Yes & Yes \\
\hline R-squared & 0.152 & 0.154 & 0.248 & 0.242 & 0.790 & 0.783 \\
\hline
\end{tabular}

Note: Correlation between parents' baseline and end-line beliefs about their children's math grades and actual grades as well as the correlation between changes in beliefs and math grades within each period. At baseline, parents were asked to At end line, parents were asked to provide their best estimate of their child's 4th-quarter math GPA, an integer between 0 and 10 . We build a 4 -point scale variable for end-line beliefs consistent with the baseline variable. The dependent variables are: an ordinal scale of parents' baseline beliefs, between 1 (corresponding to the $0-4$ bracket) to 4 (corresponding to the 9-10 bracket) (Columns 1 and 2); a 4-point scale equivalent variable for end-line beliefs (Columns 3 and 4); and the change in beliefs between the two periods (Columns 5 and 6). Columns (1), (3) and (5) include only students in the child-specific information and control groups (both within-class and pure control). Columns (2), (4) and (6) include only students in the salience and control groups (both within-class and pure control). Regressions include indicator variables for students in the (1) specific information (levels in columns 1 and 3 , and changes in column 5) or (changes in) actual math GPA and the indicator for salience messages (levels in columns 2 and 4 , and changes in column 6). 2nd-quarter math GPA included as control in columns (5) and (6). Students' controls include gender, age, race, baseline grades and attendance, and caregivers' controls include gender, age, race, family income and education. All columns are OLS regressions, with standard errors clustered at the classroom level. * if $\mathrm{p}<0.1, * * \mathrm{p}<0.05$ and $* * *$ if $\mathrm{p}<0.01$ 
Table 13: Treatment effects on Portuguese outcomes

\begin{tabular}{lccc}
\hline & \multicolumn{3}{c}{ Educational outcomes } \\
\cline { 2 - 4 } & $(1)$ & $(2)$ & $(3)$ \\
& $\begin{array}{c}\text { Portuguese } \\
\text { Attendance } \\
\text { (p.p.) }\end{array}$ & $\begin{array}{c}\text { Portuguese } \\
\text { GPA } \\
\text { (std.) }\end{array}$ & $\begin{array}{c}\text { Portuguese } \\
\text { Standardized } \\
\text { Test (std.) }\end{array}$ \\
\cline { 2 - 4 } Child-specific information & 0.007 & 0.053 & 0.047 \\
& {$[0.005]$} & {$[0.036]$} & {$[0.043]$} \\
Salience & 0.007 & $0.066^{*}$ & 0.032 \\
& {$[0.005]$} & {$[0.036]$} & {$[0.043]$} \\
\hline Observations & 12577 & 12577 & 12577 \\
Randomization strata FE & Yes & Yes & Yes \\
Student controls & Yes & Yes & Yes \\
\hline
\end{tabular}

Note: Treatment effects of child-specific information and salience messages on the parents' accuracy and students' educational outcomes in Portuguese classes. Dependent variables are 4th-quarter Portuguese attendance (Column 1), Portuguese GPA (Column 2), and Portuguese standardized test scores (Column 3). GPA and standardized test scores were normalized relative to the distribution of the pure control group. Students' controls include gender, age, race, baseline grades and attendance, and caregivers' controls include gender, age, race, family income and education. We also control for randomization strata fixed-effects, and include an indicator variable for the within-classroom control group. All columns are OLS regressions, with standard errors clustered at the classroom level. ${ }^{*}$ if $\mathrm{p}<0.1,{ }^{* *} \mathrm{p}<0.05$ and ${ }^{* * *}$ if $\mathrm{p}<0.01$. 


\section{A [Supplementary Appendix] Additional details on SMS con- tent}

As described in section 3.3, math teachers from treatment schools were oriented to fill in the platform every week with that week's dimension of students' behavior: attendance, tardiness or assignment completion, as shown in the table below. Teachers filled information regarding student behavior on each dimension considering the past three weeks.

\begin{tabular}{lll}
\hline \multicolumn{1}{c}{ Attendance } & \multicolumn{1}{c}{ Tardiness } & Assignment Completion \\
\begin{tabular}{lll} 
1. Missed more than 5 classes & 1. Was late for more than 5 classes & 1. Did not complete any of the assignments \\
2. Missed 3 to 5 classes & 2. Was late 3 to 5 classes & 2. Completed less than half of the assignments \\
3. Missed less than 3 classes & 3. Was late for less than 3 classes & 3. Completed more than half of the assignments \\
4. Did not miss any class & 4. Was not late for any class & 4. Completed all the assignments \\
\hline
\end{tabular}
\end{tabular}

The table below shows the text messages sent in each of the 18 weeks, for each treatment arm (individual information, relative information and salience). The core text for the individual information and relative information messages were the same for each week, with only the frequency filled by the teacher in the platform and the median for the class varying (denominated by@info and @info_class in the table). For the relative information arm, the platform computes the class median once the teacher submits all students' information every week. The salience messages were different each week. The messages for all the 3 groups were personalized with students names (@name). 


Week
Week 1 $\begin{aligned} & \text { Individual Info. } \\ & \text { According to the information } \\ & \text { recorded by the teacher in the } \\ & \text { system, @name @info in the } \\ & \text { past 3 weeks. }\end{aligned}$

Week 2 According to the information recorded by the teacher in the system, @name@info in the past 3 weeks.

Week 3 According to the information recorded by the teacher in the system, @name@info in the past 3 weeks.

Week 4 According to the information recorded by the teacher in the system, @name@info in the past 3 weeks.

Week 5 According to the information recorded by the teacher in the system,@name@info in the past 3 weeks.

Week 6 According to the information recorded by the teacher in the system,@name@info in the past 3 weeks.

Week 7 According to the information recorded by the teacher in the system,@name@info in the past 3 weeks.

Week 8 According to the information recorded by the teacher in the system, @name@info in the past 3 weeks.

Week 9 According to the information recorded by the teacher in the system, @name@info in the past 3 weeks.

\section{Relative Info.}

In the past 3 weeks, @name @info. In his/her class, most of the students@info_class.

In the past 3 weeks, @name @info. In his/her class, most of the students@info_class.

In the past 3 weeks, @name @info. In his/her class, most of the students@info_class.

In the past 3 weeks, @name @info. In his/her class, most of the students@info_class.

In the past 3 weeks, @name @info. In his/her class, most of the students@info_class.

In the past 3 weeks, @name @info. In his/her class, most of the students@info_class.

In the past 3 weeks, @name @info. In his/her class, most of the students@info_class.

In the past 3 weeks, @name @info. In his/her class, mos of the students@info_class. In the past 3 weeks, @name @info. In his/her class, most of the students@info_class.
Salience

If missing a class, @name can miss important parts of the content taught, which could impair his/her performance at school.

When students are late for class, they can impair the progress of the group and disturb their peers' concentration. It is important that@name arrives on time for classes.

It is important for@name to always turn in assignments, as they allow the student to reinforce the content taught in the classroom.

Learning requires constant participation. It is important that @name is always present in class.

For a good learning experience, it is important that@name is always punctual, so he/she doesn't miss important content taught in class.

@Name could fall behind if he/she does not turn in the homework, because the teacher may not be able to help him/her with his/her specific difficulties.

Participate in @name's education. Family engagement is essential for the student to attend classes daily.

It is important that @name is always punctual for class so that the teacher can complete the lesson plan successfully.

If @name does not turn in homework assignments, it may hurt his/her learning, as the content taught in class will not be reinforced. 


\begin{tabular}{|c|c|c|c|}
\hline Week & Individual Info. & Relative Info. & Salience \\
\hline Week 10 & $\begin{array}{l}\text { According to the information } \\
\text { recorded by the teacher in the } \\
\text { system, @name@info in the } \\
\text { past } 3 \text { weeks. }\end{array}$ & $\begin{array}{l}\text { In the past } 3 \text { weeks, @name } \\
@ \text { info. In his/her class, most } \\
\text { of the students@info_class. }\end{array}$ & $\begin{array}{l}\text { If he/she misses classes, @name may miss } \\
\text { important parts of the content, impairing } \\
\text { his/her school performance. }\end{array}$ \\
\hline Week 11 & $\begin{array}{l}\text { According to the information } \\
\text { recorded by the teacher in the } \\
\text { system, @name@info in the } \\
\text { past } 3 \text { weeks. }\end{array}$ & $\begin{array}{l}\text { In the past } 3 \text { weeks, @name } \\
\text { @info. In his/her class, most } \\
\text { of the students@info_class. }\end{array}$ & $\begin{array}{l}\text { Arriving late impairs the progress of the } \\
\text { class and the concentration of @name's } \\
\text { peers. It's important@name is punctual. }\end{array}$ \\
\hline Week 12 & $\begin{array}{l}\text { According to the information } \\
\text { recorded by the teacher in the } \\
\text { system, @name@info in the } \\
\text { past } 3 \text { weeks. }\end{array}$ & $\begin{array}{l}\text { In the past } 3 \text { weeks, @name } \\
\text { @info. In his/her class, most } \\
\text { of the students@info_class. }\end{array}$ & $\begin{array}{l}\text { It is important for @name to always turn } \\
\text { in assignments, as they allow the student } \\
\text { to reinforce the content taught in class. }\end{array}$ \\
\hline Week 13 & $\begin{array}{l}\text { According to the information } \\
\text { recorded by the teacher in the } \\
\text { system, @name@info in the } \\
\text { past } 3 \text { weeks. }\end{array}$ & $\begin{array}{l}\text { In the past } 3 \text { weeks, @name } \\
@ \text { info. In his/her class, most } \\
\text { of the students@info_class. }\end{array}$ & $\begin{array}{l}\text { Learning requires constant participation, } \\
\text { so it's important that @name is always } \\
\text { present in class. }\end{array}$ \\
\hline Week 14 & $\begin{array}{l}\text { According to the information } \\
\text { recorded by the teacher in the } \\
\text { system, @name@info in the } \\
\text { past } 3 \text { weeks. }\end{array}$ & $\begin{array}{l}\text { In the past } 3 \text { weeks, @name } \\
@ \text { info. In his/her class, most } \\
\text { of the students@info_class. }\end{array}$ & $\begin{array}{l}\text { For good learning, it is essential that } \\
@ \text { name is always punctual so he/she does } \\
\text { not miss important content taught in class. }\end{array}$ \\
\hline Week 15 & $\begin{array}{l}\text { According to the information } \\
\text { recorded by the teacher in the } \\
\text { system, @name@info in the } \\
\text { past } 3 \text { weeks. }\end{array}$ & $\begin{array}{l}\text { In the past } 3 \text { weeks, @name } \\
@ i n f o . \text { In his/her class, most } \\
\text { of the students@info_class. }\end{array}$ & $\begin{array}{l}\text { The teacher might not be able to help } \\
\text { @ name in his/her specific challenges if } \\
\text { he/she does not turn in his/her home- } \\
\text { work. }\end{array}$ \\
\hline Week 16 & $\begin{array}{l}\text { According to the information } \\
\text { recorded by the teacher in the } \\
\text { system, @name@info in the } \\
\text { past } 3 \text { weeks. }\end{array}$ & $\begin{array}{l}\text { In the past } 3 \text { weeks, @name } \\
\text { @info. In his/her class, most } \\
\text { of the students@info_class. }\end{array}$ & $\begin{array}{l}\text { Engage in @name's education. Family in- } \\
\text { volvement is essential for the student to } \\
\text { attend classes daily. }\end{array}$ \\
\hline Week 17 & $\begin{array}{l}\text { According to the information } \\
\text { recorded by the teacher in the } \\
\text { system, @name@info in the } \\
\text { past } 3 \text { weeks. }\end{array}$ & $\begin{array}{l}\text { In the past } 3 \text { weeks, @name } \\
@ \text { info. In his/her class, most } \\
\text { of the students@info_class. }\end{array}$ & $\begin{array}{l}\text { It is important that @name is always on } \\
\text { time so that the teacher can carry out the } \\
\text { lesson successfully. }\end{array}$ \\
\hline Week 18 & $\begin{array}{l}\text { According to the information } \\
\text { recorded by the teacher in the } \\
\text { system, @name@info in the } \\
\text { past } 3 \text { weeks. }\end{array}$ & $\begin{array}{l}\text { In the past } 3 \text { weeks, @name } \\
@ \text { info. In his/her class, most } \\
\text { of the students@info_class. }\end{array}$ & $\begin{array}{l}\text { If @name does not turn in the school } \\
\text { assignments, it may be detrimental to } \\
\text { his/her learning, as the content taught in } \\
\text { class will not be reinforced. }\end{array}$ \\
\hline
\end{tabular}


The figure below shows two examples of the SMS sequence sent to parents assigned to the nudge program (described in section 5.5.2). The figure displays a stylized sequence for a parent assigned to 3 messages a week and interactivity. Those assigned to the group without interactivity do not receive the feedback message on day 4 of every week. Those assigned to 2 messages a week do not receive the growth message on day 5 of every week. Last, those assigned to 1 message a week receive only the activity message, on day 3 of every week. Only parents who received one message per week were considered in the robustness tests performed in section 5.5.2 ${ }^{48}$.

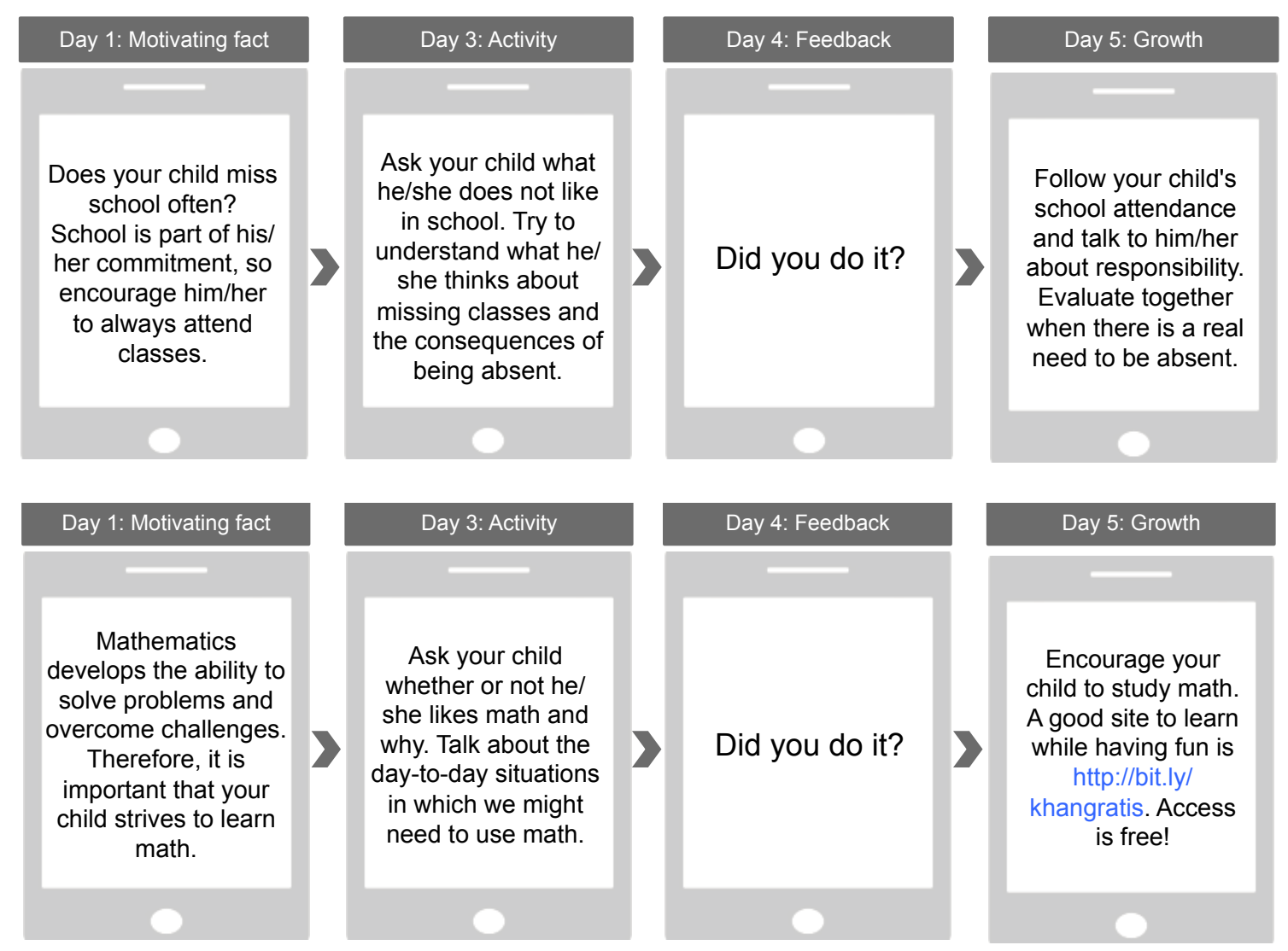

\footnotetext{
${ }^{48}$ The intellectual property rights of the content library of engagement messages belongs to our implementing partner, MGov Brasil, and therefore only two examples are provided here.
} 


\section{B [Supplementary Appendix] Additional balance and selec- tive attrition tests}

In this section, we present balance and attrition tests. Table B.1 shows descriptive statistics and balance test for the main sample used in the analysis (e.g. Tables 5, 7, 8). Table B.2 presents descriptive statistics and balance test for the theory of change sample. Next, Tables B.3 and B.4 contain a selective attrition analysis for completing the surveys by treatment status and by baseline characteristics, respectively. Because parents who opted into the program had different characteristics from those who did not opt in (as we showed in Table 2), in Table B.5 we show results for school transcripts and test scores re-weighting observations by the inverse probability of opting into the program. Finally, Table B.6 describes statistics and balance for the theory-based nudging program for the parents receiving one message per week, which is the sample used to run the differences-in-differences analysis described in section 5 . 
Table B.1: Descriptive statistics and balance tests for the whole sample

\begin{tabular}{|c|c|c|c|c|c|c|}
\hline & \multicolumn{4}{|c|}{ Means } & \multirow[t]{2}{*}{$\begin{array}{l}\text { Diff }=0 \\
\text { p-value }\end{array}$} & \multirow[t]{2}{*}{$\begin{array}{c}\text { Sample } \\
\text { Size }\end{array}$} \\
\hline & $\begin{array}{c}\text { Pure } \\
\text { Control }\end{array}$ & $\begin{array}{c}\text { Control } \\
\text { Within Class }\end{array}$ & Salience & Info & & \\
\hline \multicolumn{7}{|l|}{ Student characteristics } \\
\hline Female & 0.47 & 0.50 & 0.51 & 0.52 & 0.03 & 12577 \\
\hline Age & 14.69 & 14.67 & 14.67 & 14.71 & 0.03 & 12577 \\
\hline Brown & 0.36 & 0.35 & 0.34 & 0.35 & 0.14 & 12577 \\
\hline Black & 0.06 & 0.05 & 0.06 & 0.06 & 0.79 & 12577 \\
\hline Portuguese GPA ( $\max 10)$ & 6.39 & 6.31 & 6.27 & 6.28 & 0.69 & 12577 \\
\hline Math GPA (max 10) & 6.10 & 6.11 & 6.05 & 6.06 & 0.57 & 12577 \\
\hline Portuguese attendance & 0.92 & 0.92 & 0.92 & 0.92 & 0.50 & 12577 \\
\hline Math attendance & 0.92 & 0.92 & 0.92 & 0.91 & 0.39 & 12577 \\
\hline \multicolumn{7}{|l|}{ Adult responsible for student } \\
\hline Mother & 0.77 & 0.75 & 0.76 & 0.76 & 0.45 & 12577 \\
\hline Age & 40.39 & 40.28 & 40.34 & 40.57 & 0.68 & 12577 \\
\hline Brown & 0.36 & 0.34 & 0.34 & 0.34 & 0.15 & 12577 \\
\hline Black & 0.07 & 0.06 & 0.07 & 0.07 & 0.71 & 12577 \\
\hline Middle school incomplete & 0.32 & 0.30 & 0.30 & 0.31 & 0.32 & 12577 \\
\hline Middle school complete & 0.28 & 0.26 & 0.28 & 0.28 & 0.48 & 12577 \\
\hline High School & 0.34 & 0.33 & 0.32 & 0.31 & 0.19 & 12577 \\
\hline Earns less than $1 \mathrm{MW}(1 \mathrm{MW} \sim \$ 250)$ & 0.17 & 0.17 & 0.17 & 0.17 & 0.80 & 12577 \\
\hline Earns between 1 - 3 MW & 0.44 & 0.46 & 0.46 & 0.47 & 0.80 & 12577 \\
\hline
\end{tabular}

Note: This Table displays conditional means net of randomization strata fixed effects and p-values computed using randomization strata fixed effects. Standard errors clustered at the classroom level. Variables are computed for four sub-samples. The Table reports the following variables for students: dummies for females, brown and black students, and Portuguese and Math attendance and grades. The following variables are reported for the adults responsible for the students: age and dummies for mothers, race variables (black and brown), education variables (incomplete middle school, complete middle school, and high school), and income variables (less than one minimum wage or between one and three minimum wages). Data on students' gender, age, GPA and attendance are from administrative records, and data on students' race and on caregivers' characteristics are from the face-to-face baseline survey within those who opted-in to participate in program. 
Table B.2: Descriptive statistics and balance tests for the sub-samples with answers to the phone surveys

\begin{tabular}{|c|c|c|c|c|c|c|}
\hline & \multicolumn{4}{|c|}{ Means } & \multirow{2}{*}{$\begin{array}{l}\text { Diff=0 } \\
\text { p-value }\end{array}$} & \multirow{2}{*}{$\begin{array}{c}\text { Sample } \\
\text { Size }\end{array}$} \\
\hline & $\begin{array}{c}\text { Pure } \\
\text { Control }\end{array}$ & $\begin{array}{c}\text { Control } \\
\text { Within Class }\end{array}$ & Salience & Info & & \\
\hline \multicolumn{7}{|l|}{ Student characteristics } \\
\hline Female & 0.50 & 0.50 & 0.52 & 0.52 & 0.18 & 9539 \\
\hline Age & 14.65 & 14.65 & 14.66 & 14.68 & 0.24 & 9539 \\
\hline Brown & 0.36 & 0.35 & 0.33 & 0.34 & 0.33 & 9539 \\
\hline Black & 0.05 & 0.05 & 0.05 & 0.05 & 0.68 & 9539 \\
\hline Portuguese GPA (max 10) & 6.51 & 6.45 & 6.39 & 6.39 & 0.51 & 9539 \\
\hline Math GPA (max 10) & 6.21 & 6.22 & 6.20 & 6.17 & 0.87 & 9539 \\
\hline Portuguese attendance & 0.93 & 0.93 & 0.93 & 0.93 & 0.30 & 9539 \\
\hline Math attendance & 0.93 & 0.92 & 0.92 & 0.92 & 0.45 & 9539 \\
\hline \multicolumn{7}{|l|}{ Adult responsible for student } \\
\hline Mother & 0.78 & 0.75 & 0.76 & 0.76 & 0.43 & 9539 \\
\hline Age & 40.62 & 40.39 & 40.34 & 40.74 & 0.64 & 9539 \\
\hline Brown & 0.35 & 0.34 & 0.34 & 0.33 & 0.27 & 9539 \\
\hline Black & 0.07 & 0.06 & 0.07 & 0.07 & 0.67 & 9539 \\
\hline Middle school incomplete & 0.31 & 0.29 & 0.29 & 0.28 & 0.44 & 9539 \\
\hline Middle school complete & 0.28 & 0.26 & 0.27 & 0.28 & 0.37 & 9539 \\
\hline High School & 0.33 & 0.34 & 0.32 & 0.33 & 0.42 & 9539 \\
\hline Earns less than $1 \mathrm{MW}(1 \mathrm{MW} \sim \$ 250)$ & 0.16 & 0.16 & 0.16 & 0.16 & 0.86 & 9539 \\
\hline Earns between 1 - $3 \mathrm{MW}$ & 0.44 & 0.47 & 0.46 & 0.47 & 0.92 & 9539 \\
\hline
\end{tabular}

Note: This Table displays conditional means net of randomization strata fixed effects and p-values computed using randomization strata fixed effects. Standard errors clustered at the classroom level. Variables are computed for four sub-samples. The Table reports the following variables for students: dummies for females, brown and black students, and Portuguese and Math attendance and grades. The following variables are reported for the adults responsible for the students: age and dummies for mothers, race variables (black and brown), education variables (incomplete middle school, complete middle school, and high school), and income variables (less than one minimum wage or between one and three minimum wages). Data on students' gender, age, GPA and attendance are from administrative records, and data on students' race and on caregivers' characteristics are from the face-to-face baseline survey within those who opted-in to participate in program. 
Table B.3: Selective non-response tests

\begin{tabular}{lccc}
\hline & $(1)$ & $(2)$ & $(3)$ \\
& Baseline & Endline & Endline \\
& Survey - & Survey - & Survey - \\
& Parents & Parents & Students \\
\cline { 2 - 4 } Salience & -0.016 & 0.022 & 0.016 \\
& {$[0.020]$} & {$[0.024]$} & {$[0.016]$} \\
Information & -0.008 & 0.039 & 0.013 \\
& {$[0.021]$} & {$[0.024]$} & {$[0.016]$} \\
P-value Salience=Info=Control Within & 0.828 & 0.412 & 0.694 \\
\hline Sample Size & 4862 & 4653 & 15597 \\
Randomization strata FE & Yes & Yes & Yes \\
\hline
\end{tabular}

Note: The Table displays selective non-response tests for each survey. The pure control group is the omitted category. In all columns, the dependent variable is an indicator variable equal to 1 if parents/students completed the survey, and 0 otherwise. Students' controls include gender, age, race, baseline grades and attendance, and caregivers' controls include gender, age, race, family income and education. We also control for randomization strata fixed-effects. All columns are OLS regressions, with standard errors clustered at the classroom level. ${ }^{*}$ if $\mathrm{p}<0.1,{ }^{* *} \mathrm{p}<0.05$ and ${ }^{* * *}$ if $\mathrm{p}<0.01$. 
Table B.4: Marginal probability of completing the survey

\begin{tabular}{lccc}
\hline & $(1)$ & $(2)$ & $(3)$ \\
& Baseline & Endline & Endline \\
& Survey - & Survey - & Survey - \\
& Parents & Parents & Students \\
\cline { 2 - 4 } Student characteristics & & & \\
Female & 0.006 & -0.010 & 0.015 \\
& {$[0.012]$} & {$[0.013]$} & {$[0.007]$} \\
Age & $-0.017^{*}$ & $-0.027^{*}$ & $-0.055^{*}$ \\
Brown or Black & {$[0.009]$} & {$[0.009]$} & {$[0.006]$} \\
Math GPA (max 10) & $-0.041^{* * *}$ & $-0.012^{* * *}$ & $-0.025^{* * *}$ \\
Math attendance & {$[0.012]$} & {$[0.013]$} & {$[0.007]$} \\
Adult responsible for student & $0.012^{* * *}$ & $0.016^{* * *}$ & $0.027^{* * *}$ \\
Mother & {$[0.003]$} & {$[0.003]$} & {$[0.002]$} \\
& $0.147^{* *}$ & $0.213^{* *}$ & $0.774^{* *}$ \\
Age & {$[0.067]$} & {$[0.070]$} & {$[0.045]$} \\
Brown or Black & & & \\
Low Education (middle school incomplete) & $-0.070^{* * *}$ & $-0.059^{* * *}$ & $-0.042^{* * *}$ \\
Cash transfer beneficiary & {$[0.014]$} & {$[0.015]$} & {$[0.008]$} \\
& $-0.032^{* *}$ & $-0.039^{* *}$ & $-0.029^{* *}$ \\
& {$[0.016]$} & {$[0.018]$} & {$[0.010]$} \\
\hline
\end{tabular}

Note: The Table displays the correlation of filling-in parents baseline and endline survey as well as students' endline survey. The dependent variable in all Columns is a dummy indicating if the respective survey is completed. Surveys were considered completed if at least 11 questions were answered. Students' controls include gender, age, race, baseline grades and attendance, and caregivers' controls include gender, age, race, family income, education, and a dummy indicating whether the family is a Bolsa-Família (Brazil's flagship conditional cash transfer) recipient. We also control for randomization strata fixed-effects. All columns are OLS regressions, with standard errors clustered at the classroom level. ${ }^{*}$ if $\mathrm{p}<0.1,{ }^{* *} \mathrm{p}<0.05$ and $* * *$ if $\mathrm{p}<0.01$. 
Table B.5: School transcripts and standardized tests - re-weighting by the probability of opting-in the program

\begin{tabular}{lcccc}
\hline & $\begin{array}{c}(1) \\
\text { Math } \\
\text { Attendance } \\
(\text { p.p. })\end{array}$ & $\begin{array}{c}\text { Math } \\
\text { GPA } \\
(\text { std. })\end{array}$ & $\begin{array}{c}(3) \\
\text { Promotion } \\
\text { Rate } \\
\text { (p.p. })\end{array}$ & $\begin{array}{c}(4) \\
\text { Math } \\
\text { Standardized } \\
\text { Test (std.) }\end{array}$ \\
\cline { 2 - 5 } Salience & $0.022^{* * *}$ & $0.100^{* * *}$ & $0.038^{* * *}$ & $0.096^{* *}$ \\
& {$[0.006]$} & {$[0.032]$} & {$[0.013]$} & {$[0.046]$} \\
Information & $0.022^{* * *}$ & $0.077^{* *}$ & $0.031^{* *}$ & $0.105^{* *}$ \\
& {$[0.007]$} & {$[0.032]$} & {$[0.013]$} & {$[0.046]$} \\
Control Mean & 0.875 & 0.000 & 0.938 & -0.000 \\
P-value diff. [Info] -[Salience] & 0.854 & 0.141 & 0.162 & 0.680 \\
\hline Sample Size & 12550 & 12550 & 12550 & 12550 \\
Randomization strata FE & Yes & Yes & Yes & Yes \\
Student controls & Yes & Yes & Yes & Yes \\
\hline
\end{tabular}

Note: The Table displays treatment effects of child-specific information and salience messages on the following administrative outcomes: 4th-quarter attendance in math classes (Column 1); 4th-quarter math GPA (Column 2); grade promotion rate (=1 if the student advanced to high school, and 0 otherwise; Column 3), and math standardized test scores (Column 4). GPA and standardized test scores were normalized relative to the distribution of the pure control group. Observations were re-weighted by the probability of opting-in the program. Students' controls include gender, age, race, baseline grades and attendance, and caregivers' controls include gender, age, race, family income and education. We also control for randomization strata fixed-effects. All columns are OLS regressions, with standard errors clustered at the classroom level. ${ }^{*}$ if $\mathrm{p}<0.1,{ }^{* *} \mathrm{p}<0.05$ and ${ }^{* * *}$ if $\mathrm{p}<0.01$. 
Table B.6: Balance tests for the nudge intervention

\begin{tabular}{|c|c|c|c|c|c|}
\hline & \multicolumn{3}{|c|}{ Means } & \multirow[t]{2}{*}{$\begin{array}{l}\text { Diff }=0 \\
\text { p-value }\end{array}$} & \multirow[t]{2}{*}{$\begin{array}{c}\text { Sample } \\
\text { Size }\end{array}$} \\
\hline & $\begin{array}{c}\text { Pure } \\
\text { Control }\end{array}$ & $\begin{array}{c}\text { Control } \\
\text { Within Class } \\
\end{array}$ & Engagement & & \\
\hline \multicolumn{6}{|l|}{ Panel A: Student characteristics } \\
\hline Female & 0.47 & 0.51 & 0.50 & 0.23 & 3058 \\
\hline Age & 14.68 & 14.66 & 14.69 & 0.68 & 3058 \\
\hline Brown & 0.36 & 0.32 & 0.31 & 0.05 & 3058 \\
\hline Black & 0.06 & 0.05 & 0.05 & 0.53 & 3058 \\
\hline Portuguese GPA ( $\max 10)$ & 6.37 & 5.99 & 5.99 & 0.00 & 3019 \\
\hline Math GPA (max 10) & 6.07 & 5.79 & 5.75 & 0.00 & 3021 \\
\hline Portuguese attendance & 0.93 & 0.92 & 0.93 & 0.91 & 3037 \\
\hline Math attendance & 0.92 & 0.92 & 0.92 & 0.88 & 2975 \\
\hline \multicolumn{6}{|c|}{ Panel B: Adult responsible for student } \\
\hline Mother & 0.78 & 0.76 & 0.74 & 0.14 & 3058 \\
\hline Age & 40.38 & 40.77 & 40.47 & 0.51 & 3008 \\
\hline Black & 0.07 & 0.07 & 0.07 & 0.88 & 3058 \\
\hline Middle school incomplete & 0.31 & 0.28 & 0.26 & 0.06 & 3058 \\
\hline Middle school complete & 0.30 & 0.25 & 0.25 & 0.03 & 3058 \\
\hline High School & 0.33 & 0.32 & 0.33 & 0.85 & 3058 \\
\hline Earns less than $1 \mathrm{MW}(1 \mathrm{MW} \sim \$ 250)$ & 0.16 & 0.15 & 0.13 & 0.10 & 3058 \\
\hline Earns between 1 - $3 \mathrm{MW}$ & 0.43 & 0.46 & 0.47 & 0.11 & 3058 \\
\hline
\end{tabular}

Note: This Table displays conditional means net of randomization strata fixed effects and p-values of differences between outcomes in sub-sample $\mathrm{E}$ and the pure control group computed using randomization strata fixed effects. Standard errors clustered at the classroom level. The Table reports the following variables for students: dummies for females, brown and black students, and Portuguese and Math attendance and grades. The following variables are reported for the adults responsible for the students: age and dummies for mothers, race variables (black and brown), education variables (incomplete middle school, complete middle school, and high school), and income variables (less than one minimum wage or between one and three minimum wages). Data on students' gender, age, GPA and attendance are from administrative records, and data on students' race and on caregivers' characteristics are from the face-to-face baseline survey within those who opted-in to participate in program. 


\section{C [Supplementary Appendix] Manipulation checks}

If teachers did not fill in the platform with students' information weekly, or if parents did not even acknowledge receiving text messages from the school, then there would be no hope that our experiment could allow us detecting the effects of interest. For this reason, this Appendix looks at these manipulation checks. Figure C.1 displays statistics for platform usage and receipt of text messages across treatment arms.

Figure C.1: Manipulation Tests

Panel A: Share of weeks teachers filled in the platform by treatment status

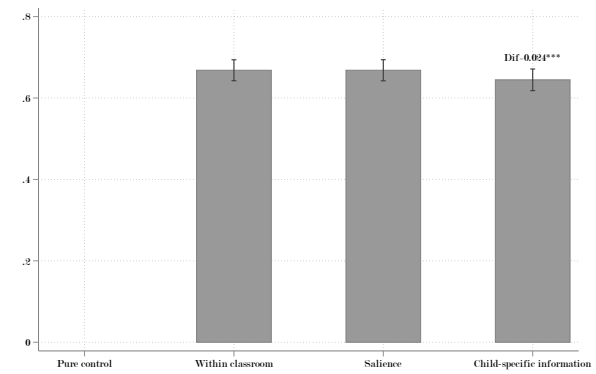

Panel B: Did parents acknowledge receiving text messages?

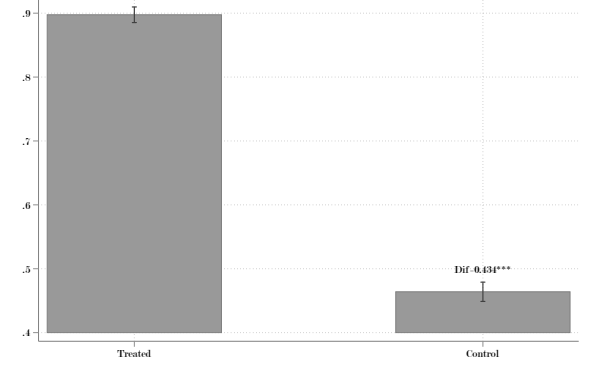

Panel C: Did students know their parents were receiving text messages?

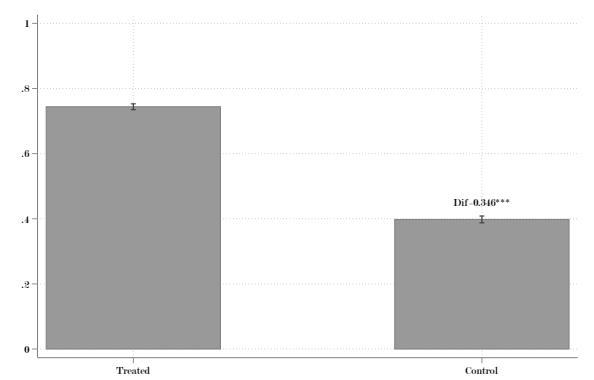

Note: The Figure displays group averages across groups. The dependent variables are: fraction of weeks that teachers filled-in the platform (Panel A), fraction of parents that acknowledged receiving messages (Panel B), and fraction of students that knew their parents were receiving messages (Panel C). The Figure also displays $90 \%$ confidence interval. All panels show the average difference between groups. This difference between categories was estimated through a simple regression. Significance levels are denoted by $*$ if $\mathrm{p}<0.1, * *$ if $\mathrm{p}<0.05$ and $* * *$ if $\mathrm{p}<0.01$.

Over the course of the 18 weeks, $66 \%$ of teachers inputted students' information through the platform in a typical week. Since this figure was slightly lower for sub-samples A and 
C relative to sub-sample D, students assigned to the information treatment are associated with a 2 p.p. lower messaging rate. In Supplementary Appendix E, we show that our results are robust to selection on unobservable variables by dropping observations from classrooms with the highest and lowest response rates, such as to equalize the rate at which teachers filled in the platform over the course of the 18 weeks across sub-samples (analogously to the bounding procedure in Lee, 2009).

At the end line surveys, we asked parents whether they had received text messages from the school, and asked students whether they knew their parents were getting such text messages. While $46 \%$ of parents in the control group acknowledge receipt of text messages (principals could send up to two notifications a month about school events to all parents, even in the pure control group), that figure is $90 \%$ across treatment groups - close to the expected $100 \%$, and statistically different from the control group. Meanwhile, $74 \%$ of students across treatment arms acknowledged their parents received text messages from the school, as opposed to $40 \%$ in the control group. Since over $50 \%$ of parents reported a different mobile phone number for their child at the enrollment form, this is not just an artifact of parents and children sharing the same handset; rather, it hints at communication between parents and children as a result of the text messages. 


\section{D [Supplementary Appendix] Beliefs vs. actual scorecard attendance}

We have two available measures of students' math attendance: actual absences reported by teachers through the platform and 4th-quarter report cards. In Table 3, we showed that the information intervention significantly increased parents' accuracy about their child's attendance. Now, in this section of the Appendix, we document the correlation between parents' beliefs and scorecard attendance.

We asked parents to guess their children's attendance over the 4th quarter (rather than over the previous 3 weeks, as we had done at baseline) because we wanted to compare their guess to actual student attendance included in children's report cards. Different from Dizon-Ross (2019), however, 4th-quarter report cards had still not been made available to parents at the time of our survey. This Appendix shows that, without report cards in hand, parents targeted with high-frequency information on their children's absences became no more accurate than control parents about their children's cumulative absences over that period. Conversely, the analysis in the main text contrasts parents' estimates at end line to students' average absences reported by teachers through the platform over the 4th quarter - matching the typical content communicated to treated parents over SMS, rather than requiring them to recall and sum over their full history of absenteeism data.

At the baseline survey, parents were asked to provide their best estimate of how many times their child had missed math classes over the past three weeks from four categories (0 absences; 1-2; 3-5; or more than 5). Thus, a comparison between beliefs and scorecard attendance requires the total number of scorecard absences. However, only the fraction of absences was registered in students' scorecards. Since the total number of classes varies from one class to another (and was also not recorded), it is not immediate how to recover the absolute number of missed classes.

We propose a simple algorithm to recover the outcome of interest. It is based on the facts that absences are integer numbers, and that the total number of classes is the same for all students within each class.

Let $a_{s c}$ be the number of absences for students $s$ in class $c$ and $N_{c}$. We observe the fraction of absences $f_{s c}$. Apart from slight rounding differences, we expect that $f_{s c} * N_{c} \in$ $\mathbb{Z}_{+}$. Therefore, we can simulate values of $N_{c}$ and, for each of them, calculate the distance between the implied $a_{s c}$ and the closest integer. Formally:

$$
\boldsymbol{N}^{*}=\underset{N_{c} \in[20,75]}{\arg \min } \sum_{c}\left[\left|f_{s c} * N_{c}-\operatorname{nint}\left(f_{s c} * N_{c}\right)\right|\right]
$$

where |.| is the absolute value function and $\operatorname{nint}($.$) is the nearest integer function. Having$ found the total number of classes, we can directly calculate the number of absences $a_{s c}$ for each student.

We test this algorithm with 3rd-quarter attendance (where we have both the number of absolute absences and the fraction of absences). We are able to recover the correct number 
of absences for over $95 \%$ of students.

We can see in Table D.1 that neither the information or salience treatments increase the accuracy of parents' beliefs about 4th-quarter scorecard attendance - which had still not been made available to parents at the time of the end-line survey. Both estimates are very close to zero and statistically insignificant.

Table D.1: Parents' accuracy about scorecard attendance

\begin{tabular}{lcccc}
\hline & $(1)$ & $(2)$ & $(3)$ & $(4)$ \\
& \multicolumn{2}{c}{ Baseline beliefs } & \multicolumn{2}{c}{ End-line beliefs } \\
\cline { 2 - 5 } Actual absences & $0.211^{* * *}$ & $0.186^{* * *}$ & $0.150^{* * *}$ & $0.152^{* * *}$ \\
& {$[0.025]$} & {$[0.024]$} & {$[0.024]$} & {$[0.023]$} \\
Child-specific information & -0.016 & & $-0.137^{*}$ & \\
& {$[0.050]$} & & {$[0.075]$} & \\
Salience & & 0.033 & & 0.029 \\
& & {$[0.050]$} & & {$[0.079]$} \\
Actual absences x Information & -0.011 & & 0.002 & \\
& {$[0.032]$} & & {$[0.057]$} & \\
Actual absences x Salience & & -0.047 & & 0.012 \\
& & {$[0.034]$} & & {$[0.034]$} \\
\hline Observations & 3,085 & 3,174 & 2,967 & 2,862 \\
Classroom FE & No & No & No & No \\
Student-level controls & Yes & Yes & Yes & Yes \\
R-squared & 0.112 & 0.120 & 0.109 & 0.112 \\
\hline
\end{tabular}

Note: Correlation between parents' baseline and end-line beliefs about their children's school attendance and actual attendance. At the baseline survey, parents were asked to provide their best estimate of how many times their child had missed math classes over the past three weeks. Parents could pick one answer from four categories (0 absences; 1-2; 3-5; or more than 5). Scorecard attendance was computed according to the algorithm described in this Appendix. Regressions include either an indicator variable for child-specific information and its interaction with actual absences (Columns 1 and 3) or an indicator variable for salience messages and its interaction with actual absences (Columns 2 and 4). Students' controls include gender, age, race, baseline grades and attendance, and caregivers' controls include gender, age, race, family income and education. All columns are OLS regressions, with standard errors clustered at the classroom level. ${ }^{*}$ if $\mathrm{p}<0.1,{ }^{* *} \mathrm{p}<0.05$ and ${ }^{* * *}$ if $\mathrm{p}<0.01$. 
Figure D.1: Parents' accuracy gap wrt their child's baseline math attendance and math GPA

Panel A: Baseline math attendance

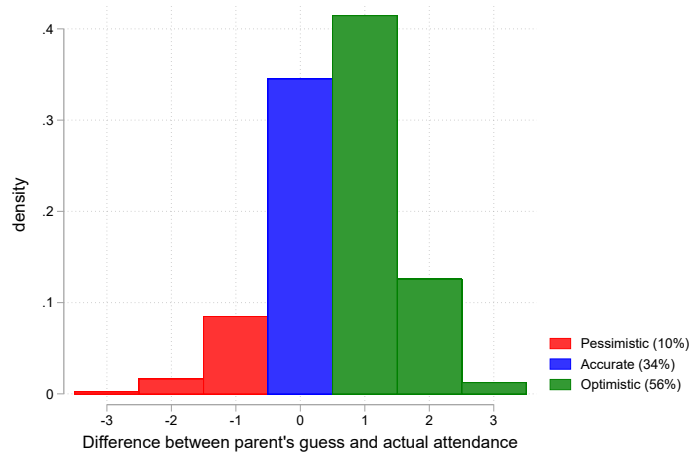

Panel B: Baseline math GPA

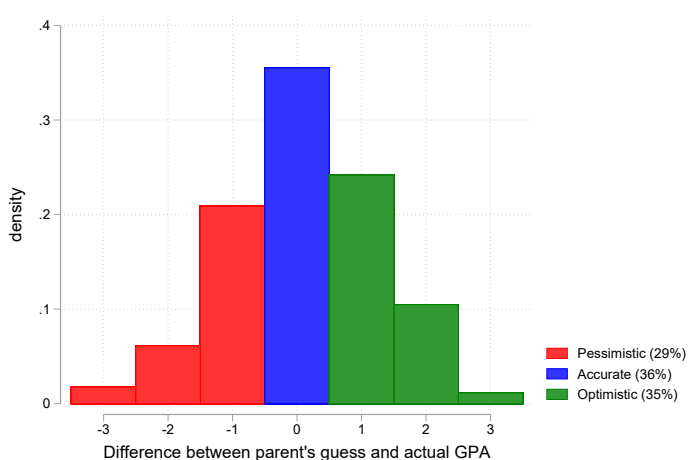

Note: Panel A displays the difference between parents' guesses and baseline student attendance in math classes, and in Panel B, that between parents' guesses and baseline student math GPA. A value of 0 indicates that parents were accurate; positive values indicate that they were pessimistic; and negative values, that they were optimistic relative to the ground truth. 


\section{E [Supplementary Appendix] Bounding treatment effects}

As shown in Figure E.1, the average number of times teachers filled in the platform over the course of 18 weeks was not statistically identical across all sub-samples. To test if ours results are sensitive to selective non-response, we trim observations (along the lines of Lee, 2009), respecting the cluster structure of the data: we drop classrooms until we equalize the average number of times teachers filled in the platform across sub-samples.

We do so by dropping 7 classrooms from schools from sub-sample D (where students were assigned to either salience or control), for which teachers had filled in the platform each and every week (over 18 weeks), and 27 classrooms from sub-sample C (where $25 \%$ of students were assigned to salience, $25 \%$ to child-specific information, $25 \%$ to information framed relatively to the classroom median, and $25 \%$ to control), for which teachers filled in the platform 3 times or less over the course of 18 weeks. This procedure maximizes sample size while eliminating selective non-response; in this new sample, the average number of times teachers fill the platform is statistically identical across sub-samples.

We then replicate our main results on school transcripts and test score (showed in Table 5 ) as well as the analyses testing if there is interaction between salience and information (showed in Table 8). Results are showed in tables E.1 and E.2.

Figure E.1: Average number of times teachers filled the platform by sub-sample during the 18 week period

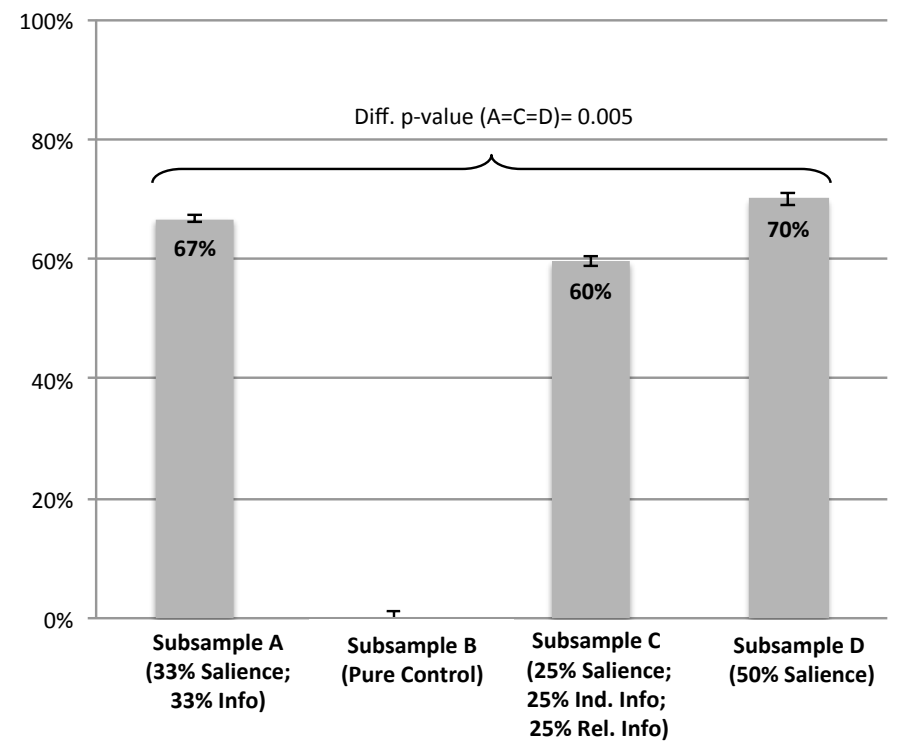

Note: The Figure displays average number of times teachers filled the platform by sub-sample during the 18 -weeks period across samples. The Figure also displays $90 \%$ confidence interval. We show the p-value for the joint test that averages are equal across samples A, C and D. Significance levels are denoted by * if $\mathrm{p}<0.1, * *$ if $\mathrm{p}<0.05$ and $* * *$ if $\mathrm{p}<0.01$. 
Table E.1: Robustness: Administrative educational outcomes (equalizing SMS received by sub-sample)

\begin{tabular}{lcccc}
\hline & $\begin{array}{c}(1) \\
\text { Math } \\
\text { Attendance } \\
\text { (p.p. })\end{array}$ & $\begin{array}{c}\text { Math } \\
\text { GPA } \\
\text { (std.) }\end{array}$ & $\begin{array}{c}(3) \\
\text { Promotion } \\
\text { Rate } \\
\text { Salience }\end{array}$ & $\begin{array}{c}(4) \\
\text { Math } \\
\text { Standardized } \\
\text { Test (std.) }\end{array}$ \\
\cline { 2 - 5 } Information & $0.019^{* * *}$ & $0.085^{* * *}$ & $0.030^{* * *}$ & $0.108^{* *}$ \\
& {$[0.006]$} & {$[0.032]$} & {$[0.011]$} & {$[0.045]$} \\
Control Mean & $0.019^{* * *}$ & $0.070^{* *}$ & $0.026^{* *}$ & $0.110^{* *}$ \\
P-value diff. [Info] -[Salience] & {$[0.006]$} & {$[0.032]$} & {$[0.011]$} & {$[0.046]$} \\
\hline Sample Size & 0.875 & 0.000 & 0.938 & -0.000 \\
Randomization strata FE & 11951 & 11951 & 11951 & 11951 \\
Student controls & Yes & Yes & Yes & Yes \\
\hline
\end{tabular}

Note: The Table displays treatment effects of child-specific information and salience messages on the following administrative outcomes: 4th-quarter attendance in math classes (Column 1); 4th-quarter math GPA (Column 2); grade promotion rate ( $=1$ if the student advanced to high school, and 0 otherwise; Column 3), and math standardized test scores (Column 4). To equalize the number of SMS received, 7 classrooms from the salience-only sample were excluded, where teachers had filled the platform all the 18 weeks; and 27 classrooms from the sub-sample containing all treatments ( $25 \%$ salience, $25 \%$ ind. info; $25 \%$ relative info, $25 \%$ control), where teacher participation was low (teachers filled 3 times or less the platform) were also excluded. GPA and standardized test scores were normalized relative to the distribution of the pure control group. Students' controls include gender, age, race, baseline grades and attendance, and caregivers' controls include gender, age, race, family income and education. We also control for randomization strata fixed-effects, and include an indicator variable for the within-classroom control group. All columns are OLS regressions, with standard errors clustered at the classroom level. $*$ if $\mathrm{p}<0.1,{ }^{* *} \mathrm{p}<0.05$ and ${ }^{* * *}$ if $\mathrm{p}<0.01$. 
Table E.2: Interactions with information? (equalizing SMS received by sub-sample)

\begin{tabular}{lcccc}
\hline & $\begin{array}{c}(1) \\
\text { Math } \\
\text { Attendance } \\
\text { (p.p.) }\end{array}$ & $\begin{array}{c}\text { Math } \\
\text { GPA } \\
\text { (std.) }\end{array}$ & $\begin{array}{c}(3) \\
\text { Promotion } \\
\text { Rate } \\
\text { (p.p.) }\end{array}$ & $\begin{array}{c}(4) \\
\text { Math } \\
\text { Standardized } \\
\text { Test (std.) }\end{array}$ \\
\cline { 2 - 5 } Salience & $0.016^{* *}$ & $0.068^{* *}$ & $0.027^{* *}$ & $0.110^{* *}$ \\
& {$[0.006]$} & {$[0.033]$} & {$[0.011]$} & {$[0.047]$} \\
Information & $0.019^{* * *}$ & $0.070^{* *}$ & $0.026^{* *}$ & $0.110^{* *}$ \\
& {$[0.006]$} & {$[0.032]$} & {$[0.011]$} & {$[0.046]$} \\
Salience Only & 0.002 & 0.030 & 0.002 & -0.004 \\
& {$[0.004]$} & {$[0.029]$} & {$[0.009]$} & {$[0.044]$} \\
\hline Sample Size & 11951 & 11951 & 11951 & 11951 \\
Randomization strata FE & Yes & Yes & Yes & Yes \\
Student controls & Yes & Yes & Yes & Yes \\
\hline
\end{tabular}

Note: The Table displays treatment effects of child-specific information, salience messages, and an interaction between treatments on the following administrative outcomes: 4th-quarter attendance in math classes (Column 1); 4th-quarter math GPA (Column 2); grade promotion rate (=1 if the student advanced to high school, and 0 otherwise; Column 3), and math standardized test scores (Column 4). To equalize the number of SMS received, 7 classrooms from the salience-only sample were excluded, where teachers had filled the platform all the 18 weeks; and 27 classrooms from the sub-sample containing all treatments (25\% salience, $25 \%$ ind. info; $25 \%$ relative info, $25 \%$ control), where teacher participation was low (teachers filled 3 times or less the platform) were also excluded. GPA and standardized test scores were normalized relative to the distribution of the pure control group. Students' controls include gender, age, race, baseline grades and attendance, and caregivers' controls include gender, age, race, family income and education. We also control for randomization strata fixed-effects. All columns are OLS regressions, with standard errors clustered at the classroom level. ${ }^{*}$ if $\mathrm{p}<0.1,{ }^{* *} \mathrm{p}<0.05$ and ${ }^{* * *}$ if $\mathrm{p}<0.01$. 


\section{F [Supplementary Appendix] Additional results on heteroge- neous treatment effects by platform scores}

As described in section 3, a web-platform was created specifically such that teachers could provide timely information about their students' behavior. Math teachers at treated schools were oriented to fill in the platform every week with that week's dimension of students' behavior: attendance, tardiness or homework completion, over the course of 18 weeks. Teachers were to fill in information with respect to each dimension of students' behavior accounting for the past three weeks ${ }^{49}$. The system required teachers to fill in information for all their students.

This appendix presents the results for treatment effects on the outcomes recorded weekly by teachers on the online platform. Because teachers did not fill in any content for pure control schools, the estimates are relative to the control group within classroom.

Each week, teachers evaluated students using a 4 point scale, where 1 was the minimum and 4 was the maximum. For this analysis, we reverse-coded scores for tardiness, to normalize estimates across dimensions such that a positive coefficient always means a positive outcome. We estimate the following model:

$$
Y_{i, c, s}=\alpha+\beta_{1} \text { Salience }_{i, c, s}+\beta_{2} \text { Info }_{i, c, s}+\sum \gamma_{k} X_{k, i, c, s}+\theta_{s}+\varepsilon_{i, c, s}
$$

where $Y_{i, c, s}$ denotes the weekly score of each dimension for student $\mathrm{i}$ in classroom $\mathrm{c}$ of stratum $\mathrm{s}$, the within-class control stand for the reference category (omitted indicator variable), $X_{k, i, c, s}$ is a matrix of student's characteristics, $\theta_{s}$ are randomization stratum $\mathrm{FE}$, and $\epsilon_{i, c, s}$ is an error term, clustered at the classroom level.

We start by plotting coefficients week-by-week in Figure F.1. As behaviors rotate weekly, we can plot coefficients in 3-week intervals.

\footnotetext{
${ }^{49}$ Students are scheduled to have 6 Math classes per week.
} 
Figure F.1: Weekly platform scores, by treatment arm

Panel A: Weekly effect on attendance

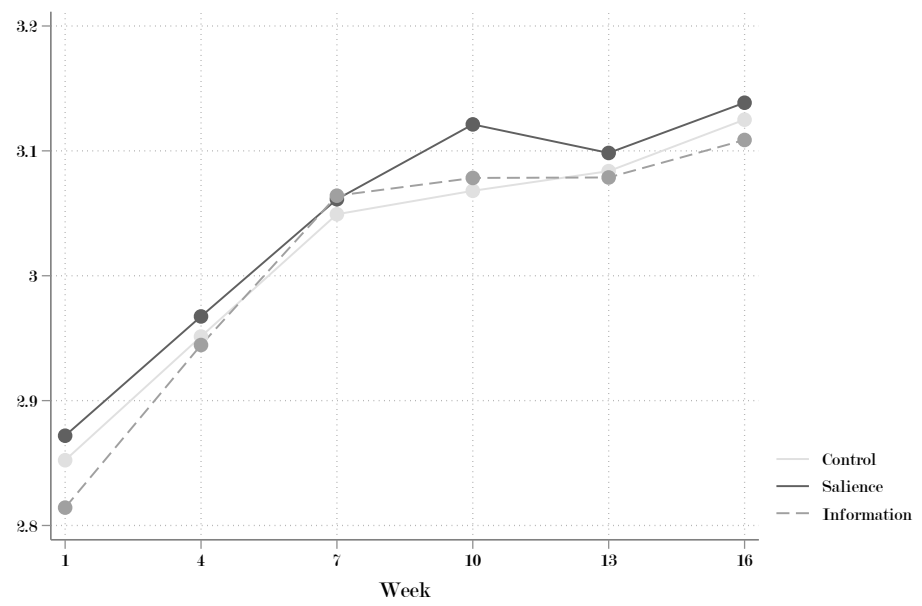

Panel B: Weekly effect on punctuality

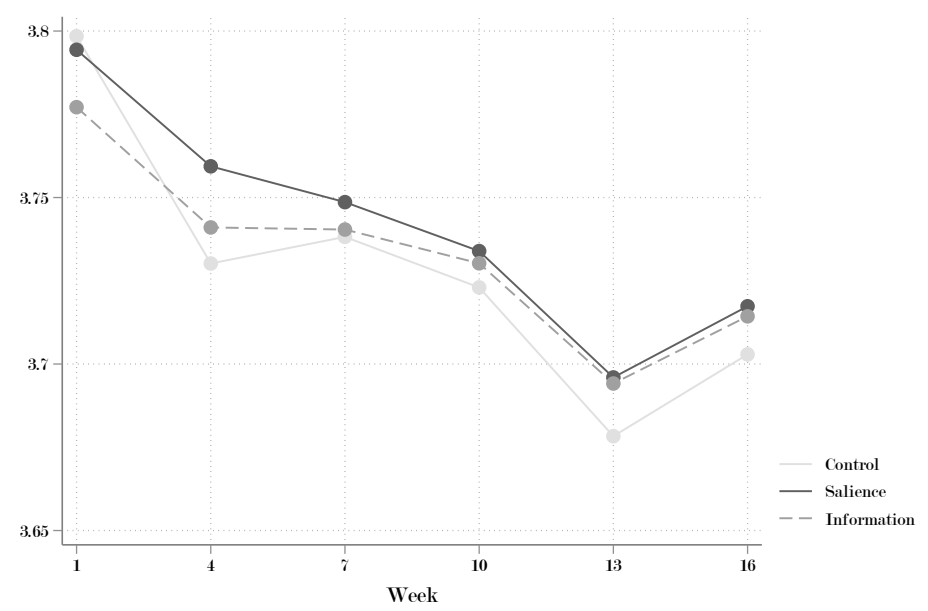

Panel C: Weekly effect on homework completion

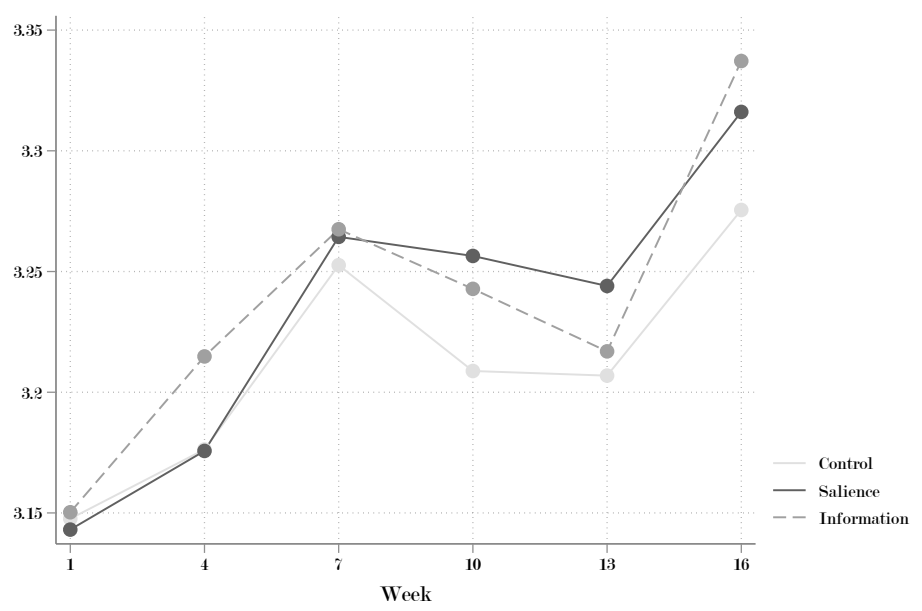

Note: This Figure reports weekly platform scores, by treatment arm, for three administrative dependent variables: attendance in math classes (Panel A); punctuality (Panel B) and homework completion (Panel C). Estimates include dummies for receiving child-specific information and salience messages. Students' controls include gender, age, race, baseline grades and attendance, and caregivers' controls include gender, age, race, family income and education. We also control for classroom fixed-effects. All columns are OLS regressions, with standard errors clustered at the classroom level. $*$ if $\mathrm{p}<0.1,{ }^{* *} \mathrm{p}<0.05$ and $* * *$ if $\mathrm{p}<0.01$. 
Despite the large spillovers within classrooms that we document in the main text, we can see that the curves for salience and information interventions drift clearly above the control one, particularly so for punctuality and homework completion. For those two dimensions of behavior, the difference between the treatment arms (information and salience) and the control group clearly did not exist the first time teachers filled in the platform, and then gradually increased over time.

Last, we analyze heterogeneity in treatment effects with respect to attendance, punctuality and homework completion scores entered into the platform by teachers.

Table F.1: Heterogeneous treatment effects by average platform scores (attendance)

\begin{tabular}{|c|c|c|c|c|}
\hline & \multicolumn{4}{|c|}{ Reported attendance } \\
\hline & $\begin{array}{c}\text { Math } \\
\text { attendance } \\
(1)\end{array}$ & $\begin{array}{l}\text { Math } \\
\text { GPA } \\
(2)\end{array}$ & $\begin{array}{c}\text { Math standardized } \\
\text { test score } \\
(3)\end{array}$ & $\begin{array}{c}\text { Grade } \\
\text { promotion } \\
(4)\end{array}$ \\
\hline \multirow[t]{2}{*}{ Child-specific information } & 0.00465 & -0.00219 & 0.0135 & -0.0335 \\
\hline & {$[0.0163]$} & {$[0.165]$} & {$[0.0844]$} & {$[0.0296]$} \\
\hline \multirow[t]{2}{*}{ Child-specific information $\mathrm{x}$ average reported } & -0.00125 & 0.0142 & -0.000167 & 0.0102 \\
\hline & {$[0.00492]$} & [0.0529] & {$[0.0274]$} & {$[0.00884]$} \\
\hline \multirow[t]{2}{*}{ Salience } & -0.0193 & 0.179 & 0.0468 & -0.0103 \\
\hline & {$[0.0172]$} & {$[0.160]$} & {$[0.0850]$} & {$[0.0294]$} \\
\hline \multirow[t]{2}{*}{ Salience $\mathrm{x}$ average reported } & 0.00603 & -0.0544 & -0.0199 & 0.00347 \\
\hline & {$[0.00511]$} & {$[0.0508]$} & {$[0.0269]$} & {$[0.00858]$} \\
\hline \multirow[t]{2}{*}{ Average reported } & $0.0966^{* * *}$ & $1.129^{* * *}$ & $0.563^{* * *}$ & $0.0721 * * *$ \\
\hline & {$[0.00420]$} & {$[0.0471]$} & {$[0.0244]$} & {$[0.00710]$} \\
\hline Observations & 12,641 & 12,337 & 12,230 & 12,519 \\
\hline Classroom Fixed-effects & Yes & Yes & Yes & Yes \\
\hline Controls & Yes & Yes & Yes & Yes \\
\hline R-squared & 0.411 & 0.319 & 0.299 & 0.193 \\
\hline
\end{tabular}

Note: This Table reports heterogeneous treatment effects of child-specific information and salience messages by students' average reported scores on four administrative dependent variables: attendance in math classes (Column 1); math GPA (Column $2)$; grade promotion rate ( $=1$ if the student advanced to high school, and 0 otherwise; Column 3$)$ and math standardized test scores (Column 4). GPA and standardized test scores were normalized relative to the distribution of the comparison group. All Columns include dummies indicating students whose parents received child-specific information and salience messages, and interactions between these treatment variables and average reported attendance. Students' controls include gender, age, race, baseline grades and attendance, and caregivers' controls include gender, age, race, family income and education. We also control for classroom fixed-effects. All columns are OLS regressions, with standard errors clustered at the classroom level. * if $\mathrm{p}<0.1,{ }^{* *} \mathrm{p}<0.05$ and ${ }^{* * *}$ if $\mathrm{p}<0.01$. 
Table F.2: Heterogeneous treatment effects by average platform scores (punctuality)

\begin{tabular}{|c|c|c|c|c|}
\hline & \multicolumn{4}{|c|}{ Reported punctuality } \\
\hline & $\begin{array}{c}\text { Math } \\
\text { attendance } \\
(1)\end{array}$ & $\begin{array}{l}\text { Math } \\
\text { GPA } \\
(2)\end{array}$ & $\begin{array}{c}\text { Math standardized } \\
\text { test score } \\
(3)\end{array}$ & $\begin{array}{c}\text { Grade } \\
\text { promotion } \\
(4)\end{array}$ \\
\hline \multirow[t]{2}{*}{ Child-specific information } & -0.0264 & -0.380 & -0.203 & $-0.130^{* *}$ \\
\hline & {$[0.0310]$} & {$[0.274]$} & {$[0.147]$} & {$[0.0519]$} \\
\hline \multirow[t]{2}{*}{ Child-specific information $\mathrm{x}$ average reported } & 0.00725 & 0.111 & 0.0556 & $0.0338^{* *}$ \\
\hline & {$[0.00802]$} & {$[0.0732]$} & [0.0395] & {$[0.0133]$} \\
\hline \multirow[t]{2}{*}{ Salience } & $-0.0433^{*}$ & 0.0191 & -0.0447 & $-0.0931^{*}$ \\
\hline & {$[0.0250]$} & {$[0.239]$} & {$[0.129]$} & {$[0.0527]$} \\
\hline \multirow[t]{2}{*}{ Salience $\mathrm{x}$ average reported } & $0.0117^{*}$ & 0.00199 & 0.00914 & $0.0252^{*}$ \\
\hline & {$[0.00650]$} & {$[0.0639]$} & {$[0.0344]$} & {$[0.0136]$} \\
\hline \multirow[t]{2}{*}{ Average reported } & $0.0718^{* * *}$ & $1.363^{* * *}$ & $0.675^{* * *}$ & $0.0962^{* * *}$ \\
\hline & {$[0.00659]$} & {$[0.0777]$} & {$[0.0482]$} & {$[0.0119]$} \\
\hline Observations & 12,208 & 11,913 & 11,808 & 12,096 \\
\hline Classroom Fixed-effects & Yes & Yes & Yes & Yes \\
\hline Controls & Yes & Yes & Yes & Yes \\
\hline R-squared & 0.248 & 0.279 & 0.263 & 0.193 \\
\hline
\end{tabular}

Note: This Table reports heterogeneous treatment effects of child-specific information and salience messages by students' average reported scores on four administrative dependent variables: attendance in math classes (Column 1); math GPA (Column 2 ); grade promotion rate ( $=1$ if the student advanced to high school, and 0 otherwise; Column 3 ) and math standardized test scores (Column 4). GPA and standardized test scores were normalized relative to the distribution of the comparison group. All Columns include dummies indicating students whose parents received child-specific information and salience messages, and

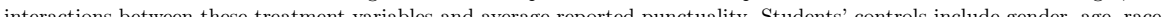
All Cor baseline grades and attendance, and caregivers' controls include gender, age, race, family income and education. We also con-
trol for classroom fixed-effects. All columns are OLS regressions, with standard errors clustered at the classroom level. * if $\mathrm{p}<0.1,{ }^{* *} \mathrm{p}<0.05$ and ${ }^{* * *}$ if $\mathrm{p}<0.01$.

Table F.3: Heterogeneous treatment effects by average platform scores (homework completion)

\begin{tabular}{|c|c|c|c|c|}
\hline & \multicolumn{4}{|c|}{ Reported homework completion } \\
\hline & $\begin{array}{c}\text { Math } \\
\text { attendance } \\
(1)\end{array}$ & $\begin{array}{l}\text { Math } \\
\text { GPA } \\
(2)\end{array}$ & $\begin{array}{l}\text { Math standardized } \\
\text { test score } \\
(3)\end{array}$ & $\begin{array}{c}\text { Grade } \\
\text { promotion } \\
(4)\end{array}$ \\
\hline \multirow[t]{2}{*}{ Child-specific information } & -0.0231 & -0.115 & -0.0740 & -0.0462 \\
\hline & {$[0.0175]$} & {$[0.147]$} & {$[0.0802]$} & {$[0.0338]$} \\
\hline \multirow[t]{2}{*}{ Child-specific information $\mathrm{x}$ average reported } & 0.00650 & 0.0315 & 0.0178 & 0.0123 \\
\hline & {$[0.00491]$} & {$[0.0450]$} & {$[0.0244]$} & {$[0.00936]$} \\
\hline \multirow[t]{2}{*}{ Salience } & $-0.0341^{*}$ & -0.00518 & -0.0340 & -0.0206 \\
\hline & {$[0.0177]$} & {$[0.142]$} & {$[0.0770]$} & {$[0.0352]$} \\
\hline \multirow[t]{2}{*}{ Salience $\mathrm{x}$ average reported } & $0.0103^{* *}$ & 0.00474 & 0.00686 & 0.00591 \\
\hline & {$[0.00493]$} & {$[0.0432]$} & {$[0.0236]$} & {$[0.00986]$} \\
\hline \multirow[t]{2}{*}{ Average reported } & $0.0528^{* * *}$ & $1.687^{* * *}$ & $0.847^{* * *}$ & $0.0967^{* * *}$ \\
\hline & {$[0.00393]$} & {$[0.0425]$} & {$[0.0230]$} & {$[0.00859]$} \\
\hline Observations & 12,025 & 11,737 & 11,624 & 11,922 \\
\hline Classroom Fixed-effects & Yes & Yes & Yes & Yes \\
\hline Controls & Yes & Yes & Yes & Yes \\
\hline R-squared & 0.277 & 0.522 & 0.497 & 0.244 \\
\hline
\end{tabular}

Note: This Table reports heterogeneous treatment effects of child-specific information and salience messages by students' average reported scores on four administrative dependent variables: attendance in math classes (Column 1); math GPA (Column 2 ); grade promotion rate ( $=1$ if the student advanced to high school, and 0 otherwise; Column 3 ) and math standardized test scores (Column 4). GPA and standardized test scores were normalized relative to the distribution of the comparison group. All Columns include dummies indicating students whose parents received child-specific information and salience messages, and interactions between these treatment variables and average reported homework completion. Students' controls include gender, interactions between these treatment variables and average reported homework completion. Students' controls include gender,
age, race, baseline grades and attendance, and caregivers' controls include gender, age, race, family income and education. We also control for classroom fixed-effects. All columns are OLS regressions, with standard errors clustered at the classroom level. $*$ if $\mathrm{p}<0.1, * * \mathrm{p}<0.05$ and $* * *$ if $\mathrm{p}<0.01$

As one would expect, attending classes more often and handing in homework more frequently correlates with better educational outcomes across the board. Also in line with the literature, the effects of information are negative when the message bears bad news, and positive otherwise: the coefficient of the interaction of information with average content 
reported is always positive when it comes to punctuality and homework completion, and either 0 or positive when it comes to attendance (although most coefficients are not statistically significant). We find that the effects of salience messages follow exactly the same pattern as those of information, even in the absence of direct inputs for belief updating. 


\section{G [Supplementary Appendix] Heterogeneous treatment ef- fects by gender}

This Appendix presents heterogeneous effects for boys and girls. Throughout, we restrict attention to a sample of 9,539 students with non-missing data for parents' behavior and aspirations, student behavior, and school transcripts and test scores.

Table G.1 starts by documenting aggregate treatment effects on educational outcomes for this sub-sample. Next, Table G.2 breaks those estimates down by student gender. Tables G.3, G.4 and G.5 follow by presenting results by student gender for treatment effects on parental engagement and aspirations, and on students' time use.

Table G.1: Average treatment effects on administrative educational outcomes

\begin{tabular}{lcccc}
\hline & $\begin{array}{c}(1) \\
\text { Math } \\
\text { Attendance } \\
\text { (p.p.) }\end{array}$ & $\begin{array}{c}\text { Math } \\
\text { GPA } \\
\text { (std.) }\end{array}$ & $\begin{array}{c}\text { Promotion } \\
\text { Rate } \\
(\text { p.p. })\end{array}$ & $\begin{array}{c}\text { Math } \\
\text { Standardized } \\
\text { Test (std.) }\end{array}$ \\
\cline { 2 - 5 } Child-specific information & $0.017^{* * *}$ & $0.058^{*}$ & $0.026^{* *}$ & $0.091^{*}$ \\
& {$[0.006]$} & {$[0.034]$} & {$[0.012]$} & {$[0.053]$} \\
Salience & $0.016^{* * *}$ & $0.072^{* *}$ & $0.030^{* *}$ & 0.075 \\
& {$[0.006]$} & {$[0.034]$} & {$[0.012]$} & {$[0.053]$} \\
Control Mean & 0.889 & 0.000 & 0.945 & 0.000 \\
P-value diff. [Info] -[Salience] & 0.634 & 0.420 & 0.477 & 0.510 \\
\hline Sample Size & 9539 & 9539 & 9539 & 9539 \\
Randomization strata FE & Yes & Yes & Yes & Yes \\
Student controls & Yes & Yes & Yes & Yes \\
\hline
\end{tabular}

Note: The Table displays treatment effects of child-specific information and salience messages on the following administrative outcomes: 4th-quarter attendance in math classes (Column 1); 4th-quarter math GPA (Column 2); grade promotion rate (=1 if the student advanced to high school, and 0 otherwise; Column 3), and math standardized test scores (Column 4). The sample is restricted to the sample of students with non-missing data for parents' behavior and aspirations, student behavior, and school transcripts and test scores. GPA and standardized test scores were normalized relative to the distribution of the pure control group. Students' controls include gender, age, race, baseline grades and attendance, and caregivers' controls include gender, age, race, family income and education. We also control for randomization strata fixed-effects, and include an indicator variable for the within-classroom control group. All columns are OLS regressions, with standard errors clustered at the classroom level. $*$ if $\mathrm{p}<0.1, * * \mathrm{p}<0.05$ and $* * *$ if $\mathrm{p}<0.01$. 


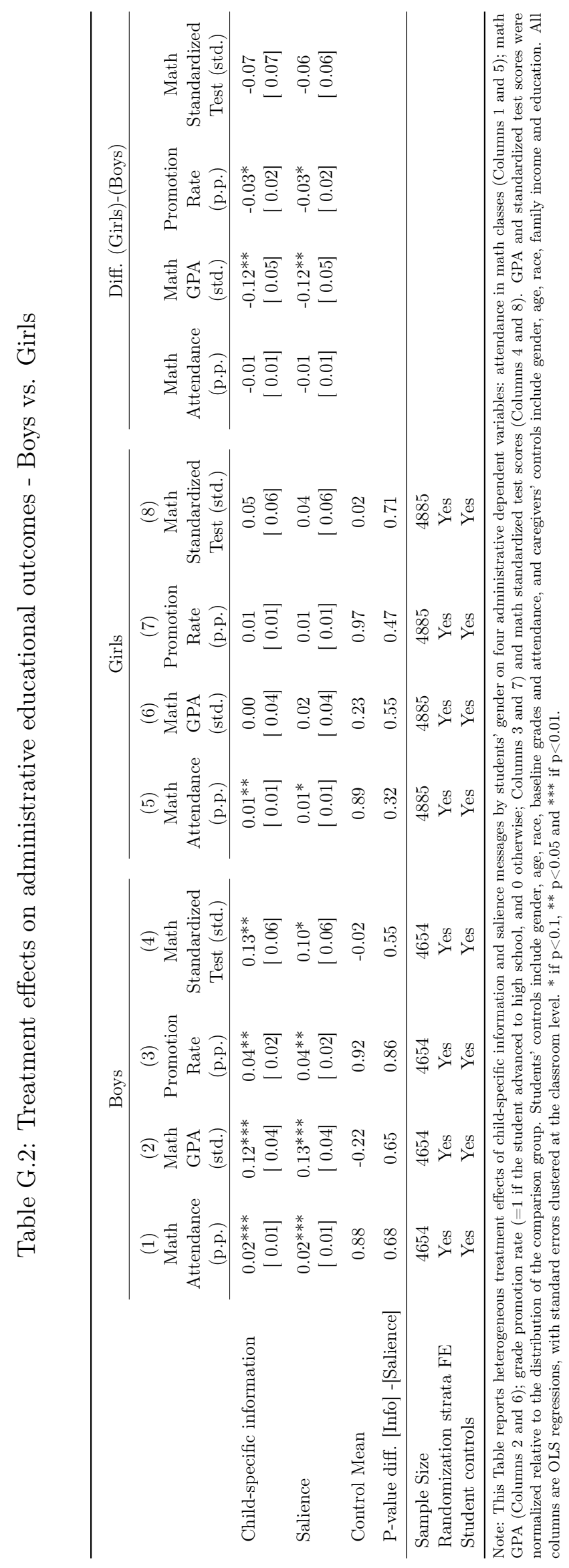


Table G.3: Treatment effects on parental engagement - Boys vs. Girls

\begin{tabular}{|c|c|c|c|c|c|c|c|c|c|}
\hline & \multicolumn{3}{|c|}{ Boys } & \multicolumn{3}{|c|}{ Girls } & \multicolumn{3}{|c|}{ Diff. (Girls)-(Boys) } \\
\hline & $\begin{array}{c}(1) \\
\text { Academic } \\
\text { activities }\end{array}$ & $\begin{array}{c}(2) \\
\text { Incentives }\end{array}$ & $\begin{array}{l}(3) \\
\text { Talk }\end{array}$ & $\begin{array}{c}(4) \\
\text { Academic } \\
\text { activities }\end{array}$ & $\begin{array}{c}(5) \\
\text { Incentives }\end{array}$ & $\begin{array}{l}(6) \\
\text { Talk }\end{array}$ & $\begin{array}{l}\text { Academic } \\
\text { activities }\end{array}$ & Incentives & Talk \\
\hline Child-specific information & $\begin{array}{l}0.13^{* *} \\
{[0.06]}\end{array}$ & $\begin{array}{c}0.05 \\
{[0.06]}\end{array}$ & $\begin{array}{c}0.17^{* * *} \\
{[0.05]}\end{array}$ & $\begin{array}{c}0.05 \\
{[0.07]}\end{array}$ & $\begin{array}{c}0.09 \\
{[0.06]}\end{array}$ & $\begin{array}{l}0.12^{* *} \\
{[0.06]}\end{array}$ & $\begin{array}{c}-0.08 \\
{[0.08]}\end{array}$ & $\begin{array}{c}0.03 \\
{[0.08]}\end{array}$ & $\begin{array}{c}-0.04 \\
{[0.07]}\end{array}$ \\
\hline Salience & $\begin{array}{l}0.13^{* *} \\
{[0.06]}\end{array}$ & $\begin{array}{c}0.07 \\
{[0.06]}\end{array}$ & $\begin{array}{c}0.14^{* * *} \\
{[0.05]}\end{array}$ & $\begin{array}{c}0.00 \\
{[0.06]}\end{array}$ & $\begin{array}{c}0.11^{*} \\
{[0.06]}\end{array}$ & $\begin{array}{c}0.11^{*} \\
{[0.06]}\end{array}$ & $\begin{array}{c}-0.12^{*} \\
{[0.07]}\end{array}$ & $\begin{array}{c}0.04 \\
{[0.08]}\end{array}$ & $\begin{array}{c}-0.03 \\
{[0.07]}\end{array}$ \\
\hline Control Mean & -0.02 & -0.02 & 0.00 & 0.02 & 0.02 & -0.00 & & & \\
\hline P-value diff. [Info] -[Salience] & 0.86 & 0.66 & 0.43 & 0.21 & 0.48 & 0.63 & & & \\
\hline Sample Size & 4654 & 4654 & 4654 & 4885 & 4885 & 4885 & & & \\
\hline Randomization strata FE & Yes & Yes & Yes & Yes & Yes & Yes & & & \\
\hline Student controls & Yes & Yes & Yes & Yes & Yes & Yes & & & \\
\hline
\end{tabular}

Table G.4: Treatment effects on parents' aspirations - Boys vs. Girls

\begin{tabular}{|c|c|c|c|}
\hline & Boys & Girls & Diff. (Girls)-(Boys) \\
\hline & $\begin{array}{c}(1) \\
\text { Parents' Aspirations } \\
\text { College }\end{array}$ & $\begin{array}{c}(2) \\
\text { Parents' Aspirations } \\
\text { College } \\
\end{array}$ & $\begin{array}{c}\text { Parents' Aspirations } \\
\text { College }\end{array}$ \\
\hline Child-specific information & $\begin{array}{c}0.10^{*} \\
{[0.06]}\end{array}$ & $\begin{array}{c}0.09^{*} \\
{[0.05]}\end{array}$ & $\begin{array}{c}-0.02 \\
{[0.08]}\end{array}$ \\
\hline Salience & $\begin{array}{l}0.12^{* *} \\
{[0.06]}\end{array}$ & $\begin{array}{c}0.08 \\
{[0.05]}\end{array}$ & $\begin{array}{l}-0.04 \\
{[0.08]}\end{array}$ \\
\hline Control Mean & -0.09 & 0.09 & \\
\hline P-value diff. [Info] -[Salience] & 0.76 & 0.79 & \\
\hline Sample Size & 4654 & 4885 & \\
\hline Randomization strata FE & Yes & Yes & \\
\hline Student controls & Yes & Yes & \\
\hline
\end{tabular}


Table G.5: Treatment effects on students' time use - Boys vs. Girls

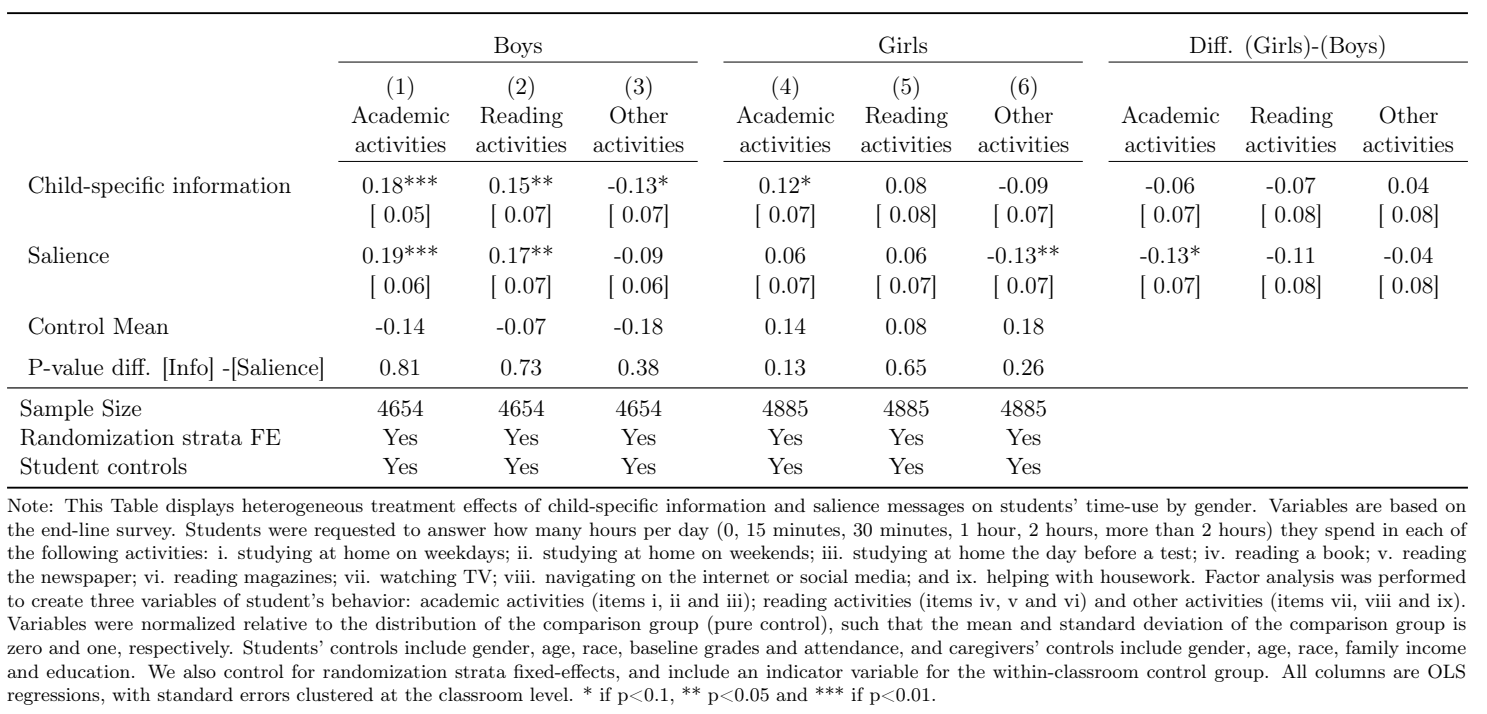




\section{H [Supplementary Appendix] Heterogeneous treatment ef- fects by willingness to receive information}

Willingness to receive information was also measured at the baseline survey. Parents were asked at baseline about their interest in receiving information about their child's school attendance, given the following options: no interest, some interest, or great interest (see Supplementary Appendix J). We define low willingness to receive information as an indicator variable equal to 1 if a parent expressed no or some interest in receiving information about school attendance, and 0 otherwise.

Table H.1 presents heterogeneous treatment effects by splitting the sample according to this indicator variable. The lower sample size reflects the fact that we can only use parents who answer our baseline phone survey in this table.

Table H.1: Heterogeneity by parents' willingness to receive information (WTR)

\begin{tabular}{|c|c|c|c|c|c|c|}
\hline & \multicolumn{4}{|c|}{ School Transcripts and Test Scores } & \multicolumn{2}{|c|}{ Parents' Beliefs } \\
\hline & $\begin{array}{c}\text { (1) } \\
\text { Math } \\
\text { Attendance } \\
\text { (p.p.) }\end{array}$ & $\begin{array}{c}\text { (2) } \\
\text { Math } \\
\text { GPA } \\
\text { (std.) } \\
\end{array}$ & $\begin{array}{c}\text { (3) } \\
\text { Promotion } \\
\text { Rate } \\
\text { (p.p.) } \\
\end{array}$ & $\begin{array}{c}(4) \\
\text { Math } \\
\text { Standardized } \\
\text { Test (std.) }\end{array}$ & $\begin{array}{c}\text { (5) } \\
\text { Accuracy } \\
\text { Math } \\
\text { Attendance (p.p.) }\end{array}$ & $\begin{array}{c}\text { (6) } \\
\text { Accuracy } \\
\text { Math } \\
\text { GPA (p.p.) }\end{array}$ \\
\hline & \multicolumn{6}{|c|}{ Low willingness to receive information (WTR) ( $63.3 \%$ ) } \\
\hline Child-specific information & $\begin{array}{c}0.03^{* * *} \\
{[0.01]}\end{array}$ & $\begin{array}{l}0.09^{*} \\
{[0.05]}\end{array}$ & $\begin{array}{l}0.04^{* *} \\
{[0.02]}\end{array}$ & $\begin{array}{l}0.16^{* *} \\
{[0.07]}\end{array}$ & $\begin{array}{l}-0.03 \\
{[0.04]}\end{array}$ & $\begin{array}{c}0.02 \\
{[0.04]}\end{array}$ \\
\hline Salience & $\begin{array}{c}0.03^{* * * *} \\
{[0.01]}\end{array}$ & $\begin{array}{l}0.12 * * \\
{[0.05]}\end{array}$ & $\begin{array}{c}0.03^{*} \\
{[0.02]}\end{array}$ & $\begin{array}{c}0.08 \\
{[0.07]}\end{array}$ & $\begin{array}{c}0.02 \\
{[0.04]}\end{array}$ & $\begin{array}{l}0.10^{* *} \\
{[0.04]}\end{array}$ \\
\hline Control Mean & 0.86 & -0.06 & 0.93 & -0.05 & 0.21 & 0.23 \\
\hline P-value diff. [Info] -[Salience] & 0.57 & 0.42 & 0.56 & 0.10 & 0.13 & 0.04 \\
\hline \multirow[t]{2}{*}{ Sample Size } & 2578 & 2578 & 2578 & 2578 & 1071 & 1071 \\
\hline & \multicolumn{6}{|c|}{ High willingness to receive information (WTR) ( $36.7 \%$ ) } \\
\hline Child-specific information & $\begin{array}{c}0.04^{* * *} \\
{[0.01]}\end{array}$ & $\begin{array}{l}0.15^{* *} \\
{[0.07]}\end{array}$ & $\begin{array}{c}0.07^{* * *} \\
{[0.02]}\end{array}$ & $\begin{array}{c}0.07 \\
{[0.10]}\end{array}$ & $\begin{array}{c}-0.16^{* *} \\
{[0.07]}\end{array}$ & $\begin{array}{c}0.04 \\
{[0.08]}\end{array}$ \\
\hline Salience & $\begin{array}{c}0.04^{* * *} \\
{[0.01]}\end{array}$ & $\begin{array}{c}0.18^{* * *} \\
{[0.07]}\end{array}$ & $\begin{array}{c}0.07^{* * *} \\
{[0.02]}\end{array}$ & $\begin{array}{c}0.14 \\
{[0.10]}\end{array}$ & $\begin{array}{c}-0.15^{* *} \\
{[0.07]}\end{array}$ & $\begin{array}{c}0.02 \\
{[0.08]}\end{array}$ \\
\hline Control Mean & 0.86 & 0.04 & 0.91 & 0.07 & 0.36 & 0.33 \\
\hline P-value diff. [Info] -[Salience] & 0.89 & 0.46 & 0.70 & 0.24 & 0.67 & 0.75 \\
\hline Sample Size & 1317 & 1317 & 1317 & 1317 & 620 & 620 \\
\hline $\begin{array}{l}\text { Randomization strata FE } \\
\text { Student controls }\end{array}$ & $\begin{array}{l}\text { Yes } \\
\text { Yes }\end{array}$ & $\begin{array}{l}\text { Yes } \\
\text { Yes }\end{array}$ & $\begin{array}{l}\text { Yes } \\
\text { Yes }\end{array}$ & $\begin{array}{l}\text { Yes } \\
\text { Yes }\end{array}$ & $\begin{array}{l}\text { Yes } \\
\text { Yes }\end{array}$ & $\begin{array}{l}\text { Yes } \\
\text { Yes }\end{array}$ \\
\hline $\begin{array}{l}\text { te: Parents were asked at baseline a } \\
\text { ne interest, or high interest. Parent } \\
\text { re defined as high-WTR. GPA norm } \\
\text { te of how many times their child mi } \\
\text { inst administrative records; we def } \\
\text { t } 0 \text { otherwise. Students' controls in } \\
\text { hily income and education. We also }\end{array}$ & $\begin{array}{l}\text { ut their inte } \\
\text { wo expresse } \\
\text { zed relative }\end{array}$ & indicat & $\begin{array}{l}\text { information } \\
\text { terest were de } \\
\text { on of the pure }\end{array}$ & $\begin{array}{l}\text { bout their child' } \\
\text { fined as low-WT } \\
\text { control group.Pa } \\
\text { as their child's } 4 \mathrm{t} \\
\text { o } 1 \text { if the parent }\end{array}$ & $\begin{array}{l}\text { Idance. They could ex } \\
\text { ile parents who expres } \\
\text { vere asked at end line f } \\
\text { rter math GPA. Data } \\
\text { the right bracket for a }\end{array}$ & $\begin{array}{l}\text { ress no intere } \\
\text { ed high inter } \\
\text { t their best es } \\
\text { as then check } \\
\text { tendance/GP }\end{array}$ \\
\hline
\end{tabular}

Willingness to receive information indicator (WTR) indeed seems to capture parents demand for information: while low-WTR parents do not update beliefs about children's attendance in response to text messages, those with high-WTR do. ${ }^{50}$ What is more, both

\footnotetext{
${ }^{50}$ The negative treatment effects on accuracy about attendance are linked to the mismatch between the
} 
salience and information treatments have positive and statistically significant effects even for low-WTR parents. Third, and most strikingly, the ratio of salience to information effects is actually systematically higher for parents with high WTR, which is consistent with attention being the primary mechanism behind the effects of communication. The reason is that, in line with Chassang et al. (2012), parents with higher demand for information should be those who exert higher effort to acquire it within the setting of the randomized control trial. Salience effects are magnified among those parents to a greater extent than information effects, highlighting the complementary nature between attention and decentralized information acquisition by parents.

time span at which we conveyed information about attendance ("over the last 3 weeks") and that for which we could verify attendance at endline (over the last quarter), as in the main text. 


\section{I [Supplementary Appendix] Pre-analysis plan}

Our pre-analysis registered at the AEA RCT Registry is presented in full in subsections I.1 through I.4. Subsection I.5 highlights the elements of the analyses that deviate from what had been specified in that pre-analysis plan.

\section{I.1 Background}

While there is increasing evidence that enhancing the communication between schools and parents significantly improves students' performance, less is known about what mechanisms drive those effects. Is it because, by providing parents with information about their children's effort, communication primarily alleviates the moral hazard problem between parents and children? Or is it because parents have limited attention, and communication makes parenting "top of mind"?

This paper attempts to decompose the effects of communicating with parents into those two mechanisms. Specifically, we investigate whether informing parents about their children's attendance, tardiness and assignment completion, improves students' outcomes above and beyond the effects of communication aimed at increasing awareness about those dimensions of children's effort. The distinction matters: providing timely and accurate information about children's behavior requires integrated systems and customized communication, which can be quite costly, particularly in developing countries. Conversely, simply nudging to raise awareness does not require any information systems in place.

Our experiment has Math teachers fill in information about students' attendance, tardiness and assignment completion, and then randomly assigns within classroom what information is conveyed to each parent over SMS. Parents in the control group receive no SMS; those in the awareness treatment group receive only general statements about the relevance of monitoring their child's behavior (e.g.: "Attending classes every day is important for Nina's grades"); and those in the awareness + information treatment group receive what the teacher informed about their child (e.g.: "Nina was absent less than 3 times in the previous 3 weeks"). The questions of interest are whether awareness alone improves student's attendance, grades, and drop-out rates, and to what extent adding pupil-level information further improves those outcomes.

\section{I.2 Intervention, sample and outcomes}

Communication interventions are randomly assigned at the school and student levels, within a sample of 223 Brazilian public schools, in order to estimate the impacts of each of those mechanisms on parental engagement and students' outcomes. The ninth grade is a crucial period in the school cycle of Brazilian schools: it is the last grade before high-school, and dropout rates are very high.

We will deliver content through sequences of text messages (SMS), alternating the dimensions of children's effort-attendance, tardiness and assignments completion. The 
intervention's treatment arms are as follows:

1) [Awareness treatment] General statements about attendance, tardiness and assignment completion (e.g. "attending school is important") - T1

2) [Awareness + information treatment] Child-level attendance, tardiness and assignment completion - T2

Comparing $\mathrm{T} 2$ to $\mathrm{T} 1$ and $\mathrm{T} 1$ to control allows separating the effects of information and awareness.

There are two main concerns about how this design may potentially underplay the effects of information. The first is that parents may already have (to a reasonable extent) information about their child, such that the key piece of information missing is how to place their child relatively to his or her classmates. In fact, other studies often focus on relative behavior: e.g. Rogers and Feller (2016) inform parents about how their children's attendance fares relatively to his/her classroom modal attendance.

To deal with this concern, we pursue two strategies. First, we survey parents at baseline about their best guess for their child's attendance, tardiness and assignment completion, so as to investigate heterogeneity of treatment effects by baseline accuracy (Annex 2). Second, for a sub-sample of schools, we add an alternative awareness + information treatment that conveys parents both with pupil- and classroom-level information, to test whether that treatment has additional effects.

3) [Awareness + relative information treatment] Child- and classroom-level attendance, tardiness and assignment completion - T3

The second concern is contamination, or peer effects. While there is a concern that assigning different treatments within the same classroom may lead to contamination, we are less worried about it in this setting parents typically have no recurring interactions at this age - most of them no longer take their children to school, and parent-teacher meetings are rather infrequent in Brazilian public schools. However, peer effects may lead us to underestimate treatment effects. To deal with this concern, our design varies the exposure to the different treatments across different sub-samples of schools, allowing us to estimate spillovers. Randomization will be performed in two steps. First, schools will be randomly assigned to 4 different sub-samples (A-D), determining the treatment arms each school will have access. Then, students will be randomized within class to each treatment arm:

A. Pure control - 25 schools

B. $\mathrm{T} 1+$ control -25 schools

C. $\mathrm{T} 1+\mathrm{T} 2+$ control -100 schools

D. $\mathrm{T} 1+\mathrm{T} 2+\mathrm{T} 3+$ control -50 schools

Sub-sample C allows separating the effects of information and awareness; sub-samples A and B allow estimating spillover effects. Sub-sample D is meant to address the concern about relative vs. absolute child-level information. In order to collect cellphones and information from parents in the control group, and also to control for the proportion of 
parents registered in the program, we will offer the control and the treatment group access to send school events through the platform.

\begin{tabular}{|c|c|c|c|c|c|}
\hline & \multicolumn{4}{|c|}{ Randomization at the school level } \\
\hline & & A - 25 Schools & B - 25 Schools & C - 100 Schools & D - 50 Schools \\
\hline \multirow{4}{*}{ 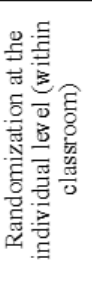 } & $\begin{array}{c}\text { T1 }- \text { [Awareness } \\
\text { treatment] }\end{array}$ & & $1 / 2$ Class & $1 / 3$ Class & $1 / 4$ Class \\
\hline & $\begin{array}{c}\text { T2- }[\text { Aw areness }+ \\
\text { information treatment] }\end{array}$ & & & $1 / 3$ Class & $1 / 4$ Class \\
\hline & $\begin{array}{l}\text { T3-[Awareness + relative } \\
\text { information treatment] }\end{array}$ & & & & $1 / 4$ Class \\
\hline & Control (events) & All students & $1 / 2$ Class & $1 / 3$ Class & $1 / 4$ Class \\
\hline
\end{tabular}

Figure I.1: Research Design

A web-platform was created specifically to this project and was designed in a simple and intuitive way so schools could easily manage it. Treatment and control schools will have access to the event feature, allowing them to notify parents of two school events per month. Once the principal registers the event, the system will send two SMS notifications to parents: one week prior and one day prior to the event. Math teachers from treatment schools will be oriented to fill in the platform every week with that week's dimension of students' behavior: attendance, tardiness or assignment completion. Teachers will fill information regarding student behavior on each dimension considering the past three weeks. The system requires teachers to fill in information for all students.

\begin{tabular}{llc}
\hline $\begin{array}{l}\text { Attend ance } \\
\mathbf{1} \text { Did not miss any class }\end{array}$ & $\begin{array}{c}\text { Lateness } \\
\mathbf{1} \text { Was not late for any class }\end{array}$ & $\begin{array}{c}\text { Assignment Completion } \\
\mathbf{1} \text { Completed all the assignments }\end{array}$ \\
$\mathbf{2}$ Missed less then 3 classes & $\mathbf{2}$ Was late for less then 3 classes & $\mathbf{2}$ Completed more than half of the assignments \\
$\mathbf{3}$ Missed 3 to 5 classes & $\mathbf{3}$ Was late 3 to 5 classes & $\mathbf{3}$ Completed less than half of the assignments \\
\hline
\end{tabular}

Figure I.2: School Platform

Teachers and schools are not aware of their assignment, nor of parents' assignment. For treatment arm T3, the platform computes the class median once the teacher submits all students' information every week. As for treatment arm T1, although teacher will fill in child-level information every week, parents will only receive general information aimed at raising awareness about that dimension of children's effort. Parents of all treatment arms only receive the text message if the teacher had completed the platform that week. This is true even for T1, in order to avoid confounding treatment effects with teachers' non-compliance. After teachers have filled the platform until Sunday of each week, parents will receive the following message on Tuesdays, according to their treatment status: 


\begin{tabular}{|c|c|c|c|}
\hline & T1 (awareness) & $\begin{array}{l}\mathrm{T} 2 \text { (awareness + } \\
\text { information) }\end{array}$ & $\begin{array}{c}\text { T3 (awareness +relative } \\
\text { information) }\end{array}$ \\
\hline Week 1 & $\begin{array}{l}\text { For a good school } \\
\text { performance, it is important } \\
\text { that Caroline doesn't miss } \\
\text { school for no reason. }\end{array}$ & $\begin{array}{l}\text { According to the information } \\
\text { registered by the teacher in } \\
\text { the system the past } 3 \text { weeks, } \\
\text { Eric missed less than } 3 \\
\text { classes. }\end{array}$ & $\begin{array}{l}\text { In the past } 3 \text { weeks, Susanna } \\
\text { missed a few classes less } \\
\text { than } 3 \text { classes. In her class, } \\
\text { most of the students didn't } \\
\text { miss any class. }\end{array}$ \\
\hline Week 2 & $\begin{array}{l}\text { Punctuality prevents } \\
\text { Caroline from missing } \\
\text { explanations given by the } \\
\text { teacher that are not always in } \\
\text { the books. }\end{array}$ & $\begin{array}{l}\text { According to the information } \\
\text { registered by the teacher in } \\
\text { the system the past } 3 \text { weeks, } \\
\text { Eric was late for more than } 5 \\
\text { classes. }\end{array}$ & $\begin{array}{l}\text { In the past } 3 \text { weeks, Susanna } \\
\text { was late for more than } 5 \\
\text { classes. In her class, most of } \\
\text { the students were late for } \\
\text { less than } 3 \text { classes. }\end{array}$ \\
\hline Week 3 & $\begin{array}{l}\text { Completing the assignments } \\
\text { is very important for } \\
\text { Caroline to leam what was } \\
\text { taught in class. }\end{array}$ & $\begin{array}{l}\text { According to the information } \\
\text { registered by the teacher in } \\
\text { the past } 3 \text { weeks, Eric } \\
\text { complete more than half of } \\
\text { the assignments. }\end{array}$ & $\begin{array}{l}\text { In the past } 3 \text { weeks, Susanna } \\
\text { completed all the } \\
\text { assignments. In her class, } \\
\text { most of the students } \\
\text { completed more than half of } \\
\text { the assignments. }\end{array}$ \\
\hline
\end{tabular}

Figure I.3: SMS examples

The content of the messages are simple and clear and messages across treatment arms were designed to have a similar length (number of characters). Each week teachers will receive a text message, reminding them which dimension they should fill in that week. Moreover, teachers who miss one week will receive an alert, emphasizing they did not fill the platform that week and encouraging them to fill in the following week. Principals will receive motivational messages, encouraging them to engage teachers in the program, as well as message alters, if the usage in the school is low. The study relies on four main stakeholders, who will contribute to the success of the intervention: the São Paulo Secretariat of Education, the Regional Board of Education Directors, school principals and teachers. São Paulo is the most populous state in Brazil and it is divided in 91 Regional Boards of Education. Each Region has an Education Director. In this project, we will work with five Regional Boards of Education. Education Directors will play an import roll of engaging schools in the program.

The implementation of the intervention involves five steps. First, on April 14th we had a meeting with the five Education Directors, as well as the team of São Paulo Secretariat of Education to present the project. Second, on the following two weeks, Directors presented the project to their schools, inviting them to participate. Participation rate was 87\%. Third, between May 9 and May 17 we had meetings with the school principals and Education Director, in each of the Regional Board of Education head offices, to explain the project and distribute the enrollment material and instructions. Forth, the schools organized parental meetings, to explain the project and enroll parents in the program, collecting their cell-phone, as well as other information. For parents who did not attend the meeting, the material was sent home trough the student. Fifth, Math teachers had two weeks to register parents' information in the system. Schools and students were then randomized to treatments and control groups and teachers began to fill the platform on the week of June 13th. The school year in Brazil runs from February to December, with a winter break in July. Parents will be exposed to the program during 6 months of the 
academic year.

\section{I.3 Outcomes}

We will conduct surveys through automated voice calls (Interactive Voice Response, IVR) at the end of the intervention to collect self-reported parenting practices and parents' views about their children. We conducted a baseline survey through IVR on the week of June 16th, surveying parents about their demand for information, as well their previous knowledge about their kids. At the end of the project, we will be able to investigate if treatment effects are heterogeneous by the accuracy of prior knowledge about children's behavior and the ones by ex-ante demand for information about child-level behavior.

One interesting lesson from our 2015 pilot is that, at least among 6th grades, about $1 / 3$ of participating families' children also have cell phones, which lead us to collect student's cell phones for this study. We were able to collect cell phones for $50 \%$ of the students. Among these families, we track students' views about themselves, their parents and their teachers. At the end of the intervention, the São Paulo Education Secretariat will provide data on student attendance and grades in 2016 (per quarter), and enrollment in 2017. Moreover, the Secretariat implements an yearly standardized test to all schools in the state of São Paulo, SARESP (System of School Performance Evaluation of the State of São Paulo). All students in grades 1st, 3rd, 5th, 7th, 9th of primary school and the 3rd (final) year of high school are tested on their knowledge of Mathematics and Portuguese. 


\section{I.4 Timeline and milestones}

\begin{tabular}{|c|c|c|c|}
\hline \# & Milestone & $\begin{array}{l}\text { Target } \\
\text { Start } \\
\text { Date }\end{array}$ & $\begin{array}{l}\text { Target } \\
\text { End } \\
\text { Date }\end{array}$ \\
\hline 1. & $\begin{array}{l}\text { Meeting with the Regional Board of Education Directors and the São } \\
\text { Paulo Secretariat of Education to explain the project }\end{array}$ & Apr-14 & Apr-14 \\
\hline 2. & $\begin{array}{l}\text { Regional Board of Education Directors meet with their schools } \\
\text { principals to explain the project }\end{array}$ & Apr-18 & Apr-27 \\
\hline 3. & Schools register to participate in the program (trough an online form) & Apr-18 & Apr-27 \\
\hline 4. & $\begin{array}{l}\text { Meeting with Education Directors and school principals in each of the } \\
5 \text { Regional Board of Education head office to explain the project and } \\
\text { distribute the enrollment material }\end{array}$ & May-9 & May-17 \\
\hline 5. & $\begin{array}{l}\text { Schools organize meeting with parents to explain the project and } \\
\text { obtain their cellphone and consent }\end{array}$ & May-10 & May-30 \\
\hline 6. & $\begin{array}{l}\text { Teacher uploads parental enrollment information through secure } \\
\text { website }\end{array}$ & May-10 & Jun-2 \\
\hline 7. & Randomization & Jun-3 & Jun-5 \\
\hline 9. & Baseline phone survey implementation & Jun-13 & Jun-24 \\
\hline 10. & SMS content and nudges begin & Jul-4 & - \\
\hline 11. & End line phone surveys implementation & Dec-12 & Dec-20 \\
\hline 12. & SMS content and nudges end & Dec-20 & - \\
\hline 13. & Impact Evaluation & Jan-30 & Mar-31 \\
\hline
\end{tabular}

Figure I.4: Timeline \& Milestones

\section{I.5 Deviations from the pre-analysis plan}

In the paper, we present all results of the hypotheses' tests pre-specified in that document (some of which are relegated to the supplementary appendices).

There are four main differences between the analyses we undertake in the paper and those that were pre-specified.

First, terminology. For ease of exposition, in the paper we distinguish between salience messages and child-specific information, while in the pre-analysis plan we referred to the former as "awareness" messages and to the latter as "awareness + information" messages. Nothing changed in terms of the analyses; we just clarify the difference to guide the reader in their examination of the pre-analysis plan.

Second, sub-sample E (nudges) was not included in the pre-analysis plan. It was added later, covering a different set of schools (not statistically identical at baseline to the other sub-samples), to allow us to rule out that treatment effects were merely driven by differential teacher behavior across treated schools and pure control schools. As the analyses of treatment effects comparing educational outcomes in this sub-sample to those 
in the pure control group is non-experimental (rather, estimated using a differences-indifferences strategy), we did not amend the pre-analysis plan at the time.

Third, the number of schools assigned to each sub-sample does not correspond exactly to those in the pre-analysis plan. The reason is that we ended up having access to a larger number of schools than we had foreseen at the time. The proportion of schools assigned to each group is, however, nearly identical to that of the pre-analysis plan.

Fourth, we incorporated some additional analyses in order to generate results comparable to the literature. Specifically, the analyses of how the interventions affect the slope of beliefs as a function of actual absences, in Sections 4 and 6.2, and of how the interventions induce conditional impacts with respect to student effort, in Section 5.3, closely follow Dizon-Ross (2019). 


\section{J [Supplementary Appendix] Survey instruments}

\section{J.1 Baseline Survey: Parents}

"Thank you for participating in the research about parental engagement in student education! Answer the following questions by dialing on your cellphone. This survey is anonymous and free and if you answer all the questions you will receive 5 reais in cellphone credit in your pre-paid phone. You will answer only 11 questions!"

1. How many times does your child usually miss Math class in a one-month period? If none, press 1; if between 1 and 3 times, press 2; if between 4 and 6 times, press 3; if more than 6 times, press 4 .

2. How many times is your child usually late to Math class in a one-month period? If none, press 1; if between 1 and 3 times, press 2; if between 4 and 6 times, press 3 ; if more than 6 times, press 4 .

3. How many times does your child usually hand in Math assignments on time in a one-month period? If none, press 1; if between 1 and 3 times, press 2; if between 4 and 6 times, press 3 ; if more than 6 times, press 4 .

4. How does your child usually behave in Math class? If very well, press 1 ; if well, press 2 ; if appropriately, press 3 ; if inappropriately, press 4 .

5. Usually, how is your child's performance in Math class? If very good, press 1; if good, press 2 ; if adequate, press 3 ; if inadequate, press 4 .

If your child's school initiated a program to inform parents and guardians about the school life of students, what would be your interest in receiving information about each of the following?

6. About the number of Math classes missed? Press 1 if you would be very interested, press 2 if you would be somewhat interested; press 3 if you would not be interested.

7. About the number of Math classes he/she was late for? Press 1 if you would be very interested, press 2 if you would be somewhat interested; press 3 if you would not be interested.

8. About the number of Math assignments he/she failed to hand on time? Press 1 if you would be very interested, press 2 if you would be somewhat interested; press 3 if you would not be interested. 
9. About his/her behavior in Math class? Press 1 if you would be very interested, press 2 if you would be somewhat interested; press 3 if you would not be interested.

10. About his/her performance in Math class? Press 1 if you would be very interested, press 2 if you would be somewhat interested; press 3 if you would not be interested.

11. About activities you could perform at home with your child, to increase parental engagement? Press 1 if you would be very interested, press 2 if you would be somewhat interested; press 3 if you would not be interested.

Final message: "Thank you! Your air credit will be delivered within 7 days!"

\section{J.2 End-line Survey: Parents}

"Thank you for participating in SMS ESCOLA research about parental engagement in student education! Answer the following questions by dialing on your cellphone. This survey is anonymous and free and if you answer all the questions you will receive 5 reais in cellphone credit in your pre-paid phone!"

1. Did you receive weekly text messages from the school in the last six-months? If yes, press 1 ; if no, press 2 .

If the answer is 1 (yes) $-2 \mathrm{~A} \& 3 \mathrm{~A}$ :

2.A. Did you talk with the professor or other parents about the text messages you received from the school? If yes, press 1 ; if no, press 2.

3.A. Did you show the text messages to your child? If yes, press 1 ; if no, press 2 .

If the answer is $2($ no $)-2 B \& 3 B)$ :

2.B. Did you hear that some of the parents were receiving text messages from the school or did you talk with the professors or other parents about the text messages? If yes, press 1 ; if no, press 2.

3.B. Did any parent show you the content of these text messages? If yes, press 1 ; if no, press 2 .

4A. Now answer how often you do each of the following things. Help your child with schoolwork or homework? If never, press 1 ; if almost never, press 2 ; if sometimes, press 3 ; if always or almost always, press 4 . 
4B. Now answer how often you do each of the following things. Help your child to organize school material, such as books, notebooks and backpack? If never, press 1; if almost never, press 2; if sometimes, press 3; if always or almost always, press 4 .

5A. Incentivize your child to not miss school? If never, press 1; if almost never, press 2 ; if sometimes, press 3; if always or almost always, press 4 .

5B. Incentivize your child to not be late for school? If never, press 1 ; if almost never, press 2 ; if sometimes, press 3 ; if always or almost always, press 4 .

6 A. Talk to your child about his day in school? If never, press 1 ; if almost never, press 2 ; if sometimes, press 3 ; if always or almost always, press 4 .

6B. Talk to your child about his classes? If never, press 1; if almost never, press 2; if sometimes, press 3 ; if always or almost always, press 4 .

7A. Go to school parent meetings? If never, press 1; if almost never, press 2 ; if sometimes, press 3; if always or almost always, press 4 .

7B. Talk to your child's teachers, for any reason. If never, press 1; if almost never, press 2 ; if sometimes, press 3 ; if always or almost always, press 4 .

8. Thinking about your child's Math class, answer each of the following questions with your best guess. On average, how many Math classes did your child miss in the last quarter? If none, press 0 ; if less than 3 , press 1 ; if between 3 and 5 , press 2 ; if between 6 and 8 , press 3 ; if more than 8 , press 5 .

9. What was your child's Math grade in the last quarter? Press a number between 0 and 10 and then pound.

10. Now thinking about your child's Portuguese class, answer each of the following questions with your best guess. On average, how many Portuguese classes did your child miss in the last quarter? If none, press 0 ; if less than 3 , press 1 ; if between 3 and 5 , press 2 ; if between 6 and 8 , press 3 ; if more than 8 , press 5 .

11. What was your child's Portuguese grade in the last quarter? Press a number between 0 and 10 and then pound.

12. If a professor suggests a list of books for your child to read during vacations, would you buy it? If you would buy it if they were required, press 1 ; if you would buy it even if 
they were optional, press 2; or if you would not buy it, press 3 .

13. Answer if you agree or disagree with the following statements. "Experiencing failure debilitates my performance and productivity." If you strongly disagree, press 1 ; if you disagree, press 2; if you somewhat disagree, press 3; if you somewhat agree, press 4; if you agree, press 5 ; or if you strongly agree, press 6 .

14. "Experiencing failure inhibits my learning and growth." If you strongly disagree, press 1; if you disagree, press 2; if you somewhat disagree, press 3; if you somewhat agree, press 4; if you agree, press 5; or if you strongly agree, press 6.

15. "Experiencing failure enhances my performance and productivity." If you strongly disagree, press 1 ; if you disagree, press 2 ; if you somewhat disagree, press 3 ; if you somewhat agree, press 4 ; if you agree, press 5 ; or if you strongly agree, press 6 .

16. "The effects of failure are negative and should be avoided." If you strongly disagree, press 1; if you disagree, press 2; if you somewhat disagree, press 3 ; if you somewhat agree, press 4; if you agree, press 5; or if you strongly agree, press 6.

Final message: "Thank you! Your air credit will be delivered within 7 days, and you will receive a text message confirmation when it is available!" 


\section{J.3 End-line Survey: Students}

Dear student,

This questionnaire should be answered with great care. We want to know more about families' engagement habits and your study habits. You can be sure that your family, your colleagues and your school teachers will not know any of your answers, so please answer honestly. Your answers will contribute to a better future for you and other young people in our State. If you do not understand a question, please call the administrator, but do not stop answering! There are no right or wrong answers! Thank you!

\begin{tabular}{|c|c|c|c|c|c|c|c|}
\hline 1. & Answer how often your parents or guardians: & & & Never & $\begin{array}{l}\text { Almost } \\
\text { Never }\end{array}$ & $\begin{array}{c}\text { Someti } \\
\text { mes }\end{array}$ & $\begin{array}{l}\text { Almost } \\
\text { always or } \\
\text { always }\end{array}$ \\
\hline a. & Help you with homework or schoolwork. & & & 1 & 2 & 3 & 4 \\
\hline b. & Ask if you did you homework or schoolwork & & & 1 & 2 & 3 & 4 \\
\hline c. & Help you to organize the school material, such as books, notebooks anc & ackpack. & & 1 & 2 & 3 & 4 \\
\hline d. & Incentivize you to not miss school. & & & 1 & 2 & 3 & 4 \\
\hline e. & Incentivize you to not be late for school. & & & 1 & 2 & 3 & 4 \\
\hline f. & Ask you about your grades in tests, activities and classes. & & & 1 & 2 & 3 & 4 \\
\hline g. & Incentivize you to study. & & & 1 & 2 & 3 & 4 \\
\hline h. & Incentivize you to read. & & & 1 & 2 & 3 & 4 \\
\hline i. & Ask you about your day in school. & & & 1 & 2 & 3 & 4 \\
\hline j. & Ask you about your classes. & & & 1 & 2 & 3 & 4 \\
\hline k. & Go to school parent meetings. & & & 1 & 2 & 3 & 4 \\
\hline I. & Talk to your teachers. & & & 1 & 2 & 3 & 4 \\
\hline 2. & $\begin{array}{l}\text { Answer if you agree or disagree with each of the following } \\
\text { statements: }\end{array}$ & $\begin{array}{l}\text { Strongly } \\
\text { disagree }\end{array}$ & Disagree & $\begin{array}{l}\text { Somewhat } \\
\text { disagree }\end{array}$ & $\begin{array}{c}\text { Somewhat } \\
\text { agree }\end{array}$ & Agree & $\begin{array}{c}\text { Strongly } \\
\text { agree }\end{array}$ \\
\hline a. & How smart you are is something that you can't change very much. & 1 & 2 & 3 & 4 & 5 & 6 \\
\hline b. & $\begin{array}{l}\text { You can learn new things, but you can't change how smart you really } \\
\text { are. }\end{array}$ & 1 & 2 & 3 & 4 & 5 & 6 \\
\hline c. & You can always change how smart you are. & 1 & 2 & 3 & 4 & 5 & 6 \\
\hline d. & $\begin{array}{l}\text { You have a certain degree of intelligence and you can't really do } \\
\text { much to change it. }\end{array}$ & 1 & 2 & 3 & 4 & 5 & 6 \\
\hline e. & $\begin{array}{l}\text { My parents ask me how my work in school compares with the work of } \\
\text { other students in my class. }\end{array}$ & 1 & 2 & 3 & 4 & 5 & 6 \\
\hline f. & $\begin{array}{l}\text { My parents would be pleased if I could show that school is easy for } \\
\text { me. }\end{array}$ & 1 & 2 & 3 & 4 & 5 & 6 \\
\hline g. & $\begin{array}{l}\text { My parents would like it if I could show that l'm smarter than other } \\
\text { students in my class. }\end{array}$ & 1 & 2 & 3 & 4 & 5 & 6 \\
\hline h. & My parents don't like it when I make mistakes in school. & 1 & 2 & 3 & 4 & 5 & 6 \\
\hline i. & $\begin{array}{l}\text { My parents want me to understand school concepts, not just do the } \\
\text { work. }\end{array}$ & 1 & 2 & 3 & 4 & 5 & 6 \\
\hline j. & $\begin{array}{l}\text { My parents think how hard I work in school is more important than the } \\
\text { grades I get. }\end{array}$ & 1 & 2 & 3 & 4 & 5 & 6 \\
\hline k. & My parents would like me to do hard work, even if I make mistakes. & 1 & 2 & 3 & 4 & 5 & 6 \\
\hline I. & $\begin{array}{l}\text { My parents want me to understand homework problems, not just } \\
\text { memorize how to do them. }\end{array}$ & 1 & 2 & 3 & 4 & 5 & 6 \\
\hline
\end{tabular}




\begin{tabular}{|c|c|c|c|c|c|}
\hline 3. & $\begin{array}{l}\text { Answer if you agree or disagree with each of the following statements: (answer thinking } \\
\text { about how you felt recently. There is no right or wrong answer) }\end{array}$ & $\begin{array}{c}\text { Strongly } \\
\text { agree }\end{array}$ & Agree & Disagree & $\begin{array}{l}\text { Strongly } \\
\text { disagree }\end{array}$ \\
\hline a. & On the whole, I am satisfied with myself. & 1 & 2 & 3 & 4 \\
\hline b. & At times, I think I am no good at all. & 1 & 2 & 3 & 4 \\
\hline c. & I feel that I have a number of good qualities. & 1 & 2 & 3 & 4 \\
\hline d. & I am able to do things as well as most other people. & 1 & 2 & 3 & 4 \\
\hline e. & I feel I do not have much to be proud of. & 1 & 2 & 3 & 4 \\
\hline f. & I feel useless at times. & 1 & 2 & 3 & 4 \\
\hline g. & Sometimes I feel that I'm a worthless person. & 1 & 2 & 3 & 4 \\
\hline h. & I wish I could have more respect for myself. & 1 & 2 & 3 & 4 \\
\hline i. & All in all, I am inclined to feel that I am a failure. & 1 & 2 & 3 & 4 \\
\hline j. & I have a positive attitude toward myself. & 1 & 2 & 3 & 4 \\
\hline
\end{tabular}

\begin{tabular}{|c|c|c|c|c|c|}
\hline 4. & Answer how you feel for each of the statements below. Do you like that your parents or guardians: & $\begin{array}{c}\text { I like it } \\
\text { a lot }\end{array}$ & $\begin{array}{l}\text { I like it a } \\
\text { little }\end{array}$ & $\begin{array}{l}\text { I don't } \\
\text { like it }\end{array}$ & $\begin{array}{c}\text { I hate } \\
\text { it }\end{array}$ \\
\hline a. & Help you with homework or schoolwork? & 1 & 2 & 3 & 4 \\
\hline b. & Ask you about your day in school? & 1 & 2 & 3 & 4 \\
\hline c. & Help you to organize school material, such as books, notebooks and backpack? & 1 & 2 & 3 & 4 \\
\hline d. & Ask you about your grades on tests, on assignments and in classes? & 1 & 2 & 3 & 4 \\
\hline e. & Go to school parent meetings? & 1 & 2 & 3 & 4 \\
\hline f. & Incentivize you to not miss school? & 1 & 2 & 3 & 4 \\
\hline g. & Incentivize you to not be late for school? & 1 & 2 & 3 & 4 \\
\hline
\end{tabular}

\begin{tabular}{|c|c|c|c|c|c|c|}
\hline 5. & $\begin{array}{l}\text { Indicate how much you identify with each of the statements below (there are no } \\
\text { right or wrong answers) }\end{array}$ & $\begin{array}{l}\text { Very much } \\
\text { like me }\end{array}$ & $\begin{array}{l}\text { Mostly } \\
\text { like me }\end{array}$ & $\begin{array}{l}\text { Somewh } \\
\text { at like me }\end{array}$ & $\begin{array}{c}\text { Not } \\
\text { much } \\
\text { like me }\end{array}$ & $\begin{array}{l}\text { Not like me } \\
\text { at all }\end{array}$ \\
\hline a. & New ideas and projects sometimes distract me from previous ones. & 1 & 2 & 3 & 4 & 5 \\
\hline b. & Setbacks (delays and obstacles) don't discourage me. & 1 & 2 & 3 & 4 & 5 \\
\hline c. & $\begin{array}{l}\text { I have been obsessed with a certain idea or project for a short time but later lost } \\
\text { interest. }\end{array}$ & 1 & 2 & 3 & 4 & 5 \\
\hline d. & I am a hard worker. & 1 & 2 & 3 & 4 & 5 \\
\hline e. & I often set a goal but later choose to pursue (follow) a different one. & 1 & 2 & 3 & 4 & 5 \\
\hline f. & $\begin{array}{l}\text { I have difficulty maintaining (keeping) my focus on projects that take more than a few } \\
\text { months to complete. }\end{array}$ & 1 & 2 & 3 & 4 & 5 \\
\hline g. & I finish whatever I begin. & 1 & 2 & 3 & 4 & 5 \\
\hline h. & I'm hard working and careful. & 1 & 2 & 3 & 4 & 5 \\
\hline
\end{tabular}

\begin{tabular}{|c|c|c|c|c|c|c|c|}
\hline 6. & $\begin{array}{l}\text { In general, indicate how much time per day you spend in each of the } \\
\text { following activities: }\end{array}$ & $\begin{array}{l}\text { I don't do } \\
\text { this activity }\end{array}$ & $\begin{array}{c}15 \\
\text { minutes }\end{array}$ & $\begin{array}{c}30 \\
\text { minutes }\end{array}$ & $\begin{array}{c}1 \\
\text { hour }\end{array}$ & $\stackrel{2}{2}$ & $\begin{array}{l}\text { More } \\
\text { then } 2 \\
\text { hours }\end{array}$ \\
\hline a. & Study at home, on weekdays. & 1 & 2 & 3 & 4 & 5 & 6 \\
\hline b. & Study at home, on weekends. & 1 & 2 & 3 & 4 & 5 & 6 \\
\hline c. & Study at home, the day before a test. & 1 & 2 & 3 & 4 & 5 & 6 \\
\hline d. & Watch TV. & 1 & 2 & 3 & 4 & 5 & 6 \\
\hline e. & Read a book. & 1 & 2 & 3 & 4 & 5 & 6 \\
\hline f. & Read the newspaper. & 1 & 2 & 3 & 4 & 5 & 6 \\
\hline g. & Read magazines. & 1 & 2 & 3 & 4 & 5 & 6 \\
\hline h. & On the internet or social media. & 1 & 2 & 3 & 4 & 5 & 6 \\
\hline i. & $\begin{array}{l}\text { Help with housework in YOUR HOUSE (clean the house, laundry, dishes, take } \\
\text { care of children...). }\end{array}$ & 1 & 2 & 3 & 4 & 5 & 6 \\
\hline
\end{tabular}




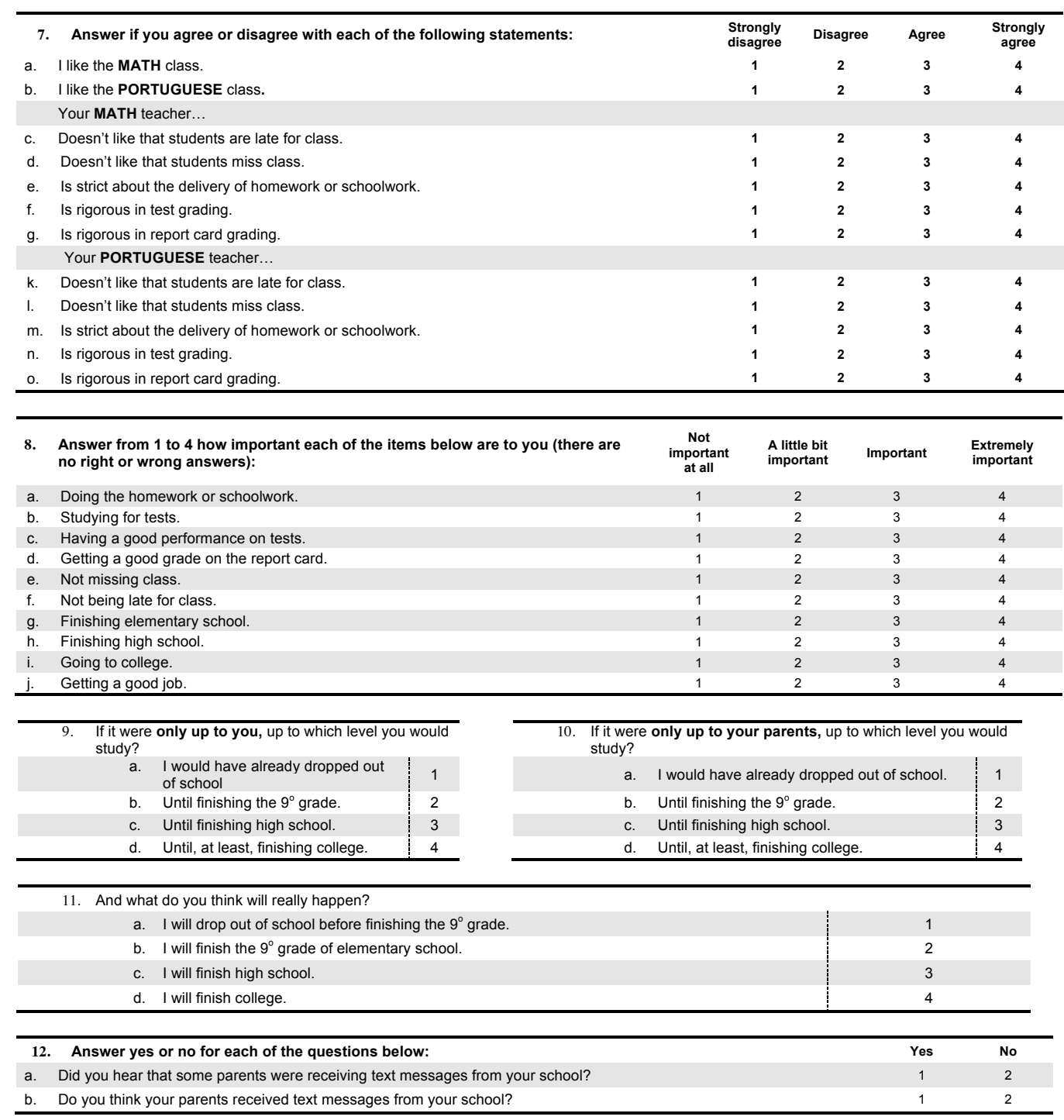




\begin{tabular}{|c|c|c|c|c|c|c|c|c|}
\hline 13. & Answer how confident you are for each of the statements below: & \multicolumn{2}{|c|}{$\begin{array}{l}\text { Not at all } \\
\text { confident }\end{array}$} & $\begin{array}{l}\text { Slightly } \\
\text { confident }\end{array}$ & $\begin{array}{l}\text { Somewhat } \\
\text { confident }\end{array}$ & $\begin{array}{c}\text { Quite } \\
\text { confident }\end{array}$ & \multicolumn{2}{|c|}{$\begin{array}{l}\text { Extremely } \\
\text { confident }\end{array}$} \\
\hline a. & $\begin{array}{l}\text { How confident are you that you can complete all the work that is assigned in your } \\
\text { classes? }\end{array}$ & \multicolumn{2}{|c|}{1} & 2 & 3 & 4 & \multicolumn{2}{|c|}{ 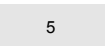 } \\
\hline b. & $\begin{array}{l}\text { When complicated ideas are presented in class, how confident are you that you } \\
\text { can understand them? }\end{array}$ & \multicolumn{2}{|c|}{1} & 2 & 3 & 4 & \multicolumn{2}{|r|}{5} \\
\hline c. & $\begin{array}{l}\text { How confident are you that you can learn all the material presented in your } \\
\text { classes? }\end{array}$ & \multicolumn{2}{|c|}{1} & 2 & 3 & 4 & \multicolumn{2}{|r|}{5} \\
\hline d. & $\begin{array}{l}\text { How confident are you that you can do the hardest work that is assigned in your } \\
\text { classes? }\end{array}$ & \multicolumn{2}{|c|}{1} & 2 & 3 & 4 & \multicolumn{2}{|r|}{5} \\
\hline e. & $\begin{array}{l}\text { How confident are you that you will remember what you learned in your current } \\
\text { classes, next year? }\end{array}$ & \multicolumn{2}{|c|}{1} & 2 & 3 & 4 & \multicolumn{2}{|r|}{5} \\
\hline 14. & $\begin{array}{l}\text { To answer the questions below, think of how you compare to most people. Fo } \\
\text { following statements, please indicate how often you did the following during t } \\
\text { past school year (there are no wrong or right answers): }\end{array}$ & & $\begin{array}{c}\text { Almost } \\
\text { never }\end{array}$ & $\begin{array}{l}\text { About } \\
\text { once a } \\
\text { month }\end{array}$ & $\begin{array}{l}\text { About } 2 \\
3 \text { times } \\
\text { month }\end{array}$ & $\begin{array}{l}\text { About } \\
\text { once a } \\
\text { week }\end{array}$ & & $\begin{array}{l}\text { At least } \\
\text { ice a day }\end{array}$ \\
\hline a. & I forgot something I needed for class. & & 1 & 2 & 3 & 4 & & 5 \\
\hline b. & I interrupted other students while they were talking. & & 1 & 2 & 3 & 4 & & 5 \\
\hline c. & I said something rude. & & 1 & 2 & 3 & 4 & & 5 \\
\hline d. & I couldn't find something because my desk, locker, or bedroom was messy. & & 1 & 2 & 3 & 4 & & 5 \\
\hline e. & I lost my temper at home or at school. & & 1 & 2 & 3 & 4 & & 5 \\
\hline f. & I did not remember what my teacher told me to do. & & 1 & 2 & 3 & 4 & & 5 \\
\hline g. & My mind wandered when I should have been listening. & & 1 & 2 & 3 & 4 & & 5 \\
\hline h. & I talked back to my teacher or parent when I was upset. & & 1 & 2 & 3 & 4 & & 5 \\
\hline 15. & Answer from 1 to 6 for the following questions, where 1 is a little and 6 is a le & & & 1 & 2 & 4 & 5 & 6 \\
\hline \multicolumn{9}{|c|}{$\begin{array}{l}\text { How much do you think that your MATH teacher takes each of the following items into account when } \\
\text { defining your report card grade? }\end{array}$} \\
\hline a. & Grades on tests. & & & 1 & 2 & 4 & 5 & 6 \\
\hline b. & Grades on homework, schoolwork and activities. & & & 1 & 2 & 4 & 5 & 6 \\
\hline & Classroom participation. & & & 1 & 2 & 4 & 5 & 6 \\
\hline & Delivery of homework on time. & & & 1 & 2 & 4 & 5 & 6 \\
\hline e. & Absences. & & & 1 & 2 & 4 & 5 & 6 \\
\hline f. & Lateness. & & & 1 & 2 & 4 & 5 & 6 \\
\hline g. & If you disturbed your peers. & & & 1 & 2 & 4 & 5 & 6 \\
\hline h. & If you talked about non-class related subjects during class. & & & 1 & 2 & 4 & 5 & 6 \\
\hline i. & Other characteristics of yours. & & & 1 & 2 & 4 & 5 & 6 \\
\hline \multicolumn{9}{|c|}{$\begin{array}{l}\text { How much do you think that your PORTUGUESE teacher takes each of the following items in account } \\
\text { when defining your report card grade? }\end{array}$} \\
\hline j. & Grades on tests. & & & 1 & 2 & 4 & 5 & 6 \\
\hline k. & Grades on homework, schoolwork and activities. & & & 1 & 2 & 4 & 5 & 6 \\
\hline I. & Classroom participation. & & & 1 & 2 & 4 & 5 & 6 \\
\hline $\mathrm{m}$. & Delivery of homework on time. & & & 1 & 2 & 4 & 5 & 6 \\
\hline n. & Absences. & & & 1 & 2 & 4 & 5 & 6 \\
\hline o. & Lateness. & & & 1 & 2 & 4 & 5 & 6 \\
\hline p. & If you disturbed your peers. & & & 1 & 2 & 4 & 5 & 6 \\
\hline q. & If you talked about non-class related subjects during class. & & & 1 & 2 & 4 & 5 & 6 \\
\hline r. & Other characteristics of yours. & & & 1 & 2 & 4 & 5 & 6 \\
\hline
\end{tabular}

